PACIFIC LINGUISTICS

Series B - No. 65

\title{
BASIC MATERIALS IN WANKUMARA (GALALI): GRAMMAR, SENTENCES AND VOCABULARY
}

by

M. McDonald \& S.A. Wurm

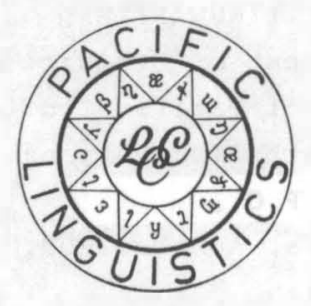

Department of Linguistics

Research School of Pacific Studies

THE AUSTRALIAN NATIONAL UNIVERSITY 
PACIFIC LINGUISTICS is issued through the Linguistic Circle of Canberra and consists of four series:

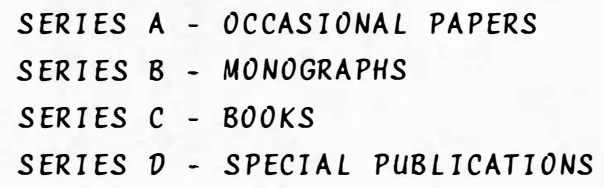

EDITOR: S.A. Wurm.

ASSOCIATE EDITORS: D.C. Laycock, C.L. Voorhoeve, D.T. Tryon, T.E. Dutton. EDITORIAL ADVISERS:

B. Bender, University of Hawaii

D. Bradley, University of Melbourne

A. Capell, University of Sydney

S. Elbert, University of Hawaii

K. Franklin, Summer Institute of Linguistics

W.W. Glover, Summer Institute of Linguistics

G. Grace, University of Hawaii

M.A.K. Halliday, University of Sydney

A. Healey, Summer Institute of Linguistics

L. Hercus, Australian National University

N.D. Liem, University of Hawaii
J. Lynch, University of Papua New Guinea

K.A. McElhanon, University of Texas

H. McKaughan, University of Hawaii

P. Mühlhăusler, Linacre College, Oxford

G.N. O'Grady, University of Victoria, B.C.

A.K. Pawley, University of Hawai

K. Pike, University of Michigan; Summer Institute of Linguistics

E.C. Polome, University of Texas

G. Sankoff, Université de Montréal

E. Uhlenbeck, University of Leiden

J.W.M. Verhaar, University of Indonesia, Jakarta

ALL CORRESPONDENCE concerning PACIFIC LINGUISTICS, including orders and subscriptions, should be addressed to:

\author{
The secretary, \\ PACIFIC LINGUISTICS, \\ Department of Linguistics, \\ School of Pacific Studies, \\ The Australian National University,
}

Canberra, A.C.T. 2600.

Australia.

Copyright (C) The Authors.

First published 1979.

The editors are indebted to the Australian National University for help in the production of this series.

This publication was made possible by an initial grant from the Hunter Douglas Fund.

National Library of Australia Card Number and ISBN $085883202 \mathrm{x}$ 
TABLE OF CONTENTS

MAPS

2. PHONOLOGY 5

2.1. Stress 5

2.2. Syllable Structure 5

2.3. Phoneme Inventory 6

2.4. Articulation and Allophony of Consonants 7

2.4.1. The Voicing Distinction 7

2.4.2. Apical Consonants 8

2.4.2.1. Alveolar: $t d n \mid r$

2.4.2.2. Retroflex: t d ! ! 8

2.4.3. Laminal Consonants 8

2.4.3.1. Interdental: t d I I 8

2.4.3.2. Palatal: 5 \& $n$ b $y$. 9

2.4.4. Peripheral Consonants 9

2.4.4.1. Bilabial: p b m w 9

2.4.4.2. Velar: $k g \mathrm{D}$

2.5. Vowel Allophony 9

2.6. Phonemic Contrasts 9

2.6.1. Consonants - Restrictions on Distribution 9

2.6.1.1. Oral Stops 10

2.6.1.2. Nasals 11

2.6.1.3. Laterals 12

2.6.1.4. Rhotics 12

2.6.1.5. Semi-vowels 12 
2.7. Phonotactics 13

2.7.1. Distribution of Consonants 13

2.7.2. Distribution of Vowels 13

3. MORPHOLOGY 13

3.1. Parts of Speech 13

3.2. Morphology of Nominals 15

3.2.1. Case Systems in Australian Languages 15

3.2.2. The Nominative and Accusative Cases: -ani (NOM) and 16

3.2.2.1. The Pronouns nani and nana 17

3.2.2.1.1. Form and Distribution 17

3.2.2.1.2. Function and Meaning 17

3.2.2.2. -ani and -ana as Case Clitics 19

3.2.3. Noun Case Forms 21

3.2.3.1. Discussion of Case Forms 22

3.2.4. Noun Cases - Function 23

3.2.4.1. Ergative 23

3.2.4.2. Nominative 24

3.2.4.3. Accusative 24

3.2.4.4. Dative 25

3.2.4.5. Locative 25

3.2.4.6. Instrumental 26

3.2.4.7. Ablative 26

3.2.5. Derivational Suffixes 27

3.2.5.1. Singular and Dual Stems 27

3.2.5.2. Comitative and Privative Stems 27

3.2.6. Pronouns - Personal and Interrogative 27

3.2.6.1. Personal Pronouns 27

3.2.6.1.1. Notes on Pronouns - Form and Function 29

3.2.6.1.2. Orientational Suffixes 30

3.2.6.2. Interrogative Pronouns 31

3.2.6.2.1. Notes on Interrogative Pronouns 31

3.2.7. Location and Time 32

3.2.7.1. Locational Suffixes 32

3.2.7.2. Location and Time Nominals 32

3.2.8. Nominalisations 33

3.3. Morphology of Verbs 33

3.3.1. Structure of the Verb 33

3.3.2. Transitivity 33 
3.3.3. Inflections

3.3.3.1. Tense Inflections 34

3.3.3.2. Aspect Inflections: Irrealis, Factive 34

3.3.3.3. Possibility: -lagu 35

3.3.3.4. Purposive and Imperative -ra 36

3.3.4. Derivational Suffixes 36

3.3.4.1. Derivational Suffixes not Affecting Transitivity 36

3.3.4.2. Suffixes Affecting Transitivity 37

3.3.4.3. Verbalising Suffixes 38

$\begin{array}{lll}3.3 .4 .4 \text {. Other Suffixes } & 38\end{array}$

3.3.5. Particles 38

3.3.5.1. Location and Time 38

3.3.5.2. Predicate Qualifiers 39

3.3.5.3. Modal Particles: wa ba (NEG), banini ('unable'),
bar! ('think'), mura ('finished')

3.3.5.4. Other Particles 40

$\begin{array}{ll}3.3 .6 . & 40\end{array}$

4. SYNTAX $\quad 40$

4.1. Noun Phrase Constituency 40

4.2. Simple Sentences 40

4.2.1. Non-verbal Sentences 40

4.2.2. Verbal Sentences 43

4.3. Order of Constituents 46

4.3.1. Declarative Sentences 46

4.3.2. Questions 46

4.3.2.1. Polar Questions 46

4.3.2.2. Information Questions 46

4.3.3. Imperatives 47

4.4. The use of -iyi (Reflexive) 47

4.4.1. The Reflexive 47

4.4.2. The Passive 48

$\begin{array}{lll}\text { 4.4.3. Other uses of -iyi } & 50\end{array}$

4.5. Possession 51

4.6. Complex Sentences 53

4.6.1. Conjoined Clauses 53

4.6.2. Temporal Clauses 53

4.6.3. Purposive Clauses $\quad 55$

4.6.4. Other Clauses $\quad 56$

$\begin{array}{lr}\text { BIBLIOGRAPHY } & 57\end{array}$

$\begin{array}{lr}\text { TEXT } & 61\end{array}$ 
vi

Page

VOCABULARY

107

TABLE 1: Consonants

7

TABLE 2: Noun Case clitics

22

TABLE 3: Personal Pronoun Paradigm

28

TABLE 4: Orientational Suffixes

31

TABLE 5: Interrogative Pronouns

31 

SOME ABORIGINAL LANGUAGES OF SOUTH-WESTERN QUEENSLAND

(as approximately located at the time of the first major white contact)

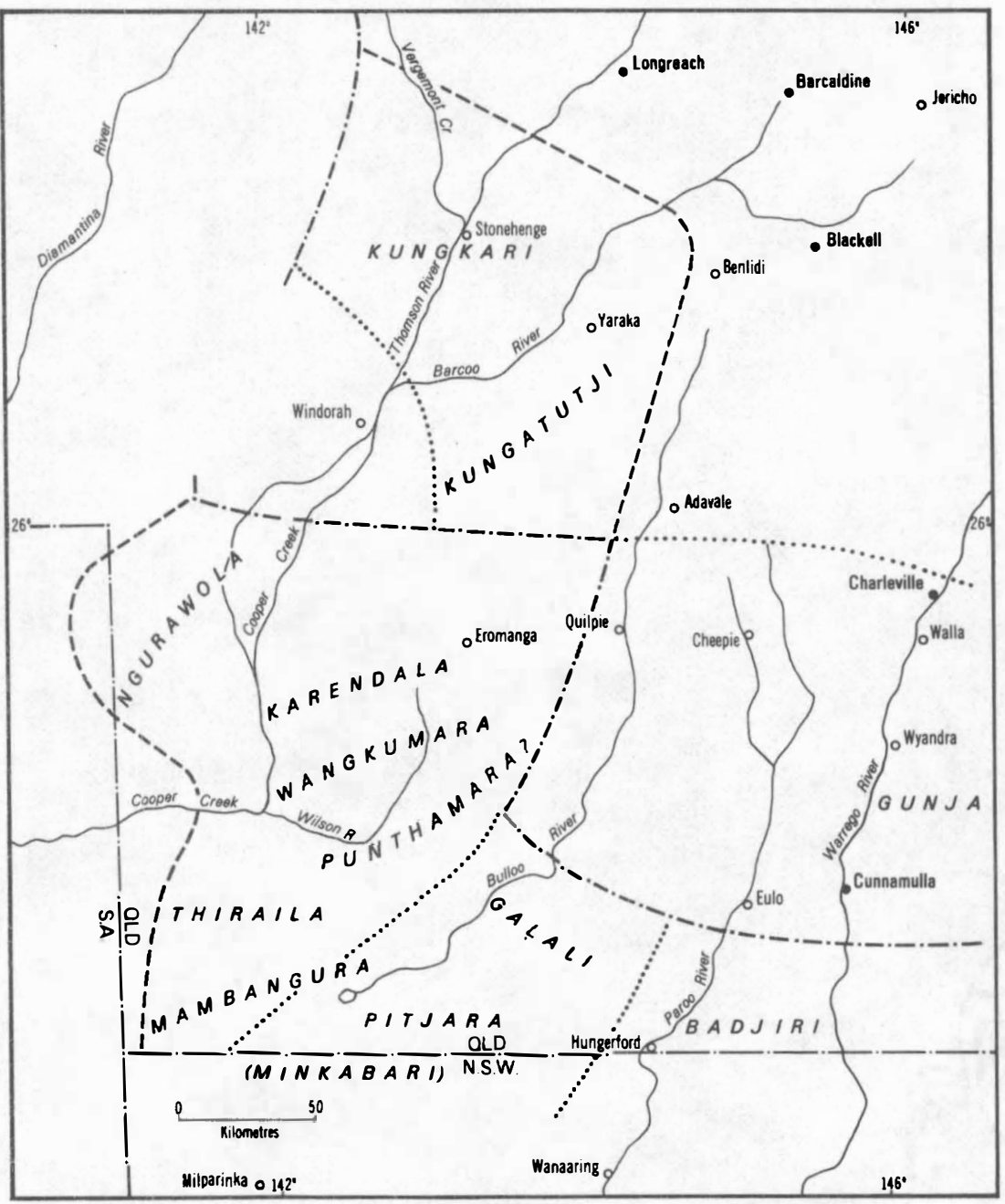

Boundary between languages belonging to the same subgroup

Boundary between languages belonging to different subgroups of the same group

Boundary between languages belonging to different groups of the same family

Boundaries between dialects of a language are not shown 
SOME ABORIGINAL LANGUAGES OF SOUTH-WESTERN QUEENSLAND (as approximately located in post-contact times)

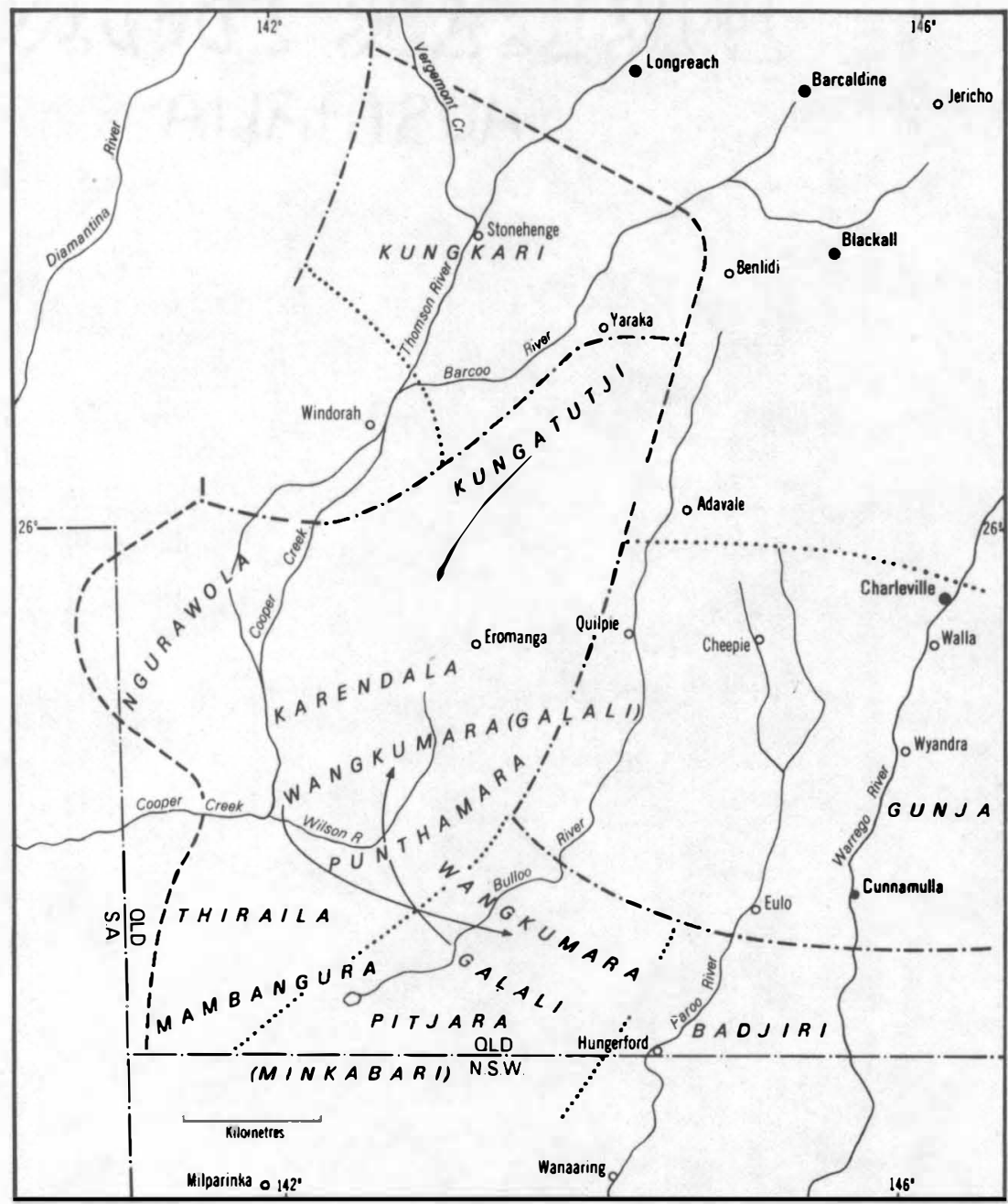

Boundary between languages belonging to the same subgroup

Boundary between languages belonging to different subgroups of the same group

Boundary between languages belonging to different groups of the same family

Boundaries between dialects of a language are not shown 
McDonald M. and Wurm, SA Basic materials in Wankimarara (Galali): Grammar, sentences and vocabulary.

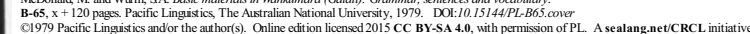




\section{INTRODUCTION}

\subsection{LANGUAGE AND BACKGROUND}

The language presented in this monograph is one of the dialects of what Breen (1971) has called the 'Wllson River Language'. The informant, Charles Phllips, called this language Galal1, but it is clearly different from a language in which Breen (personal communication) has obtalned highly consistent materlals from several informants who also referred to their language as Galal1. It appears that this latter Galall is a dlalect of what Breen refers to as the 'Bulloo River Language' and to which, In addition to Galall, also the dialect called Wajkumara belongs on which Curr (1886-87) has published materials. Also included in this language is a dialect referred to as Pitfara (not to be confused with the different Bldjara language spoken further north and described in Breen 1973) as well as probably Minkabarl if it really is a dialect name. At the same time, the Wilson River language Includes, In addition to Charles Ph1llps' 'Galal1', Bundanamara, modern Wankumara, Th1ra1la, Mambangura, the nodern form of Kungatutj1, as well as Karendala and perhaps Ngurawola (Breen 1971). These two languages, together with the Badj1r1 language, constitute, according to Breen, the Ngura Subgroup of what he calls the Karn1c Group wh1ch comprises the former Araban1c, Dier1c, Mitakudic and P1ttap1tt1c Groups (Wurm 1972 ).

Charles Phllips' 'Galal1' is very close to modern Wankumara and Bundamara, though a small proportion of its vocabulary is Bulloo River Galal1 (and a somewhat larger proportion is common to the Wilson River language in general, and to Bulloo River Galali). The grammar of Charles Ph1l1ps' 'Galal1' is however very much like that of modern Wankumara, with one 1mportant difference: In modern Wankumara, two noun classes exist, one comprising masculine singular nouns, and the other masculine plural and non-masculine nouns. In Charles Ph1l1ps' 'Galal1', which may well be called Walkumara (Galali) for the purpose of this monograph, only the non-masculine class is in general evidence, and all nouns belong to 1t. Conversely, in the Bundamara dlalect, only the masculine class is preserved, and all nouns are members of 1 t.

Breen (1971) points out that some groups of Southwest Queensland appear to have abandoned their orlginal languages (but not their names) and adopted the Wilson River language when moving into a new language area as a result of tribal disruption. He says that one such group seems to have been the Wankumara; he draws attention to the fact that modern informants 1dentify Wankumara w1th the Nockatunga area, but Curr's correspondent F.W. Myles (Curr 1886-87, vol.II:36-41) puts 1t 
Into the Thargomindah area. Breen suggests the possibility that the Wajkumara may have moved in the early days of settlement from Thargomindah to Nockatunga and adopted the local language there.

Tindale (1974) suggests a movement in the opposite direction in saying about the Wankumara:

Loc.: Cooper Creek east of Nappa Merrie and Orientos to the Wilson River at Nockatunga. In post contact times at Charleston and Ngarcowlah where they mixed with uncircumcised Kalali ....

and in Tindale 1940 he says that "tribal disruption took some to Thargomindah where they mixed with uncircumcised Kalal1".

It appears that the linguistic evidence favours Tindale's assumption: Curr's (1.e. Myles') Wankumara and Bulloo River Gaḷal1 appear to be dlalects of one language. If the speakers of that Wankumara, on moving into the Wilson River area, adopted the language spoken there, to produce modern Wajkumara, and some Bulloo River Galal1 speakers did the same - as evidenced by Charles Philips' 'Galali' - one would expect both these adopted languages to show identical characteristics. Insead, one of them, modern Wajkumara, shows a quite elaborate, marked two-class system of noun classification, whreas the other one, Charles Philips' 'Galal1', shows a simplified system which suggests that the speakers of Bulloo River Galal1, probably a non-classifying language, had difficulties in understanding the system and functioning of the Wilson River language noun-classes, and resorted to adopting the markers of only one - the non-masculine - of the two noun classes. Bundamara shows a comparable simplification, in assigning all nouns to the masculine class only, which makes it possible to assume that it does also not represent the original Wilson River language. It too, may be the result of the adoption of that language by some other outside group whose original language had no noun-classes. It seems likely that modern Wankumara, with 1ts fully operating noun class system, is the direct descendant of the original Wilson River language, and Curr's (1.e. Myles') Wankumara a Bulloo River dialect resulting from the adoption of that language by Wajkumara 1mmigrants from the Wilson River area - an immigration corroborated by Tindale's remarks. If Bulloo River Wankumara has no noun classes, as seems likely to be the case, this constitutes no difficulty: the loss and simplification of grammatical features as a result of language take-over is a common phenomenon. A tendency has been observed for class or gender systems to disappear or simplify in a language in strong contact with another language which lacks these features, especially if the latter is socially, regionally or otherwise dominant (Wurm 1978). 
The lexical relationship between the dialects making up the Wilson River and Bulloo River languages respectively is very close, certalnly close enough to justify their classification as dialects. Charles Ph1l1ps' 'Galal1', 1.e. Wankumara (Galal1), stands lex1cally somewhat apart from the other dialects of the Wilson River language, and is closer to Bulloo R1ver Gaḷal1 than they are, because, as has been pointed out above, it shares a greater proportion of 1 ts vocabulary with the latter language than with the other dialects of the Wilson River language. Nevertheless, the close resemblance between modern Wankumara and Wankumara (Gaḷal1) is evident from the ex1sting materlals. The lexical relationship between the Wilson River and the Bulloo River languages is close enough for their inclusion into the same subgroup: 1t lies around the 55-60\% mark.

A sizeable amount of data on Bundamara, recorded by S.A. Wurm, is yet to be studied. Fleldwork on Wankumara has been done by J. Breen and $\mathrm{L}$. Hercus, and a rather detalled description of that language is expected to become avallable in the future from them. A paper on Wankumara by J. Breen, frequently c1ted here, is included in Dixon ed. 1976 .

The Wankumara (Gaḷal1) data presented in this paper are from fleldnotes and tapes recorded by S.A. Wurm in Canberra, April 1963. The material, analysed by M. McDonald, C.C.A.E., consists of 70 pages of fleldnotes and corresponding tape recordings, edited of all extraneous material but maintaining the original order of elicitation. Word-forword glosses were provided for nouns and verbs, and in many cases an acceptable English translation was provided. Often, however, the translation was more in the splrit than the letter of the utterance. Reasonable English translations are provided in the text, but where the reading is in some doubt, alternatives are included in square brackets.

Dr Harold Koch of the A.N.U. provided a number of valuable comments and insights during the preparation of this paper.

The data include 517 'sentences' and 342 vocabulary 1tems. The 'sentences', referred to herein as the 'text', are included in section 5 , and the vocabulary is given in section 6. The 'phrase' and 'sentence' units distinguished are based on the intonation patterns of the informant.

The informant, Charles Philips, was 74 years old, born at Backwood Station south of Hungerford in southwest Queensland. He spoke both Wankumara (Galal1) and modern Wagkumara (and possibly a smattering of other languages of the area). Although he had not used the language conversationally for 40 years, his speech was fluent and confident. 
It is the alm of this paper to provide an analysis of, and guide to, the text. No attempt has been made to include material on related languages or to cross-reference this material with earlier records. The analys 1s presented is based purely on the text material and tapes.

Certain problems must be accepted as intrinsic to the analysis of $11 \mathrm{~m} 1$ ted recorded material. In this case, phonetic information is extensive. It derives, however, from one speaker, whose speed and manner of articulation often obscured the consonants. Difficulties encountered in transcription from the informant are only occasionally resolved by the tapes. Thus, particularly in the case of interdental consonants, the record is faulty; some apparently homophonous words must in reality differ in unrecorded consonant features. Text material Is adequate for most of the morphological analysis, although the exact shape of several of the case suffixes is uncertain. The informal style 1s the chlef syntactic weakness, as very few complex structures were elicited. Nevertheless, syntactic analysis of the text may be presented with reasonable certainty. It should be reiterated that the speaker appeared to know his language very well and that there is remarkable consistency in the structures he provided.

\subsection{GENERAL CHARACTERISTICS OF THE LANGUAGE}

Wankumara (Galal1) is entirely suffixing and morphologically fairly simple. It has the following word classes: nominal (noun and pronoun), verb, particle and interjection. Word order appears to be free.

The phonemes consist of three vowels and 26 consonants, all common In Australian languages. A volcing distinction in stops 1s, however, a relatively unusual feature.

There are seven noun cases. Wagkumara (Galal1) is unusual among Australian languages in having distinctive marking for nominative, accusative and ergative case functions throughout the nominal system. Kin nouns appear to have had case suffixes slightly different in form from common nouns. Pronouns have a unique set of inflections, and are free form, except for (a) the occasional bound - $\mathbf{i}$ (the second syllable of the first singular nominative pronoun gani) and (b) bound third person nominative and accusative pronouns, discussed in section 3.2.2.1.

There is no conjugational contrast in Wankumara (Gaḷal1) verbs. Transitivity is usually not indicated morphologically, and it is not always easy to determine in the text material. Variations in case marking of NPs pose interesting problems.

A passive transformation is 1dentified in the data, but no ant1passive (S1lverste1n 1976) may be discerned. A stralghtforward 
'conjolning' structure is apparent, along with certain 'adjolned' structures (as described by Hale 1976a:78-105). A purposive construction is amply attested, and sufficient data exists for 1dentification of conditional and temporal clauses.

\section{PHONOLOGY}

\subsection{STRESS}

Primary stress occurs normally on the first syllable of a word, with secondary stress on third and fifth syllables - except that final syllables are unstressed in connected speech. The first syllable of a two-syllable suffix recelves secondary stress. Where the suffix attaches to a two-syllable stem, the final syllable of the stem is often quite reduced and very occasionally some assimilation between 1 t and the inftial vowel of the suffix may take place. Where the vowels are 1dentical, a long vowel is often produced. However, equally of ten no assimilation or reduction takes place, and there is a clear fall in pitch between the final vowel of the stem and the inftial vowel of the suffix, as in [gúnà-àna]. food AĈC

Emphasis motivates a shift of stress. Thus the informant gives ńina 'him', and nińa 'him EMPH'. Many stems heard in cltation form have pronounced stress on the final syllable as well as strong final aspiration (described by the informant as final ' $h$ '). These features are absent in connected speech, except at the end of an intonation pattern. The final stress and aspiration appear to be suprasegmental features marking the end of an utterance, as well as emphasis.

\subsection{SYLLABLE STRUCTURE}

There are no monosyllab1c words; most nouns and verb stems (56\%) are disyllabic. Many of the trisyllabic and four-syllable nouns exhibit recurrent final syllables which suggest that they are not monomorphemic. When only the most probable monomorphemes are considered, $10 \%$ of the corpus is trisyllab1c, and only $6 \%$ comprise four syllables.

Syllable division 1s falrly easy to establish where (phonet1c) gemination of consonants occurs (see section 2.4.1.); division falls between the two consonants. Th1s is true whether the geminate consonants occur alone or with another consonant in a cluster. Where a volced consonant occurs in a cluster, division falls between the two consonants. Thus the patterns are as follows: 


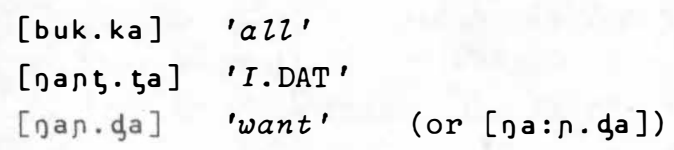

Where three-element consonant clusters [ $1 d r]$ and [ndr] occur, the sonorants [1] and [n] appear slightly lengthened and the syllable div1sion is apparently as follows: [nan.dra].

The word above 1llustrates syllable-initial [dr]. This sequence is often pronounced very rapidly, sometimes closely resembling the single segment $[r]$. [dr] and [lr] are the only syllable-initial clusters; in addition [dr] occurs word-1nitially, in three words.

On the basis of this syllable division, Wagkumara (Galali) free morphemes have two basic syllable types: CV and CVC. CVC syllables almost always occur word-1nitially. There are only two words in which a CVC syllable occurs in second position, resulting in a consonant cluster between second and third syllables.

There are several minor deviations from the basic syllable pattern. The inftial clusters $1 r$ and $d r$ have been discussed. In addition, the vowel [i] occurs inftially in three words. There are no occurrences of [yu] in the text and only two if [yi]. Thus the inftial vowel [i] may represent underlying/yi/ or /yu/. Note that the second person pronouns (singular) ini and ina also occur, where the general second person pronominal root is probably yu-.

Bound morphemes have wider possibilities of syllable structure in that they may occur with initial vowels.

\subsection{PHONEME INUENTORY}

Wankumara (Galal1) has three vowels and 26 consonants as segmental phonemes. The vowels are /i/, /a/ and /u/. The consonants are set out in Table 1 opposite.

\footnotetext{
$\overline{l_{\text {Some }} \text { of the }}$ [ndr] and [ldr] clusters may derive from a sequence [ndVr]. For example, the informant gave a word dumpindra 'te Zl (PURP)' and then offered the alternative dumpindira. The verb stem here is possibly dumpa 'show' plus suffixes indi? and ra (purposive).
} 
TABLE 1

Consonants

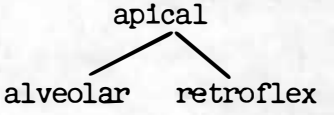

volceless stops

volced stops

nasals

laterals

rhotics

sen1-vowels

$\begin{array}{ll}\mathrm{t} & \mathbf{t} \\ \mathrm{d} & \mathbf{d} \\ \mathrm{n} & ! \\ \mathrm{r} & ! \\ \mathrm{r} & ?\end{array}$

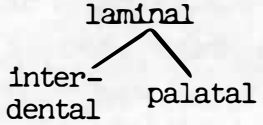

$\begin{array}{ll}t & 5 \\ d & 5 \\ n & 5 \\ 1 & b\end{array}$

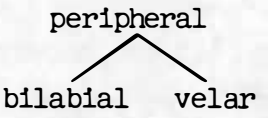

p k

b g

m $\quad$ o

\subsection{ARTICULATION AND ALLOPHONY OF CONSONANTS}

\subsubsection{The Voicing Distinction}

Unlike most Australlan languages, Wankumara (Galal1) has a volcling distinction in the oral stops. The contrastive value of voling is limited to certain environments. There is no distinction initially or before $/ r /$, and 1 t may be demonstrated intervocalically only for laminals and peripherals. It can be shown for all the consonant series in homorganic clusters following nasals, but to only a limited extent following laterals and rhotics. Absence of a full set of distinctions after laterals and rhotics is probably a function of the limited material. It should be noted that volced stops occur in only $20 \%$ of the vocabulary 1tems. ${ }^{1}$

Volceless stops, which have falrly tense articulation in all positions, are particularly tense - and geminate - following a stressed vowel. 2

Volced stops are weakly articulated, with bllablals and velars in particular being realised as lenis fricatives. A stressed vowel preceding a volced stop is often lengthened, whether the consonant is single or in a cluster. Thus a long vowel is usually assoclated with the volced stops while a preceding short vowel characterises the volceless series. The relevant contrast could then be 1dentifled elther as

\footnotetext{
$\overline{1}_{A}$ voicing contrast was noted by J. Breen for Wankumara (1976b:339) and for Yandruwanda (1976a:597), where he said: "the Yandruwanda phoneme inventory appears to include a fuîl set $(6)$ of both voiced and voiceless stops (although the opposition may be significant only in certain environments."

${ }^{2}$ Gemination is an areal feature, occurring also in Malangada and Ba:gandi, languages which seem not to be closely related ( $P$. Austin - personal communication).
} 
vowel length or as consonant volcing. The welght of evidence favours a distinction residing in the consonants, however. Vowel length is not malntained as consistently as consonant volcing; the fleldnotes and tapes record numerous varlations in vowel length for different occurrences of a single word. Moreover, where a volced consonant occurs in a cluster, it is sometimes the sonorant that is lengthened. Thus we have the word panga 'want' realised as [nan:da], [nanga] and [na:nga].

There is no volcing contrast word-initially. Initial stops are represented here as volced, the predominant mode of realisation. Where volceless stops are heard inftially, there is always a volceless consonant in the word, possibly (though not consistently) conditioning inftial volcelessness. The inftial consonants of most suffixes are volced, heard as lenis fricatives. One exception, -ka (gloss unknown) occurs.

\subsubsection{Apical Consonants}

\subsubsection{Alveolar: $t d n \mid r$}

The tongue t1p makes contact with the front of the alveolar ridge, Just behind the top teeth, a little more 'fronted' than alveolar art1culation in English. The alveolar rhotic is usually a strong trill, but intervocalically it is sometimes a strongly fricative sound. There are no observed allophonic varlants of the other alveolar consonants.

\subsubsection{Retroblex: ț ! ! !}

The tongue tip makes contact just behind the alveolar ridge. A preceding 'r-coloured' vowel is the chief perceptual correlate. Retroflexes are readily discernible in the speech of the informant.

The retroflex rhotic is a central approximant. There are no allophonic variants of interest.

\subsubsection{Laminal Consonants}

\subsubsection{Interdental: $t d n !$}

The blade of the tongue makes contact with an area of the mouth extending from just behind the upper teeth to the lower teeth.

Interdental consonants were difficult to distinguish in the fleld. The interdental lateral is not recorded definitely in the data, but several 'susplcious' laterals were selected from the tapes and fleldnotes for instrumental investigation. The results confirm the presence of interdental laterals in several words. The spectrographic parameters 
for determining interdental articulation of laterals are those discussed In 'A Study of the Phonetics and Phonology of Yarald1 and Associated Dialects' (McDonald 1977). No attempt has been made to carry the investigation further to see how common the interdental lateral is.

There 1s an allophone [ð] of /d/ in the environment following / $/$ /.

\subsubsection{Palatal: 5 \& $\cap$ b y}

The lamino-palatal is articulated with the blade of the tongue in contact with the palate. An allophone [3] of / $/$ / is occasionally heard intervocalically and after / $/$ /.

\subsubsection{Peripheral Consonants}

\subsubsection{Bilabial: p b m w}

The articulators are the two lips. A lenis fricative allophone [ $\beta$ ] of $/ b /$ frequently occurs intervocalically and after $/ 1 /$. Occasionally an allophone $[w]$ of $/ b / 1$ s heard, where /b/ is the initial consonant of a suffix.

\subsubsection{Velar: kg}

The dorsal part of the tongue makes contact w1th the velar area.

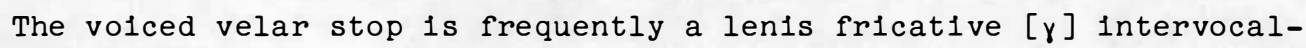
1cally.

\subsection{VOWEL ALLOPHONY}

The vowels display a limited range of allophonic varlants. /a/ is predominantly a low central vowel, approximately [e]. A more 'fronted' allophone [a] is heard in the environment before $/ w /$.

$/ i /$ is a tense high front vowel [i] when long, and before /y/. / $i /$ 1s approximately [i] in other environments.

/u/ is a falrly tense high back rounded vowel when long. It is slightly laxer, but still quite tense before $/ 1 /$ and $/ w /$, but is predominantly the less rounded, laxer allophone [0] in other environments.

Vowels are long in stressed syllables before volced stops and $/ \mathrm{r} /$.

\subsection{PHONEMIC CONTRASTS}

\subsubsection{Consonants - Restrictions on Distribution}

The following general restrictions are part of the distributional pattern of consonants: 
(1) The retroflex serles, laterals and rhotics do not occur in wordinftial position.

(2) The volcing distinction is restricted as indicated in section 2.4.1.

(3) There are very few ap1co-alveolars in inftial position. Those that are recorded may well be recorded in error.

(4) The palatal stop occurs only three times initially, in each case before the vowel / $i /$. Since 1 t contrasts with /d/ in this environment and position, a very limited laminal contrast must be recognised initially.

(5) $/ d r /$, which sometimes sounds like a single segment, can be shown to be distinct from / $r /$ intervocalically and from /d/ after nasals. In 1ts marginal occurrence initially, /dr/ cannot be shown to be distinct from $/ d /$. It appears that the three $d r$ - inftial words are related drapa 'tooth', dratita 'bite' and draba 'sting'. These probably reflect a common Australian word for 'tooth' - dira. If so, the /dr/ cluster might well be represented as underlying $/ \mathrm{dVr} /$, and the cluster removed from phonemic representation (see further discussion in section 2.6.1.6.).

The phonemic system proposed, limited in 1 ts distribution as noted, is substantiated by the following sets of minimal or near-minimal contrasts.

\subsubsection{Oral Stops}

Initial Position:

$\begin{array}{ll}\text { buli } & \text { 'falz' } \\ \text { dulka } & \text { 'heart' } \\ \text { dunda } & \text { 'grow' } \\ \text { gulu } & \text { 'knee' } \\ \text { dila } & \text { 'blow' } \\ \text { dilpa } & \text { 'dew' } \\ \text { dini } & \text { 'foot' } \\ \text { dini wara } & \text { 'thunder' }\end{array}$

Intervocalic:

voiceless:

$\begin{array}{ll}\text { dapa 'Zick' } & \text { draba 'sting' } \\ \text { gața 'cockatoo' } & \text { gadi 'Zie' } \\ \text { ma ţa 'Zong ago' } & \text { naga 'see' } \\ \text { mata 'trunk or bark of tree' } & \\ \text { gați 'bezt' } & \\ \text { baka 'hide, send' } & \text { waga 'Zie down, sleep' }\end{array}$


In Clusters:

Homorganic clusters have been 1llustrated. Only aplcal nasals may

be 1llustrated in non-homorganic clusters.

$$
\begin{array}{ll}
\text { gankura 'hair' } \\
\text { wanki 'find' }
\end{array}
$$

2.6.1.3. Laterals

Intervocalic:

$\begin{array}{ll}\text {-gala } & \text { 'present tense' } \\ \text { gaba } & \text { 'wing' } \\ \text { gala } & \text { 'hey!' } \\ \text { gila-gila } & \text { 'galah' }\end{array}$

In Clusters:

na bba 'knife'

Dalka 'think'

wa!ka 'put'

\subsubsection{Rhotics}

Intervocalic:

mura 'finished'
mura 'day'
guru 'ankle'
guru 'windbreak'

In Clusters :

$\begin{array}{ll}\text { narki } & \text { 'Zean' } \\ \text { mirkirini } & \text { 'moon' }\end{array}$

\subsubsection{Semi-vowels}

Initial Position:

yaña 'rain'
wana 'boomerang'
yantana 'go'
wanta 'short'

Intervocalic:

draya 'tooth'
yawara 'Zanguage'




\subsection{PHONOTACTICS}

\subsubsection{Distribution of Consonants}

Restrictions on environments of contrast have been described in section 2.6.1.

The most common consonant clusters result from the co-occurrence of CVC and CV syllables. Cl of the consonant cluster may be any sonorant other than /w/. C2 is predominantly an oral stop. The major exceptions in 62 position are (1) nasals - which may follow another nasal (/nm/ and /ng/ clusters are attested) - and (2) sonorants (/w/, /n/, $/ \mathrm{m} /$ and $/ \mathrm{r} /$ are attested) - which may follow $/ \mathrm{y} / .^{1}$

The clusters, then, are probably as indicated below. Those not attested, but strongly suggested by the distributional pattern, are bracketed.

(1) Homorganic nasal + stop: mp, (mb), nt, nd, $n t$, ng, $n t$, nd, nț, ṇ̣, $\eta k$, $\eta g$.

(2) Homorganic lateral + stop: $1 \mathrm{t}, 1 d, b 5,(b d), 1 \mathrm{t}, 1 d$, ! t, !d.

(3) Lateral + peripheral stop: $(\not p),(\lfloor b),(\lfloor k),(\lfloor g),(\zeta F), b b,(\zeta k)$, $(b g), 1 p, 1 b, 1 k, l g,(! p),(! b), ! k, ! g$.

(4) Rhot1c + peripheral stop: rp, (rb), rk, rg, (rp), (rb), rk, rg.

(5) Aplcal nasal + peripheral consonant: $n k, n g,(n g), n p, n b, n m, n ̣ k$, ng, ṇn, (ṇp), (ṇb).

(6) $y+r, m, w, n$.

(7) $\mathrm{ir}, \mathrm{rt}$.

\subsubsection{Distribution of Vowels}

The vowel /a/ is the most common. 52\% of the words in the corpus have the vowel /a/ in the first syllable. The vowels / i/ and / u/ occur occur almost equally in initial syllables. In final position, the vowel /a/ is even more predominant - $64 \%$ of the stems end in the vowel /a/. The vowel /i/ is the scarcest, occurring in only $17 \%$ of the words.

\section{MORPHOLOGY}

\subsection{PARTS OF SPEECH}

The following parts of speech can be distinguished:

\footnotetext{
IAnalysis of the sequence [ai] as vowel plus consonant augments the class of type 1 consonant clusters. There is no sequence [ao].
} 


$$
\begin{aligned}
& \left.\begin{array}{l}
\text { noun } \\
\text { pronoun }
\end{array}\right\} \text { nominals } \\
& \text { verb } \\
& \text { particle } \\
& \text { interjection }
\end{aligned}
$$

The most important criterion for assignment to word classes is potentiality of occurrence with particular derivational or inflectional suffixes. In addition, a unique pattern of occurrence is considered evidence of probable word class membership.

The only grounds for distinguishing a class of adjectives would be semantic, based on the semantic criterion suggested by Dixon (1977:122, 123). No formal grounds appear in the text, nor does any distributional pattern suggest separate status of an 'adjective' class. There is a derivational (verbalising) process involving the modifying noun dali 'good'; while no such derivation involving a non-modifying noun is attested, the discrepancy is very likely fortultous.

Nouns form an open class; 257 noun stems are included in the vocabulary. There is very little evidence of synchronic processes deriving nouns. The noun stem commonly occurs with one of the case inflections, although it may also appear uninflected.

There are several hints (In the form of the ergative case suffix, for instance) that $\mathrm{k}$ in nouns $\mathrm{mlght}$ have been inflected slightly differently from other nouns.

Pronouns form a closed class; separate forms are distinguished for six cases. Where case-markers are discernible, they are similar to but not identical to - the nominal inflections.

Many locational words occur only once in the corpus; their potential for inflection and their range of meaning cannot be accurately determined. These words are placed in elther nominal or particle categorles on the basis of falrly slight evidence.

Verbs form an open class with a characteristic set of derivational and inflectional suffixes. There are 93 verb stems in the corpus. Where an English translation suggests adverblal status, corresponding Wa gkumara (Galal1) terms never recelve verbal inflection. They are tentatively classed as nominals.

Particles are uninflected, occurring freely within a sentence. Several particles of a modal nature occur sentence inftially but without the pause characteristic of interjections. Interfections occur sentence initially, followed by a pause. The interfections ga 'yes' and waba 'no' constitute complete utterances. 


\subsection{MORPHOLOGY OF NOMINALS}

\subsubsection{Case Systems in Australian Languages}

In the following discussion, the terms 'agent function', 'subject function', and 'object function' are used in the sense described by Dixon (1979:53):

The only obligatory NP in an intransitive clause is $S$, the $N P$ in a transitive clause which can be agent is $A$, and the other obligatory NP in a transitive clause is 0 . These functions do appear to be valid for all natural languages and to be the basis for all grammatical operations.

$A, O$ and S-functions are 'core categorles' which exist in underly ing structure by virtue of a universal dichotomy of transitive and intrans1tive verbs. During the course of a derivation, NPs may be assigned from one core function to another - or may be given peripheral status. NPs are then in derived grammatical functions. Case marking proceeds at a late stage, encoding the derived relationships of NPs to the verb. The sole criterion for case marking of NPO and NPS is their grammatical function in the clause; a semantic criterion - agent - is used to distinguish NPA.

The terms $A, O$ and $S$-function have been particularly useful in the description of Australian languages, many of which exhibit a case marking system known as ergative-absolutive. That is, the NP in subject function to an intransitive verb is treated in a similar way to the NP in object function to a transitive verb, both recelving absolutive (often zero) case inflection; the NP in A function is distinct - inflected in the ergative. This system may be distinguished from the nominative-accusative system, which overtly marks the object of trans1tive verbs (accusative) and treats the subjects of both transitive and intransitive verbs similarly, often with (nominative) zero inflection. Australian languages often exhibit what is known as a split case system, in which some or all pronouns (and often some nominals) inflect for case according to a nominative-accusative pattern, and other nominals inflect according to the ergative-absolutive system. (For a discussion of the split case system and hierarchies existing in nominals, see Silverstein 1976, Heath 1976.)

It is not unusual for Australian languages to have different forms of at least some pronouns for all three functions, S, A, and 0 . This three-way system is sometimes extended to all pronouns - and occasionally, to a small category of nouns (such as kin or proper nouns). Diyari extends $S, A$, and $O$ marking more fully - to non-singular nouns and some proper nouns (Austin 1978). Further, a practice of elther 
optional or limited accusative marking of object NPs with -na or some reflex of that morpheme occurs in a number of languages. Use of this suffix in itself provides a three-way distinction of $\mathrm{S}, 0$, and $A$ function. However, Wankumara (Galal1) goes further than any of these: it marks nominals for all three functions by the use of overt inflections. The systematic use of accusative (for 0 -function) and nominative (for S-function) case-markers in this language is of interest both for its own sake and for 1ts relevance to lingulstic theory.

\subsubsection{The Nominative and Accusative Cases: -ani (NOM) and -ana ( $A C C$ )}

Since the case system of Wankumara (Galal1) appears at first glance to involve redundancies, it is of interest to examine both the extent of 1 ts use and any avallable hint to 1 ts origin.

In fact, Charles Philips very seldom omitted the nominative and áccusative case-markers. Nominative marking is the one most frequently omitted, mainly on $\mathrm{k}$ in and abstract nouns in verbal sentences. Accusative case omission occurs occasionally, correlating well in the text with lack of reference to a particular NP - or to contexts where such a lack might make sense to the informant. This is discussed further later in this section.

With regard to origin, the form of the case markers is of interest. The morphemes -ani (NOM) and -ana (ACC) are identical to the third person singular pronouns nani and nana, without the initial nasal. In fact, in our analysis, bound -ani occurring in the predicate of nonverbal sentences is considered a pronoun, identical in form to the case-markers. Thus the exact status of the case-markers is open to question.

As a preliminary, it should be noted that we refer to nani and nana as 'third person pronouns' with certain reservations. Clearly a more neutral label, signifying a wider range of function, would be more adequate. While occurring in distributional patterns in conformity with those of the first and second person pronouns, the third person pronouns have a wider distribution and function, and some of the properties of determiners, demonstratives, person markers and number markers. They are used adnominally much of the time, while retaining pronominal use. To 1llustrate these statements, we list below the various characteristics of nani and nana. 


\subsubsection{The Pronouns nani and nana}

\subsection{Form and Distribution}

The personal pronouns are set out in Table 3, section 3.2.6.1.

The pronouns nani and nana appear to belong to the same form class as bula (thirdperson dual) and to be similar in form and distribution to the other pronouns - as exemplified by dana (third person plural) and yula (second person dual).

(1) All the above forms occur suffixed by the orlentational suffix -guru 'there', and then further marked for case. Nouns do not occur with the set of orientational suffixes which includes guru. (These are set out in Table 4.)

(2) bula, like nani and nana, occurs as an enclitic to nouns; optionally marking an entire NP.

(3) Like bula, nani 'coples' into the predicate of a non-verbal sentence. This is shown below. The use of -ani (or nani) in nonverbal sentences is discussed in section 4.2.2.1.

(215) gana-bula ga!gu-ga!gu-bula mañ -2 weak weak-3.dl: NOM

'Two men are weak.'

$\begin{array}{lll}\text { makura-ni nani-yi } & \text { ga!gu-ga!gu-nani } \\ \text { stick -NOM 3.S:NOM-here rotten } & \text { 3.S:NOM } \\ \text { 'This stick is rotten.' } & \end{array}$

\subsection{Function and Meaning}

(1) nani and nana function anaphorically, like the other pronouns, occurring as the sole constituent of an NP, both with and without orlentational suffixes. They are usually glossed in English as demonstratives. In many Australian languages, demonstratives function as third person pronouns; however, there is no indication here that the root forms convey any orientational information.

(2) nani and nana, like bula and dana, occur most commonly in adnominal use. Most NPs consist of head noun plus adjunct pronoun. Where there is separation of the two, the noun is usually marked for case; however, the noun is often unmarked when it occurs in close proximity to the pronoun. Thus the pronoun alone often serves to indicate the case of an NP.

(3) We have noted that bula, like nani and nana, occurs as an enclitic to nouns, optionally marking an entire NP. This ralses the question of the function of nani, nana as number markers. The pattern is 1llustrated below. 


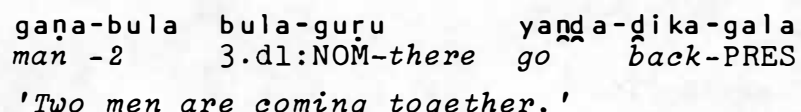

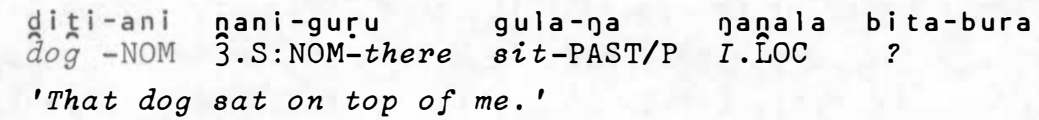

Note that a discrepancy exists in the gloss, in that -bula is identified as a number-, not a case-, marker, while-ani is 1dentified as a case-, not a number-, marker. The exact status of -bula with respect to case must remain unresolved: an adjunct pronoun almost always occurs, so that case-marking may be omitted on a noun. Moreover, nouns in Sfunction are sometimes unmarked; thus bound -bula, here, may or may not function to signify case. It appears that the primary function of -bula is to mark number. On the other hand, -ani appears to function primarliy to mark case, slgnifying very little with respect to number. The free forms nani and nana specify singularlty when used pronominally in verbal sentences. But in adnominal use, there is some variation. Thus in the sentences below, dana-guru may be seen once registering plurality (486), whereas nani-guru appears in the other (456).

(456) diți-ani wandru-ani nani-guru buka yanta-dika-gala-ri do $\hat{g}$-NOM many -NOM $3 . S: N O M-t h e r e$ all go-back-PRES-IRR?? 'A 22 those dogs are coming up together.'

(486) mura dana-guru gana-ani buka mari-mari-gala

finished 3.pl:NOM-there man-NOM all dance-dance-PRES

maṇi-anani

corroboree-DAT

'O.K. the people all together are dancing a corroboree.'

The bound forms -ani and -ana are even less assoclated with number. dana does not occur enclitically; only the 'singular' bound forms occur - In singular and plural contexts. The form -ani 1s, however, in complementary distribution with -bula (we have no dual noun in 0-function). It appears, then, that if number is specifled by these enclitics, it is only dual and non-dual that are distinguished.

Furthermore, -ani and -ana (and nani, nana), are used where number specification has little relevance. Their pattern of occurrence in the text does not colnclde absolutely with elther definiteness or specif1c1ty. A tendency may be discerned for the absence of -ana to coinclde with an indefinite gloss or with (probable) first mention of an NP.

Thus, compare (31) w1th (33) below.

(31) Dat̂u nada-gala daldra
I.ERG see-PRES kangaroo
'I see the kangaroo.'


(33) yundru nada-gala daldra-ana

you.S:ERG see-PRES ḱangaroo-ACC

'You see the kangaroo.'

Here, in spite of the translation, the NPO is first mentioned in (31), and might well be non-specific in the speaker's mind. But the presence of -ana (nana) does not exclude an indefinite gloss - nor is -ana excluded from obviously 'first-mentioned' NPs.

Thus, we have (150) below:

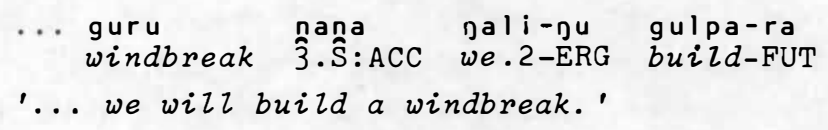

(4) Both nani (and -ani) and bula occur in the comment NP of non-verbal sentences (see section 4.2.2.1. for details). These are 1llustrated in sentences (215) and (369) previously clted. dana does not occur in this way. A 'plural' non-verbal sentence is 1llustrated below:

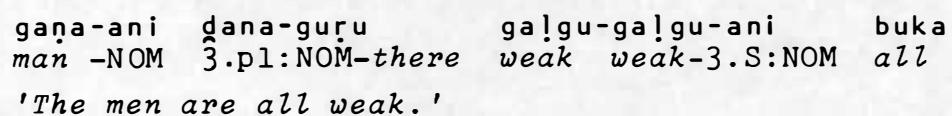

Here aga 1n, we may note that dual - non-dual is the only possible number specification. We speculate further, in section 4.2.2.1. that -ani in the comment NP of non-verbal sentences is linked with the notion 'stative', and its nature as a pronoun and its specification of number are relatively obscured by a pattern of occurrence in stative sentences.

We have adopted an assymmetrical gloss (with respect to bula) and a somewhat non-specific interpretation of the forms -ani and -ana when they occur enclitic to nouns in $S$ and 0 -function, respectively. We label them only NOM and ACC, in line with thelr (percelved) primary function in indicating case. Other occurrences of these pronouns we label 3(rd person) S(ingular) although aware that singularity exists only in strictly pronominal use; in other functions - in adnominal use or in non-verbal sentences - the number specification, if it exists at all, is apparently only non-dual.

\subsubsection{2. -ani and -ana as case clitics}

We have noted that the pronoun is sometimes the only morpheme marked for the case of an NP. Commonly, however, all members of an NP are marked. The following further arguments may be advanced for considering the bound forms -ani and -ana to have the status of case clitics. 
(1) The1r pattern of occurrence differs in no way from the casemarkers. Thus, their optional application to all members of an NP (or optional omission in the presence of a pronoun) parallels the pattern of the ergative and oblique cases.

(2) Their formation differs in no way from that of the ergative. In all three, the bound morpheme appears to be a reduced form of the third person singular pronoun. If we were to consider -ani and -ana to retain the functions of pronouns, rather than case-markers, then we must log1cally interpret the ergative the same way. Such treatment would relegate case-marking to a secondary function of a bound pronoun system, whose pattern of occurrence would be largely unexplained. Moreover, the ergative suffix occurs elsewhere in the area - it is an alternate ergative in Diyar1, for instance (Austin 1978:266).

(3) The type of boundary that exists between noun and case-marker is the same for all cases except for the locative, where the inftial consonant renders the nature of the juncture less discernible. Note also, however, that orientational suffixes intervene between pronoun and case clitic, with the notable exception of the locative.

(4) All personal pronouns form their accusative cases by the addition of -na. It would, then, be absurd to maintain that this represents an enclitic pronoun. Given that a common accusative inflection na (and varlants) occurs in many Australian languages, we can presume that the pronominal ending derives from that source. The simplest view of the whole system would assume no functional distinction between -(a)na occurring on nouns and na occurring on pronouns. The same argument then prompts a uniform view of -ani (NOM).

(5) The case-markers are termed 'clitics' partly because of the weak juncture that exists between noun and bound morpheme. There is little phonological fusion or assimilation between the final vowel of the noun stem and the initial vowel of the bound form. Alternative forms of the clitics may sometimes be heard - where no initial vowel occurs and a tighter boundary may exist. But commonly there is a clear drop in pitch between the two vowels, not only for -ani and -ana, but for the ergative (Instrumental) -andru, and the dative -apa, as well.

In summary, the simplest and most satisfactory analysis of -ani and -ana is one which identifies their primary role as case-markers, and their status as clitics. It is reasonable to postulate that at least -ani, and possibly -ana, evolved from third person pronouns that earlier occurred in a relatively fixed position, and which registered the case of an NP. There may even yet be some residual number specification 
in these forms. A development very similar to this is mentioned by Strehlow (1942:73-4) in Aranda:

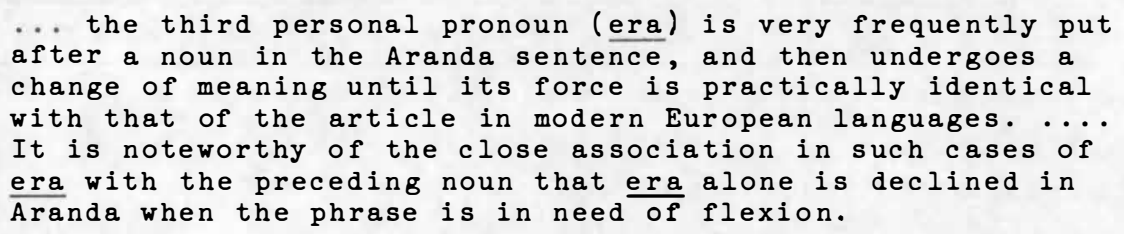

If the case clitics did evolve in this way, then we must envisage a language that originally had an ergative-absolutive system for most nouns, or which overtly marked only accusative and ergative cases. We have not 1dentified the function of unmarked noun stems in the text as absolutive, but the question is open as to what extent a genuine option exists in the language for zero inflection, signifying absolutive case. (Note that unmarked NPs are most often probably peripheral in function.)

Before the extension of the system, the language must have had a three-way distinction for pronouns, as many languages of the area do. In this instance, then, the three-way system was extended to all nominals, using bound forms of the third person pronouns. It may be that an older inflectional system was displaced in the process certainly the locative case appears to be signiflcantly different, and there is a very marginal occurrence of $-1 \mathrm{u}$ as an ergative case-marker. It may be that the relatively weak boundary characteristic of nouns and case-markers spread as a pattern from the enclitic 'pronoun' forms to the entire inflectional system.

\subsubsection{Noun Case Forms}

The noun stem normally occurs with one of a set of seven case clitics. If an NP contains an adjunct (third person) pronoun (which registers case), or an inflected modifying noun, the accompanying noun optionally occurs without case-marker. The case clitics are presented in Table 2 below. 
TABLE 2

Noun Case Clitics

\begin{tabular}{|l|l|c|}
\hline & Normal Inflections & Variants Recorded \\
\hline 1. Nominative & -ani (-ni) & $-1 u$ \\
2. Ergative & -andru (-ndru) & \\
3. Accusative & -ana (-na) & \\
4. Dative & -ana(ni) & \\
5. Locative & -laja, -luna & \\
6. Instrumental & -andru (-ndru) & \\
7. Ablative & -andru (-ndru) & \\
\hline
\end{tabular}

\subsubsection{Discussion of Case Forms}

In their normal occurrence, the case forms are vowel-initial. The alternant forms without the vowel occur very seldom, generally on words of three syllables, which end in the vowel /a/. In fact, certain words appear with these vowel-less clitics consistently - words like janida 'father', makura 'stick', and several others, while others of equal length and structure never occur with the alternant form.

The clitic -ani is the only nominative case clitic attested in Waijkumara (Galal1); Breen (1976b:336) records a 'masculine' alternate for Wankumara: - $i a$. This form is recognisable in Waijkumara (Galali) in one third person pronoun root, but is totally absent on nouns.

The ergative clitic is principally -(a)ndru. There are three examples of $-1 \mathrm{u}$ in the text, one enclitic to a kin term, another to an interrogative pronoun wara 'who', and a third to a numeral barkulu 'two'. Breen mentions both $-1 \mathrm{u}$ and $-\mathrm{ulu}$ as ergative suffixes in Wankumara, describing them as 'masculine'. There are plentiful examples of semantically masculine nouns in the ergative case in Wajkumara (Galali), always marked by -andru. Although the 'masculine' set of nouns in Wankumara is evidently quite heterogenous, there is no evidence in Waijkumara (Galal1) of systematic use of -lu. The ergative clitic -(a)ndru is homophonous with both the ablative and the instrumental clitics.

The variant forms of the locative (lana, luna) are impossible to differentiate on the basis of phonological environment or semantics (see sentences $(506,507)$ ). I una is used most frequently. Breen records -jala as an alternate locative suffix in Wankumara. This is the locative pronoun in Wankumara (Gaḷal1). 
There are no grounds in the text for differentiating an allative case from a dative. Both the long and short forms -(a)pa and-(a)pani occur, with no clear pattern of use distinguishing a separate allative case (see sentences $(62,63))$. The short form -aja is by far the most common on nouns. Equally, there are no grounds for distinguishing a separate genltive form. The clitic heard most often indicating possession has no inftial vowel (-na, -nani). But it occurs most commonly on pronouns or on the noun ganida 'father', where omission of the initial vowel is normal. We presume absence of the inftial vowel to be irrelevant, and identify the dative clitic (a)pa(ni) as the case-marker indicating possession. A possible source of the final syllable of the long form of this suffix is discussed in section 4.5. The long form occurs uniformly on pronouns, while varlation takes place on nouns.

There are no examples of a dative of possession further suffixed for case. A number of sentences - like (167) - occur in which the possessor might well have recelved further inflection.

There is a suffix -wara, which appears to mean 'belonging to'. It occurs with the dative form of the pronoun to signify 'mine, yours', etc.

\subsubsection{Noun Cases - Function}

The forms of the ergative, instrumental, and ablative case clitics are 1dentical. Three different cases are identified with respect to the one form, In line with syntactically different patterns of occurrence. NPs marked by the instrumental clitic may occur with intrans1t ive verbs and reflexives, while ergative NPs cannot. Ergative NPs occur in core function within the transitive clause, while ablative NPs occur in non-core function within the clause. In addition, separate forms exist in the pronouns for ergative and ablative case.

\subsubsection{Ergative}

The ergative case encodes the NP in agent function; where a clause occurs with an NP in ergative case, that clause is considered transitive.

Ergative inflection usually co-occurs in a clause with an NP in the accusative case, but 1 t also occurs occasionally with another core NP that is unmarked (140).

The ergative is used with all types of nouns: kin (101), human animate (398), non-human animate (195, 97), and abstract (477). 


\subsubsection{Nominative}

Nominative case normally marks an NP in subject function in an intransitive clause. Occasional omission of the nominative case clitic was mentioned in section 3.2.2. This clitic also commonly marks the topic NP of non-verbal sentences, although there, too, it is occasionally omitted. Thus sentence (6) may be compared with sentence (78).

(6) Danta diți mipa

I. DAT dog bad

'My dog is bad.'

(78) nani-gari diti-ani gampa dali-ani

3.S:NOM-there (far) dog far good-3.S:NON

'That dog (far away) is good.'

Note that it could be argued that the bound form -ani on the comment NP is another instance of nominative case-marking. While this might be true for these non-verbal sentences, it is harder to argue for interrogative non-verbal sentences, where the bound -ani probably represents a pronominal copy of the topic NP. We presume all occurrences in comment NP, then, to be instances of pronominal copying of the topic NP.

Association of -ani with equational sentences, and more generally with a stative reading, comes out clearly in the text. It is possible that the use of -ani in the comment NP of the sentences above reflects the speaker's focus on permanency - that is, whether he is predicating a state of affairs rather than asserting a (possibly temporary) fact. A further discussion of the use of -ani in non-verbal sentences is in 4.2.1.

\subsubsection{Accusative}

The accusative case marks the NP in object function in a transitive clause. It also encodes both direct and indirect object NP in ditransitive clauses. With ditransitive verbs a nominal direct object may appear uninflected. Sentence (72) appears with full marking of both object NPs in accusative case, while (74) and (478) exhib1t partial marking.

Since the accusative case marks the NP in 0-function, it normally occurs in a clause containing an ergative NP. It is also attested in clauses with nominative NP, however. This is discussed in section 4.2.2.

A clitic homophonous with the accusative is used to mark time in sentence (504). Only one such occurrence is recorded. 


\subsubsection{Dative}

The dative generally encodes the NP in indirect object function in transitive clauses, but not in ditransitives.

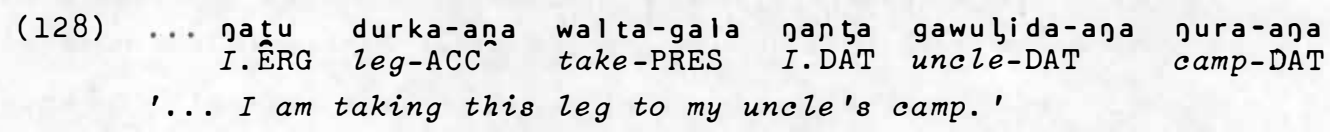

The dative appears to indicate goal, passive reciplent or addressee of the action of the verb. It appears in the complement of certain intransitive verbs, as in (112) below.

$$
\begin{aligned}
& \text { … nani wanki-na ganta makura-nani } \\
& \text { I.NOM find-PAST/P I.DAT stick-DAT } \\
& \text { '... I didn't find my stick.' }
\end{aligned}
$$

The dative has both local and non-local uses (as discussed by Lyons (1968:295, 298-301)). In sentences (7) and (175), in local use, it designates the actual goal of action:

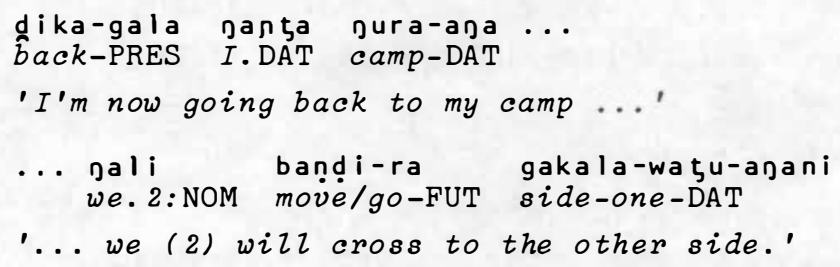

And in sentences like (61) or (130) - shown below - the dative may be seen in non-local use, indicating logical goal or purpose:

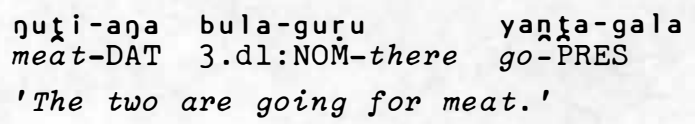

\subsubsection{Locative}

The locative case specifies the locale of a predication. It is attested in the text with the following functions:

(1) It marks location at rest at, on, or in a place.

$$
\begin{aligned}
& \text {... muna-ani yandra-l una } \\
& \text { snake-NOM stone-LOC } \\
& \text {... the snake is on the stone.' }
\end{aligned}
$$

(2) It indicates action in, on, or into a specified (possibly contained) space.

$$
\begin{aligned}
& \begin{array}{lllll}
\text { gațu } & \cdots & \text { winbi-ga } & \text { gațu } & \text { wiyi-luna } \\
\text { I.ERG } & & \text { throw-PAST/P } & \text { I.ERG } & \text { fire-LOC }
\end{array} \\
& \text { 'I ... threw it on the fire.' }
\end{aligned}
$$


In (408) below, the locative expresses action within a specified location.

(408) yandra nani-guru buli-wari-ra mirgala-luna naka-ana stone 3.S:NOM-there fall-vertical-FUT bank-LOC water-DAT

'This stone will fall down along the steep bank into the water.'

(3) In (462) the locative phrase is glossed 'against a tree'. In this use 1t might perhaps be described as marking an inert object partic1pating in the action, but not used as instrument.

(4) Locative indicates a specific point of time in sentence (455) below:

$$
\begin{aligned}
& \text {... nawu-lana } \\
& \text { night-LOC } \\
& \text {... at night.' }
\end{aligned}
$$

(5) It is used to mean 'in company with' in sentence (117) below.

(117) nugala-guru birki-birki-wa dali-luna diți-luna

3.S:LOC-there play play-EMPH? good-LOC dog-LOC

'That one down there is playing with the good dog.'

\subsubsection{Instrumental}

The instrumental case marks an inanimate instrument or tool (or body part) controlled by a human being to perform an action. A typical example may be seen below:

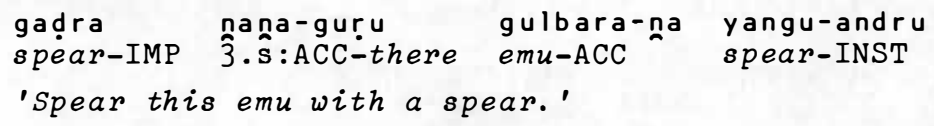

\subsubsection{Ablative}

The ablative is attested in local use specifying motion from a place. This is exemplified in sentences (64), (133) and others.

A non-local use of the ablative occurs only once, in sentence (292), in the use of an ablative pronoun. It appears here to indicate the reason for, or cause of, an event - that is, the logical point of initiation of the action of the verb.

(292) galka-iyi-ga Dani nupura-guru dina-ana $\ldots$
hit-REF-PAST/P I.NOM 3.S:ABL-there foot-AĈC
'I knocked my foot (because of) on it ...' 


\subsubsection{Derivational Suffixes}

\subsubsection{Singular and Dual Stems}

Specification of number in an NP may be achleved through the use of the third person pronouns, used adnominally. Alternatively, -wa tu 'one' may be added to the noun root. The form -wa thi is usually glossed as indefinite in English, as in sentence (85). It is sometimes translated 'other' as in sentence (175). Most occurrences of -waţu appear to be bound morphemes, but it is possible that it also occurs as a free form. Although -bula appears to parallel -watu in distribution, it is not obvious that -bula is a derivational suffix. It never occurs further suffixed. Plural may be indicated by (a) the free form buka 'all, together' or (b) the noun wandru 'many, a lot'.

\subsubsection{Comitative and Privative Stems}

Most Australian languages have a comltative derivational affix which marks qualities, afflictions or characteristics of a noun, as well as human company. A privative suffix marking the lack of certain characteristics or possessions may also occur. Wankumara (Galal1) has the privative suffix -mundu amply attested (see (508)). It is difficult to 1dentify a comitative with certainty. The morpheme -dinga in sentence (224) may be an example.

\subsubsection{Pronouns - Personal and Interrogative}

\subsubsection{Personal Pronouns}

The pronouns are marked by six morphologically distinct cases. The forms of the pronouns are presented in Table 3 below. 
TABLE 3

Personal Pronoun Paradigm

\begin{tabular}{|c|c|c|c|c|c|c|c|}
\hline REFERENT & NUMBER & NOM & ERG & $\mathrm{ACC}$ & DAT & LOC & $\mathrm{ABL}$ \\
\hline $\begin{array}{l}\text { lst } \\
\text { person }\end{array}$ & $\begin{array}{l}\text { sg. } \\
\text { dl. } \\
\text { pl. }\end{array}$ & $\begin{array}{l}\text { gani } \\
\text { gali } \\
\text { gandra }\end{array}$ & $\begin{array}{l}\text { gațu } \\
\text { gali-gu } \\
\text { gandra-gu }\end{array}$ & $\begin{array}{l}\text { gana } \\
\text { gala-ná } \\
\text { gandra-na }\end{array}$ & $\begin{array}{l}\text { ganţa } \\
\text { gala-nani } \\
\text { gandra-gani }\end{array}$ & $\begin{array}{l}\text { Danala } \\
\text { galapala } \\
\text { gandragala }\end{array}$ & $\begin{array}{l}\text { ganura } \\
\text { galagura } \\
\text { gandragura }\end{array}$ \\
\hline $\begin{array}{l}\text { 2nd } \\
\text { person }\end{array}$ & $\begin{array}{l}\text { sg. } \\
\text { dl. } \\
\text { pl. }\end{array}$ & $\begin{array}{l}\text { ini } \\
\text { yula } \\
\text { yura }\end{array}$ & $\begin{array}{l}\text { yundru } \\
\text { yula-gu } \\
\text { yura-gu }\end{array}$ & $\begin{array}{l}\text { ina } \\
\text { yula-ná } \\
\text { yura-ña }\end{array}$ & $\begin{array}{l}\text { ijka } \\
\text { yula-gani } \\
\text { yura-gani }\end{array}$ & $\begin{array}{l}\text { inala } \\
\text { yulagala } \\
\text { yuranala }\end{array}$ & $\begin{array}{l}\text { inura } \\
\text { yulaiura } \\
\text { yuragura }\end{array}$ \\
\hline $\begin{array}{l}3 \mathrm{rd} \\
\text { person }\end{array}$ & $\begin{array}{l}\mathrm{sg} \cdot \operatorname{masc} ? \\
\mathrm{sg} . \\
\mathrm{dl} \text {. } \\
\mathrm{pl} \text {. }\end{array}$ & $\begin{array}{l}\text { nia } \\
\text { nani } \\
\text { bula } \\
\text { dana }\end{array}$ & $\begin{array}{l}\text { nulu } \\
\text { nandru } \\
\text { dana-gu }\end{array}$ & $\begin{array}{l}\text { nina } \\
\text { nanna } \\
\text { bula-nna } \\
\text { dana-nूa }\end{array}$ & $\begin{array}{l}\text { nujka } \\
\text { najoka } \\
\text { bula-gani } \\
\text { dana-gani }\end{array}$ & $\begin{array}{l}\text { nuijala } \\
\text { najala } \\
- \\
-\end{array}$ & $\begin{array}{l}\text { numura } \\
\text { - } \\
\text { - }\end{array}$ \\
\hline $\begin{array}{l}\text { Form added } \\
\text { to root }\end{array}$ & & $\emptyset$ & $-\eta u \sim n d r u$ & - na & - gani & -gala & -nura \\
\hline
\end{tabular}




\subsection{Notes on Pronouns - Form and Function}

Note that morpheme boundaries are indicated between pronoun root and ending where orlentational suffixes are attested intervening between root and ending. Where one such instance is attested, the pattern is extended by analogy to all forms simflarly structured. That is, if we have yula-guru-na in the text, by extension, the first person gala-na is also indicated with morpheme boundary. Conversely, as nupala-guru appears in the text, all locative first and second pronouns appear without morpheme boundaries. This system is obviously faulty, but there is no way of ascertalning the correct form.

The pronoun morphology is open to a certain amount of analysis.

A base na- may be suggested for the first person. Note that Dixon (1977:172) has 1dent1fled * pay- as the protoform for this root. Traces of this latter form are apparent in the table. For example, the first person singular nominative root may represent gay $+-n i$, that is, base form plus nominative case-marker, with assimilation.

A postulated final laminal consonant in the base form *nay may account for the laminal articulation in jatu. (A common Australian ergative suffix is /Cu/, where /C/ represents a stop homorganic with the final consonant of a stem.) Note that the medial nasals of the locative and ablative may also be interdental, with the feature unrecorded.

A base form yu-may be suggested for the second person. Dixon (1977:172) suggests nun as the protoform. In the second person singular, the base form appears to be the vowel /i/. This may reflect development from an earlier nominative form *yuni.

Base forms na or nu may be identified in the third person singular. These are similar to Breen's third person pronouns (Breen 1976b:336), which he Identifles as 'feminine' and 'masculine'. Equally, nia (NOM), nina ( $A C C$ ) and nulu (ERG) occur in the 'masculine' paradigm in Wagkumara. In Wankumara (Galal1) there is no consistent use of 'masculine' forms. The variants in locative appear to occur randomly, whlle nunka is the most common dative form. The other masculine forms clted by Breen are present in the text in reference to male relatives - but nulu occurs only three times, nina only four times, and nia only twice. The 'nonmasculine' forms also refer to male relatives, as well as to all other categories of noun. If a gender distinction exists in Waykumara (Galal1) 1t is very marginal - the non-masculine forms appear to have generalised to normal use.

The different cases of all dual and plural pronouns are formed from the nominative root. 
The ergative second and third persons singular are suppletive; the bases are yu- and -na, postulated for the rest of the paradigms, but the form added is -ndru, which is identical to the case-marker of the nominal paradigm.

The forms added to the pronoun roots differ somewhat from those of the noun system. Locative -nala differs from -luna (the latter form is mentioned by Breen as a varlant of the pronominal locative in Wankumara). Ablative - jura is not apparently related to the form on nouns: -andru. (An ablative - pura occurs in Yandruwanda and Yawarawarga, to the west.) Pronominal - ju (ERG) is quite different from the noun form -andru. (A case suffix -ndru occurs in nearby Diyari. P. Austin (1978:294) has called 1t 'source' case, distinct from ergative and instrumental.) Although there are traces of a possible earlier $-n i$ in the nominative, no form can now be sald to be added to the pronoun base in the nominative. The added pronominal case forms that most resemble their noun counterparts differ in consistently lacking the initial vowel; thus there is not the same drop in pitch between pronoun root and case marker.

The nominative, accusative, ergative and ablative case roles of the pronouns are identical to those of nouns. The locative pronoun is attested in all the roles of the noun, with the addition of 'goal' of the verb yanda.

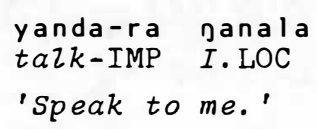

Pronouns are used in the dative case as nouns are, and in addition appear as indirect pronoun objects in transitive clauses (263, 340) and as the human beneficiaries of the action of a verb.

\subsection{Orientational Suffixes}

A set of orlentational suffixes occurs exclusively on pronouns. The set is presented in Table 4 below. Glosses may not be provided with certainty. 
TABLE 4

Orientational Suffixes

\begin{tabular}{|ll|}
\hline (1) -gari & This suffix 1s used falrly consistently with an English \\
& gloss 'far'. It may be heard as [gay]. \\
(2) -guru & Breen (1976b:336) glosses this very common suffix as \\
& there'. It 1s treated completely Inconsistently in \\
& a directional suffix. It Is glossed as 'there' in the \\
& text, following Breen. \\
(3) -bulu & This is glossed both as 'down there' and over there'.
\end{tabular}

\subsubsection{Interrogative Pronouns}

The gloss in the text reveals only the interrogative meaning of the pronouns in Table 5 below. A discussion of the usual indeterminate sense of these forms is presented in D1xon 1977:183.

TABLE 5

Interrogative Pronouns

\begin{tabular}{|c|c|c|c|c|}
\hline Form & Reference & Gloss & Inflections Attested & Gloss of inflected forms \\
\hline (1) wara- & human & 'who' & $\begin{array}{l}\text { Nominative, Accusa- } \\
\text { tive, Dative, Erg- } \\
\text { ative. The ergative } \\
\text { is Irregular }\end{array}$ & $\begin{array}{l}\text { wara-lu 'who' (ERG) } \\
\text { waṛa-na 'whose' (DAT) } \\
\text { wara-na 'who' (ACC) } \\
\text { wara-ni 'who' (NOM) }\end{array}$ \\
\hline (2) mina & non-human & 'what' & Dative & mina-na \\
\hline (3) gala- & place & & $\begin{array}{l}\text { Nominative, Ablative, } \\
\text { Dative }\end{array}$ & $\begin{array}{l}\text { gala-ani 'where' } \\
\text { gala-ana 'where to' } \\
\text { gala-andru 'where from' }\end{array}$ \\
\hline
\end{tabular}

\subsection{Notes on Interrogative Pronouns}

Interrogatives of time and quantity are formed by the nominals wandru ('much' - quantity) and wandu ('much' - time) plus suffixed forms -wara and-gutcu, respectively. -wara appears to be the genitive form 'belonging to'.

The locative root - jala probably represents a re-interpretation of a form inflected with this suffix.

A different form wani occurs in sentence (332), apparently a nonhuman interrogative pronoun. 


\subsubsection{Location and Time}

Time and location are indicated both by bound morphemes and by location and time words which are difficult to classify. Some are nominals; some occur in ways that suggest they are constituents of the predicate; and some are always uninflected, apparently qualifying the sentence as particles. The last two types are included in section 3.3 .5 .1 .

\subsubsection{Locational Suffixes}

(1) -yi : occurs on all nominals with both spatial and temporal meaning. It is glossed 'here' and 'now':

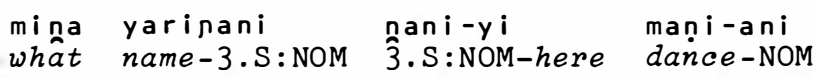

'What name is this dance?'

(2) -ya : 'there' (visible).

(3) - ba : glossed 'there'. Fleldwork suggests elther an indefinite meaning like 'focus away from speaker' or perhaps 'In the proximity of' (a place away from speaker).

\subsubsection{Location and Time Nominals}

The forms wina and gampa occur with meanings 'close' and 'far away', respectively. wina occurs inflected and is thus identified as a noun. gampa does not occur inflected but is treated consistently with wina. Several forms are obviously based on a form yala - presumably a demonstrative. One of the set occurs with the accusative inflection, suggesting that the whole set may be provisionally identified as nominals. Examples may be seen in the sentences below:

$\begin{array}{ll}\text { (372) yala-guba } & \text { 'somewhere' } \\ (387) \text { yala-guba-nu 'over that way' } \\ \text { (394) yala-iri }\end{array}$

The form yala may be seen in sentence (233) functioning as a discourse de1ct1c:

\begin{tabular}{|c|c|c|c|c|}
\hline $\begin{array}{l}\text { yala-apa } \\
\text { DEM-DAT }\end{array}$ & $\begin{array}{l}\text { nani-guru } \\
3 . S \text { :NOM-there }\end{array}$ & $\begin{array}{l}\text { inka } \\
\text { you.S:DAT }\end{array}$ & $\begin{array}{l}\text { ma bu } \\
\text { anger }\end{array}$ & $\begin{array}{l}\text { wa!pa-gala } \\
\text { rise/lift-PRES }\end{array}$ \\
\hline
\end{tabular}




\subsubsection{Nominalisations}

The purposive suffix - ra appears to have figured at least diachronically in the derivation of nouns. Very little can be seen of synchronic derivational processes.

\subsection{MORPHOLOGY OF VERBS}

\subsubsection{Structure of the Verb}

The minimal form of the verb is root plus inflection (with the inflection of the singular imperative 1dentified as zero). There are a number of derivational stem-forming suffixes which intervene between root and inflection. One set of such suffixes is adverbial in nature, specifying the direction of the action of the verb with respect to some point of reference - proto-typlcally the speaker. This set does not alter the transitivity of the verb. Reciprocal and reflexive suffixes form another set which alters transitivity.

Wajkumara (Galal1) differs from many Australian languages in having no confugational contrast; but note that this is an areal feature of western N.S.W., Queensland and eastern South Australla.

\subsubsection{Transitivity}

No phonological correlation can be established between verb stems and transitivity. In most Australian languages, transitivity is inherent to a particular stem, and derivational processes, of ten involving morphological marking alter transitivity.

There are several suffixes in Wankumara (Galal1) wh1ch alter trans1tivity, and there are also different verb stems for transitive and intransitive senses of certain verbs (for example 'burn'). However, other verb stems appear unaltered in both transitive and intransitive clauses. (The criteria for determining transitivity and the problems of case-marking a re discussed in section 4.2.2.). The meanings of the 1dentical verbs sometimes alter significantly, depending on trans1t1vity. For example: baka 'hide (1ntr)', baka 'send (tr)'; walpa 'rise (1ntr)', wa!pa 'Zift (tr)'. In such cases - where there is significant change of meaning - we accept the analysis that different, homophonous, verb stems exist.

\subsubsection{Inflections}

The 'tense' inflections appear to be mostly 'portmanteau' morphemes, specifying both tense and aspect. Irrealis and factive aspect 
Inflections are in paradigmatic contrast to these tense suffixes, except in several sentences, where irrealis appears to follow tense (see sentences (455), (237), and (238)).

\subsubsection{Tense Inflections}

(1) Present tense, continuous aspect -gala PRES

(2) Past tense, perfect aspect -na PAST/P

(3) Past tense - ? -gali PAST

(4) Future tense -ra FUT

The present suffix -gala is translated by the English present or present continuous, even where the action is semantically future, as in (35) below:

(35) Danta nanida dika-gala wikala I.DAT father back-PRES tomorrow

'My father is coming tomorrow.'

It 1 s also used to denote habitual action in the past $(67,68)$.

The past and perfect - ja is translated in English by the past perfect, the simple past, or a present tense in stative sentences. The last is lllustrated in (23) below:

(23) landru
we.pl:NOM thirsty-PAST/P

'We are thirsty ...'

The past suffix -gali cannot be described even as well as -ja. It is never translated with the past perfect or the present tense in English, but otherwise 1t overlaps with -na. The text 1llustrates a full range of use in the past tense, both punctual and durational (see sentences $(36,86,204,309))$. (Note that 1 ts form suggests a progresslve sense.) In the pair (311) and (313), -gali and -ga appear with a very similar gloss.

The future tense -ra is translated by the English future. It is homophonous with the Waykumara (Gaḷal1) purposive and with one form of the Imperative. These might all be grouped under one label; there appears to be a common semantic element of the type 'anticipatory' in all these uses of -ra.

\subsubsection{Aspect Inflections: Irrealis, Factive}

The Irrealis - $r i$ occurs malnly on the compound verb formative dika, although it is attested with other verbs occasionally (sentence 281). 
In sentences (321) and (322) - ra (purposive) and -ri (1rrealis) alternate apparently indifferently with regard to translation.

The Irrealis is generally assoclated with requests for action or with probable future action; the gloss in (237) and (238) indicates only futurity; (237) may well mean 'two men may be coming' rather than 'two men are coming'. Notice that the 1rrealis is used in sentence (199), in an apparent conditional clause.

The factive inflection, - la appears to indicate certainty or immediacy of action. It may usually be translated by 'now'. This inflection has the same form as, and a similarity of function with, Austin's 'New information' - la suffix in Diyari (1978:469).

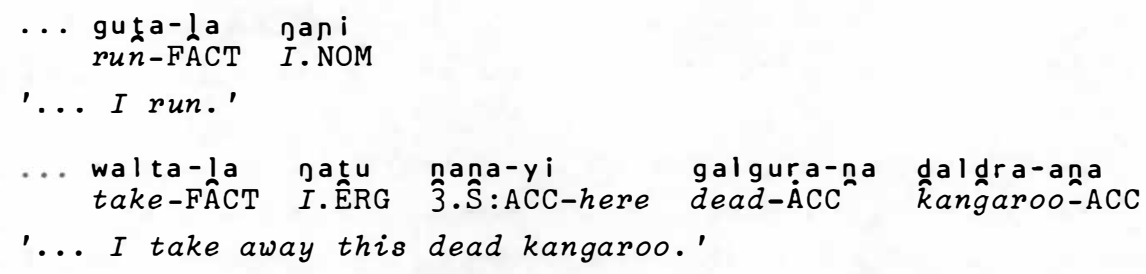

A further use of - $l a$, as a clause-marker in temporal clauses, is discussed in section 4.6.2.

\subsubsection{Possibility: -lanu}

-lapu is a modal suffix used to indicate the possibility of a future event or action, or the speaker's ability to perform some future action. It is often glossed 'might' or 'could'; It differs from the particle banini in that it may apply to an event. Use with an event is exemplifled by $(97)$ :

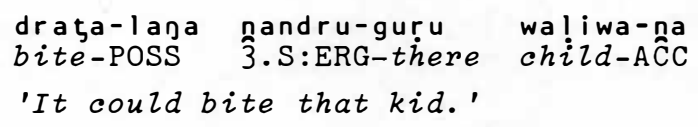

In sentence (382) below, it expresses the speaker's ab1lity to perform an action. Note that the use of waba plus a verb suffixed with -lagu overlaps with banini plus verb. This is exemplified in (171) below.

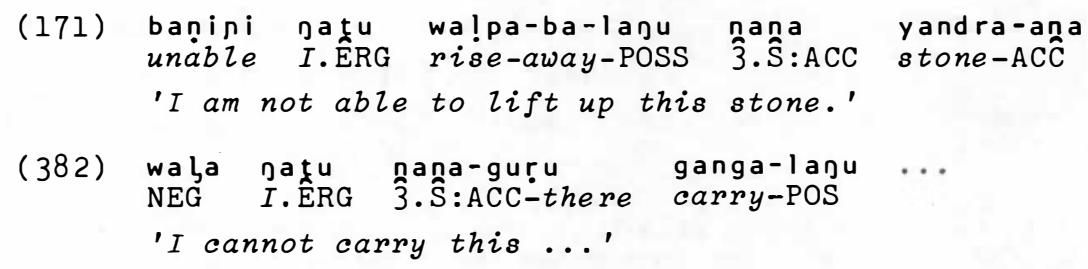


The two senses of English 'can' are encompassed by these two forms, but a clear application of one form to one sense is not clear: -lanu appears to handle both; banini seems to reflect malnly 'Inability'.

In sentences (322) and (325) -lapu occurs following the irrealis inflection; but the utterances might reflect a change of mind on the part of the speaker.

\subsubsection{Purposive and Imperative - ra}

The purposive inflection is -ra, identical to the future. In simple sentences, like (373), it expresses desire or intention. The purposive construction is discussed in section 4.6.3. We distinguish two inflections, the future and the purposive, because of inadequate information on permissible variations in the gloss of the verbs in some adjoined sentences.

The imperative verb occurs in two forms: bare stem or stem suffixed by - ra. Although a pattern is not consistent in the text, fleld information suggests that the bare stem was not normally used to a plural addressee; the -ra form is both more polite and more applicable in plural contexts. ${ }^{1}$

\subsubsection{Derivational Suffixes}

\subsubsection{Derivational Suffixes not Affecting Transitivity}

Derivational suffixes not affecting transitivity are of two types. One well-defined group, set 1 below, is adverblal in nature, specify ing direction of the action of a verb with respect, usually, to the speaker. Another two suffixes appear to be modal in nature, and are tentatively glossed as 'factual' and 'clrcumstantially possible'. These and several others are included in set 2 .

\section{SET 1:}

(1) (-)dika- Th1s morpheme occurs also as a free form, meaning 'to go back' or 'return'. It should probably be classifled as a compound verb formative rather than a stem-forming suffix, but it is the one exception in the set of bound morphemes. (-)dika- indicates movement back to a point of reference that is proto-typlcally the camp but occasionally simply the speaker. It always co-occurs with movement verbs, unlike some of the others. Reduplicated (Imparting a continuous

\footnotetext{
In fact, in the text the second person pronoun is usually present with the -ra form (it is deleted with the bare stem). The form of the second person pronoun is the singular. Identification of the differing imperative forms as singular and plural is based solely on information from fieldwork.
} 
sense), it is often translated as 'around'. It is glossed in the text simply as 'back'. '

(2) -ba- Indicates that the action of the verb is directed away from the speaker.

(3) -wari- Indicates that the action of the verb is either up or down (vertical) with respect to the speaker.

(4) -dara- In sentence (389) and (491) seems to mean 'through' or 'beside'.

(5) $-1 \mathbf{i}$ - occurs in sentences $(277,278,280)$, where 1 t forms a stem meaning 'break' from the root 'go'. Action may thus be movement 'apart' of two 1tems or parts of one 1tem.

(6) -walpi- In sentence (356) derives a stem translated 'turn around' from the root gali 'put'.

(7) -baru- in sentence (409) is translated 'far down'.

(8) bara- In (196) is translated 'out'. May be the same as (7).

SET 2:

(1) -na- occurs once in sentence (390) and is 1dentified (from fleldnotes) as a factual suffix.

(2) -dali- is attested in (298), is labelled 'circumstantial ability' from fleldwork. It is identical in form to the nominal 'good'.

(3) -dari- occurs in sentence (303), and may be an adverbial suffix: it is not glossed in the text.

(4) -dira- emphatic (119).

(5) -indi- meaning not clear.

\subsubsection{Suffixes Affecting Transitivity}

(1) -iyi-reflexive. The form of this suffix is set up as -iyi although 1t manifests 1tself phonetically as follows: the stem-final vowel of the verb is either deleted or assimilated to the initial vowel of the suffix. Only a long vowel [i:] is heard stem-finally. Thus murta-iyi-gala is [murti:gala]. Analysis of the underlying form rests

\footnotetext{
This form dika occurs in pamini as the second element of a main verb sequence, and in Diyari and Yandruwanda (Austin 1978:229). In Yandruwanda (Breen 1976a:752), as in Wankumara ( $\mathrm{G} a \mathrm{l} a \mathrm{l} i$ ), $\hat{a}$ general system of suffixation performs the adverbial functions performed in other languages of the area by main verb sequences. The one example of a compound verb formative in both languages is dika.
} 
partly on the similarity of its effect on the verb stem to that of the suffix-indi, where elision of the final vowel of the verb stem occurs. Further, the word for 'fire' is usually [wi:], but occaslonally clearly [wiyi], suggesting an analogous realisation.

The reflexive suffix derives an intransitive stem from the trans1tive root; it is glossed in the text as REFlexive, although it also marks the passive construction. For a full discussion of the use of -iyi, see section 4.4 .

(2) -nala - reciprocal. This derives an intransitive verb from a transitive root.

\subsubsection{Verbalising sufbixes}

(1) -munka - causative. Serves to derive a transitive verb 'heal' from the nominal dali 'good' in sentence (469). This suffix is identical in form with the verb 'make/do'.

(2) -minda - inchoative. In sentence (470) this suffix derives an intransitive verb 'heal' from the nominal dali 'good'.

\subsubsection{Other subfixes}

A post-inflectional suffix -ba-occurs several times. It is tentatively 1dentified as 'emphatic'.

\subsubsection{Particles}

\subsubsection{Location and Time}

The following words occur uninflected in the text, and are provisionally considered location and time particles.

$$
\text { Duration of time or space }
$$

(1) gabi (388): 'far away'

(2) ma ţa (391) : 'already' (some time ago)

(3) wada : 'Zong ago'

(4) Dalta : 'Zate'

(5) maba: 'Zate'

(6) gada (355) : 'yet' translated 'yet' w1th a negative; possibly

(362) 'stizl' in the positive.

(7) duna : may simply signify 'time'. It occurs in the following combinations:

$$
\begin{array}{cl}
\underset{\text { duna-wira }}{\text { wait }}(390) & \text { : 'wait a while' } \\
\begin{array}{c}
\text { duna-tiri } \\
\text { ? }
\end{array} & (318,320) \\
\underset{\text { duna-gula }}{\text { sit }} & \text { : 'soon' }
\end{array}
$$




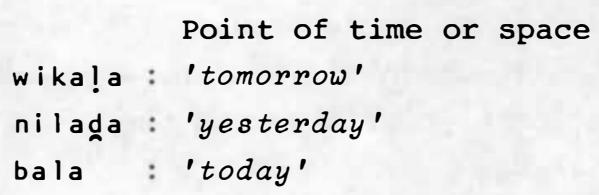

\subsubsection{Predicate Qualifiers}

Several particles appear to be constituents of the predicate, qualifying the verb:
(1) guri
'Zike this'
(2) gagalari 'this way'

\subsubsection{Modal Particles: waba (NEG), baṇini ('unable'), baṛi ('think'), mura ('finished')}

(1) The particle waba, when it functions as a sentence negator, stands initially, even in imperative sentences. It also occurs occasionally in pre-verbal position within a sentence, perhaps with lessened scope. It is used to negate a noun in waba gampa 'not far away'.

(2) baṇini occurs sentence inftlally; 1t serves as a sentence negator, glossed 'unable', but it is not always clear how it differs from the suffix -lagu with waba NEG. For instance, compare sentences (382) and (171).

As mentioned previously, the suffix -lapu applies to events, while baṇini does not. baṇini denotes inabll1ty through physical ineptness, inadequacy, or something similar. In sentence (298) baṇini also cooccurs with a suffix-dali, which indicates clrcumstantial ab1lity.

banini always occurs in clauses in which the verbs are inflected in the past tense (or perfect aspect). The translation is always present tense. Both -ja (PAST/P) and -gali (PAST) appear. For example:

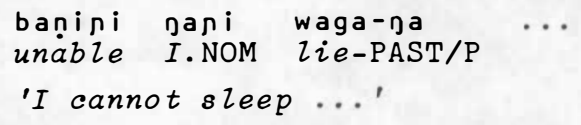

Note that the negative particle waba frequently occurs with banini perhaps redundantly. In sentence (177), where a comblnation of banini and -lapu may be seen, the reading is also negative.

Two other particles indicate a speaker's commitment with respect to the factual status of what he is saying.

(3) bari is inserted at any point in a sentence to indicate uncertainty about an assertion. It is glossed 'think'. 
(4) mura is translated 'O.K.', 'finished', or 'already'. It occurs sentence inftially, indicating that a statement is true or acceptable in the sense elther of completed action or confidence in the truth of the assertion. It is glossed 'finished'.

\subsubsection{Other Particles}

(1) guntu 'so'. This may be a discourse particle of the type 'thus, then', a confunction like 'so that', or simply a time particle 'soon'. (2) yuru 'only'?

\subsubsection{Interjections}

(1) ga 'yes'. Th1s can constitute an entire utterance, 1 t occurs initially in a sentence with an intonational pause. ${ }^{1}$

(2) wala- use parallels that of ga when used as an interjection.

(3) gala 'hey'.

(4) gari 'stop'.

(5) gawa 'come, come on'.

\section{SYNTAX}

\subsection{NOUN PHRASE CONSTITUENCY}

A noun phrase can consist of a pronoun, or one or more nouns appropriately marked for case.

A sequence of one or more nouns plus adjunct pronoun is also possible. Where a sequence occurs, case marking frequently appears on all 1tems. However, omission of case inflection on the head noun is fairly common in the presence of pronouns.

\subsection{SIMPLE SENTENCES}

\subsubsection{Non-verbal Sentences}

L1ke many Australian languages, Wankumara (Gaḷal1) has no copula verb. The simplest form of a sentence has a two-part structure consisting of a topic NP and an NP commenting on 1t. Non-verbal sentences are equational, attributive, and locational.

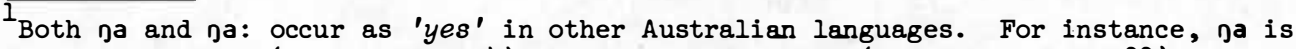
found in Dyirbal (Dixon 1972:124), and na: in Niyamba: (Donaldson 1977:288).
} 
The topic NP is normally marked by a nominative case clitic, although several sentences occur with unmarked topic NPs.

In section 3.2.2.1.1., we noted the occurrence of nani in the comment NP of a non-verbal sentence (369). The bound form -ani is customarliy present in a comment NP, rather than the full form. A typical example of an attributive non-verbal sentence may be sentence (506) below.

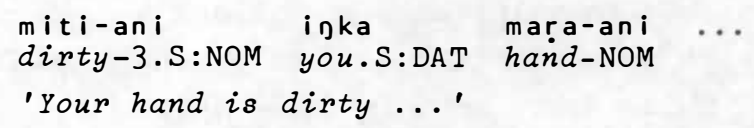

Sentences (189) and (190) shown below lllustrate the use of -ani in locational sentences. The locative comment NP does not occur with the nominative pronoun:

$$
\begin{aligned}
& \text {... muna-ani yandra-luna } \\
& \text { snake-NOM stone-LOC } \\
& \text {... snake on the stone.' }
\end{aligned}
$$

But the interrogative pronoun applying to locative NP reselves -ani in (190):

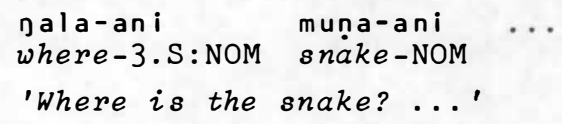

In fact, in every non-verbal sentence in which the comment NP is questioned, a clitic occurs on the interrogative pronoun. The clitic appears best 1dentifled as a pronoun, granting once agaln the functional diversity of these forms. In (105), for instance, we may see the dative of possession with enclitic pronoun. Note that the dative never occurs further marked by case clitics, unless -ani alone is considered an exception.

wara-na-ani

who-DAT-3.S: NOM

'Whose is that?' (a previously mentioned spear)

It is reasonable, then, to analyse nani in the comment NP of (369), and -ani in (506) as pronominal coples of topic NPs. The systematic occurrence of pronoun coples in the comment NPs of non-verbal sentences may well have extended to become mandatory where no noun is present in the comment, as in interrogative sentences.

In 'conjolned' clauses (discussed in section 4.6.1.), a non-verbal sentence may consist of a comment NP with enclitic pronoun. This may be seen in (278): 


$$
\begin{aligned}
& \text { gini-ani } \\
& \text { strong-3.S:NOM } \\
& \text {... it is strong.' }
\end{aligned}
$$

Here the pronominal topic NP may have deleted as a function of the relationship of the clauses.

Th1s occurrence of -ani on nouns in apparent bi-clausal constructions prompts a re-interpretation of some of the translations given in the text. The alteration involves postulating a bi-clausal structure where the English translation is a simple sentence. One of the postulated clauses is a non-verbal. This may be seen in (165) below.

$$
\begin{aligned}
& \text {... gatu ina nuta-dika-ra inka guti-ani } \\
& \text { I. ERG you.S:ACC give-back-FUT you.S:DAT meat-3.S:NOM } \\
& \text { '... I will give you back your meat.' }
\end{aligned}
$$

The case marking of NPs with the ditransitive verb 'give' is elther accusative on both ONPs, or accusative on the indirect object, with no marking on the direct (noun) object. The reading here must be: ' $I$ wizl give (it) back - it is your meat'. That 1s, the speaker is asserting a state of affairs with respect to ownership of the meat, not referring to a possessed NP. The structure, then, is complex, with one of the underlying clauses an equational one. This appears to be the case also in (29) and others like 1t:

$$
\begin{aligned}
& \text { waywa bungu-ani } \\
& \text { small guil tree-3.S:NOM NEG I. ThG see-PRES } \\
& \text { 'I don't see the small gum tree.' }
\end{aligned}
$$

The appropriate gloss must indicate assertion by the speaker of the smallness of the gum tree - that is, something like: 'it is a small gum tree, I don't see it'. Note that omission of object determiners is common practice, and that deletion of an identical determiner in bi-clausal constructions in the same intonation group is normal in the language.

Through 1ts characteristic occurrence in equational sentences, -ani appears in the text to have a close assoclation with the notion 'stative'. There are several instances in which-ani occurs enclitic to an inflected verb. In one case (336) the reading provided by the informant is stative:

$$
\begin{aligned}
& \text { bakarani-ani nani-yi } \\
& \text { boomerang-NOM } 3 \text { Satsi-gali-ani } \\
& \text { 'This boomerang is broken.' }
\end{aligned}
$$

Perhaps, in view of the pronominal copying into comment NPs of stative (non-verbal) sentences, there is also a tendency to have pronominal copying when an active agentless verb is functionally a passive. 
The translation of (366) is less helpful, but it too may be intended in a stative sense:

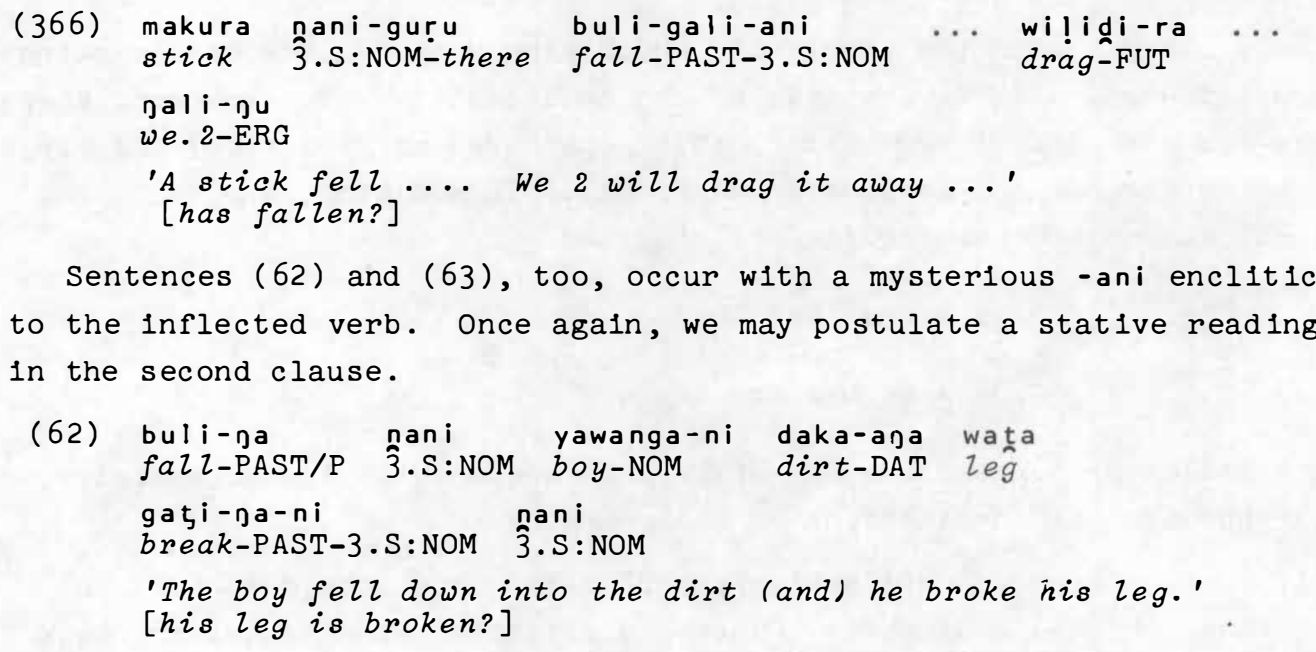

\subsubsection{Verbal Sentences}

It is assumed here that verb stems are intrinsically e1ther trans1tive or intransitive and that unusual patterns of case marking have their origin in the derivational history of the clause. Criteria for the determination of transitivity are as follows:

(1) Transitive verbs occur in clauses with an NP in A-function (usually marked by ergative case, but in two sentences (with unmarked noun stems) determined by semantic criteria (see section 3.2.1.)).

(2) Intransitive verb stems occur in clauses with an NP in S-function. Clauses in which an S NP co-occurs with an accusative-marked NP present problems, which are discussed later.

It is unfortunate that the nature of the Wajkumara (Galal1) material precludes identification of sets of verbs with common semantic features. For example, Chafe (1970) discusses such labels as 'process', 'action process', 'action', etc. If the nature of the verbs could clarify the relationships of the NPs in the clauses to be discussed here, then case marking might well be predicted and the interplay of case marking, verb transitivity, and syntactic processes in the language be better understood. ${ }^{1}$

$\overline{I_{\text {In his work }}}$ on Diyari, Austin (1978) describes five mutually exclusive sets of transitive verbs, distinguished on the basis of the syntactic and semantic effects of the addition of the "de-transitivizer" - tãri. Different combinations of case-marking are attested in Diyari with each group of verbs. His description of the Diyari verbs will be referred to here, where it relates to variations in case-marking in the text. 
In intransitive clauses the S NP is usually marked by the nominative case. However, unmarked S NPs occasionally occur, with no semantic consequence (see section 3.2.2.).

In clauses with two (probable) underlying core NP, the case-marking usually designates an ergative NP and an accusative NP. However, there are two examples of NPs in A-function that are unmarked ( 60$)$ and (195) - where the NPs and verbs are 1dentical). In addition, the following combinations of case-marking are attested:

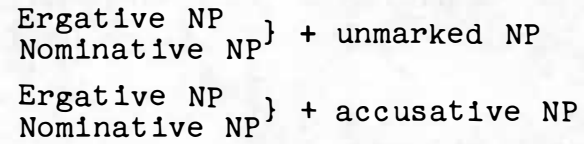

The following suggestions are of fered to account, at least partially, for the unusual combinations of case marking.

(1) The pattern 'ergative NP + unmarked NP' 1s attested in (31) as compared to (33) and others. There is a pattern here suggesting lack of specificity in the unmarked NP (first mention, indefinite gloss) but a careful study of the correlation of case omission and lack of specificity does not reveal a systematic correlation - rather, a tendency. The nature of the NP appears to play no part in the casemarking.

(2) Nominative NP and unmarked NP occur slightly more frequently. The verbs of interest are those that are basically transitive.

For all the verbs that occur w1th unmarked NPs (266), (306), (334), the translation is somewhat different from that applying to a normal transitive clause. For example, (203) may be contrasted with (217) below:

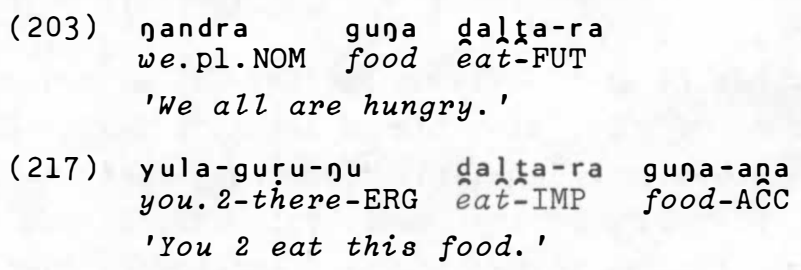

We might consider (203) and others as examples of object incorporation, or alternatively as derived intransitive constructions in which the NP functions have altered as follows:

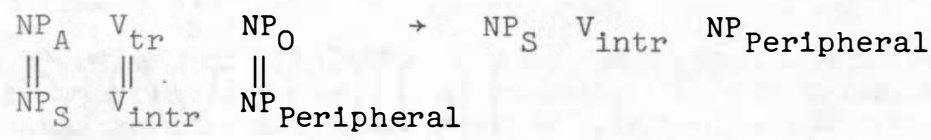

That 1s, it is the same change observed in the NP functions of 'ant1passive' clauses often noted in Australlan languages, and which 
sometimes impart a tense intermediate between active and passive (see Keen 1972 for this process in Yukulta).

(3) Nominative and accusative NPs co-occur in many reflexive clauses (these are discussed and exemplified in section 4.4.1.). In several other cases ((242) and (307)) analogy may be made with Austin's Diyari (1978:264): "na (ACCusative) is used in the complements of certain intransitive verbs. These NPs are so-called cognate objects ...." Austin specifically mentions verbs 'speak (a Zanguage)' and 'dance (a corroboree)'. These are the clauses represented in (242) and (307), with unusual case-marking.

Sentences (14) and (297) below 1llustrate other instances of nominative and accusative case-marking: ${ }^{1}$

$$
\begin{array}{llll}
\text {... nali } & \text { wiyi-ana galka-ra/ pali marpa-ra } \\
\text { we.2:NOM fire-AĈC hit-FUT we.2:NOM cook-.FUT }
\end{array}
$$

'... we (2) will light the fire. We will cook.'

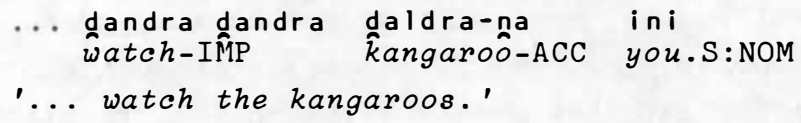

If the verb is intransitive, (297) may be equated with (242) and (307) as a verb with 'cognate' object in accusative case. As for (14), Austin (1978:168) describes a class of verbs in Diyari (including a verb 'cook') whose clauses undergo a syntactic change - In the presence of the "de-transitivizer" tari - that he describes as follows:

$$
A \rightarrow S \quad O \rightarrow O
$$

This change registers a semantic shift from focus on the agent to focus on the activity being carried out. We cite this syntactic change because of similarity of the case markings with that of Wankumara (Galal1). However, there is no morphological indication on the verb of the syntactic (and semant1c) change in Wagkumara (Galali).

One other sentence appears similar. We may contrast (5) with (4) below. The exact semantic effect of (5) can only be guessed at.

$$
\begin{aligned}
& \text { (4) ... bula-guru-gu muruba-na gum gumana } \\
& \text { 3.dl-there-ERG finish-PAST/P food-AĈC } \\
& \text {... they (2) have finished the food.' }
\end{aligned}
$$

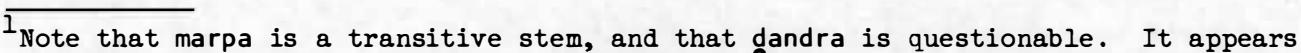
in (364) with a dative NP and a slightly different interpretation. Note also that we don't know that the (deleted) pronoun in clause two of (14) is in 0-function.
} 
(5) yura muruba-pa

you.pl:NOM finish-PAST/P

'You alz are finished.'

Note that an alteration in meaning is observable systematically where a transitive verb occurs alternatively with ergative NP, then with nominative NP. It seems unlikely that the variations in casemarking are a result of simple optionality in the use pf pronouns. Further, we might expect many more examples in the case of optionality.

\subsection{ORDER OF CONSTITUENTS}

\subsubsection{Declarative Sentences}

Word order is very free. An English svo pattern is exemplified quite frequently, undoubtedly prompted by elicltation. There are indications of a process of topicalisation, which involves shift of a noun phrase to sentence-initial position. The determiner is then often considerably separated from the rest of the noun phrase, presumably marking a more normal position of the NP. Glosses of such sentences read contrastively in English, but presumably warp the semantic effect of topicalisation.

\subsubsection{Questions}

\subsubsection{Polar Questions}

There are only four polar questions in the text. All exhibit verbinitial construction, which is very rare in declarative sentences:

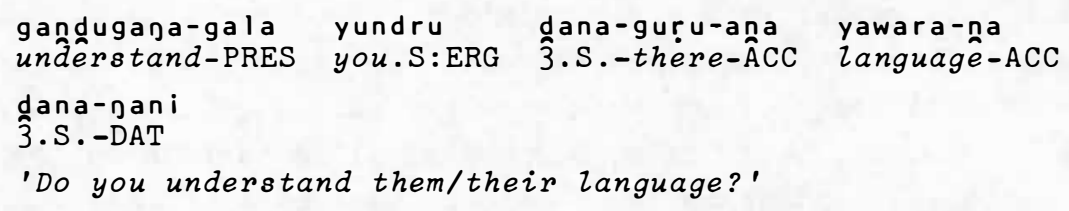

'Do you understand them/their Zanguage?'

An intonation rising to the end of the clause also marks the question.

\subsubsection{Information Questions}

A set of interrogative pronouns (set out in section 3.2.6.2.), is used in forming information questions. The pronouns occur sentenceinftially:

(133) Dala-andru ini

where-ABL you.S:NOM

'Where are you from?' 


\subsubsection{Imperatives}

In the plural imperative the second person pronoun is normally present, following the verb. In the singular, the pronoun sometimes appears (e1ther ergative or nominative) but is more often omitted. The imperative sentence is verb-initial, except in the negative, where the verb is preceded by the negative particle waba. In sentence (357) a locative determiner precedes the imperative verb; this is presumably an instance of topicalisation.

\subsection{THE USE OF - iyi (REFLEXIVE)}

\subsubsection{The Reflexive}

A true reflexive, in which the underlying agent and the underlying patient NP are co-referential, is exemplified in (86):

(86) galka-iyi-gali nani-guru darana-andru hit-REF-PAST 3.S:NOM-there axe-INST

'He hit himself with a stone axe.'

The characteristic features of the reflexive are:

(1) addition of morpheme -iyi to the verb root;

(2) absence of an NP in object function (but see discussion below);

(3) nominative inflection on the NP in subject function.

A reflexive construction is sometimes used where the activity of the verb affects a body part of the agent. In such cases the body part may be inflected in accusative case. This may be seen in (155), (329), (497), and is 1llustrated in (292) below:



This construction must be considered in the light of the overall treatment of body part possession (see section 4.5. for deta1ls). Body part possession is usually indicated by juxtaposition of NPs, both in the same grammatical function. In (292), then, body part and possessor NP would at one stage both be in object function. Reflexivisation appears to require only that the $O \mathrm{NP}$ include a noun co-referential to the A NP. Thus the configuration triggers the reflexive construction, and the appropriate morphological and syntactic response results. The body part remains, presumably in o-function. ${ }^{1}$

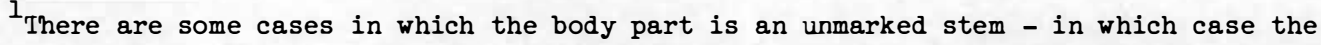
status of the NP is questionable. It may be in peripheral function or be an unmarked object.
} 
The syntactic change is:

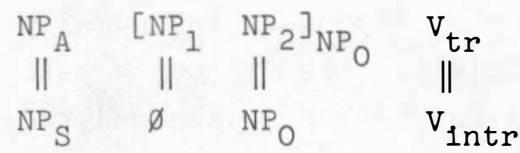

Note that we have other examples of nominative and accusative NPs in the same clause. The reflexive is particularly interesting, as in every other case it might be argued that: (a) the accusative marking is an accident; (b) the accusative marking is a strange convention for marking a peripheral NP. Reflexives occur in sufficient number to eliminate doubt; the verbs necessarlly involve underly ing transitive verbs with agent NPs; the NPs marked accusative can be considered to be in O-function.

The Wankumara (Galali) examples clted (reflexives and others) in which $S$ and $O$ NPs co-occur in the same clause - and Austin's verb set which exhibits the syntactic change $A \rightarrow S, O \rightarrow O$ (in the presence of -tari ) - all constitute derived intransitive clauses that retain two core NPs.

These clauses are of interest to linguistic theory, presenting problems for some theorles of case-marking (including the one used here) that leave case-marking until a late stage in a derivation. The descriptive framework we use here, where an $O \mathrm{NP}$ is defined as 'the other obligatory NP in a transitive clause', must be modified to acoount for the data.

\subsubsection{The Passive}

There are a number of examples of a construction that may be described as a passive. Several of these are shown below.

(496) mina munkV-iyi-gali ini mom mara-ani
whât make/do-REF-PAST you.NOM hand-NOM
'What happened/was done to your hand?'
(450) nani-yi hothi-ani marpa-iyi-na
3.S:NOM-here meat-NOM cook-REF-PAST
'... this meat is/was cooked.'

We must envisage a change here as follows:

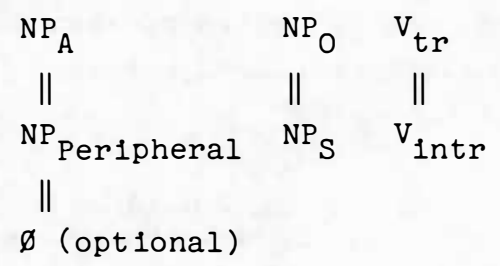


In sentence (496), the unmarked NP mina appears to question the underlying agent. We presume peripheral function for the NP mina.

The shift of the object NP into subject function in these sentences may be motivated by the occurrence of an unspecified underlying agent.

Other sentences which may be considered passive are presented below. Note that (46) and (477) are included for contrast w1th (44) and (142), respectively.

(44) murta-iyi-gala
hurt-REF-PRES

'He feels sick.'

(46) waba murta-gala jani

NEG hurt-PRES I.NOM

'I am not sick.'

(41) munkv-iyi-gala gani

feel-sick-REF-PRES I. NOM

'I feel sick.'

(142) yawura balti-iyi-gala jani

hot feê-REF-PRES I. NOM

'I feel hot.'

(477) yawura-ndru Jana galka-gala

heat-ERG I. ÂCC hit-PRES

'Heat is hitting me.'

(441) munka-iyi-gala gani guka-ani ... make-REF-PRES I.NOM head-NOM

'I am having pains in the head ....'

(148) dilaba drata-iyi-gala jani cold bite-REF-PRES I. NOM

'I feel cold.'

In (41), (44) and (441), the agent is unspecified and the NP is in S-function. Note that although the final vowel is not obtainable, it appears to be the verb munka 'make, do' with the translation 'feel sick' (when suffixed by -iyi). The underlying sentence may resemble 'something affects me', with the pragmatic interpretation of 1llness.

The alternation between the interpretation 'to feel sick' (munka with - $i y i$ ) and 'to be sick' (without -iyi) is clearly evident in the text.

In sentences (142) and (148), the underlying A NP is present - uninflected and presumably peripheral - in the clause. The underlying agents are forces which instigate the action of the verb rather than 
controling agents. (But note that sentence (477) indicates that such agent NPs may also appear in A-function in surface structure.) $)^{1}$

One further sentence, (176) below, may be mentioned in connection with the passives. In (176) the changes of basic functions of $S A$ and 0 is similar to the passives. An apparent intransitive verb stem (as evidenced by sentence (175)) is shown in combination with a probable underlying peripheral (dative) NP in derived S-function. The underlying S NP has presumably been deleted after grammatical 'demotion'. We suggest something like 'one cannot cross this water' as the underlying intransitive clause.

$$
\begin{aligned}
& \text { waba bandi-lanu paka-ni } \\
& \text { NEG movelgo-POSS water-NOM 3.S:NOM-there } \\
& \text { 'Cannot cross the water, ...' } \\
& \text { [This water is not crossabie.] }
\end{aligned}
$$

Here the change 1s:

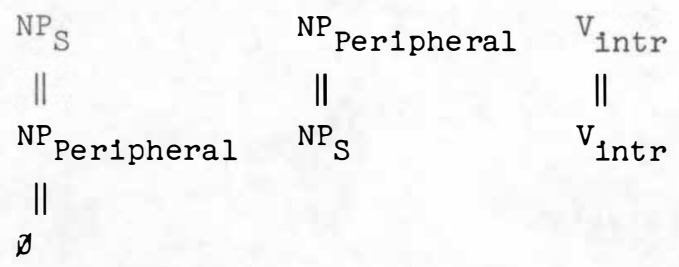

The characteristic features and structural changes in these-iyi constructions are very similar - particularly in the reflexive and passive. If we were to presume, in the case of the reflexive, that the $O N P$ went into subject function, and that the A NP became peripheral and deletable, then the reflexive would be only a speclal case of the passive. 2

\subsubsection{Other Uses of $-i y i$}

There 1s one other type of sentence in which -iyi appears:

\footnotetext{
Austin (1978:183) notes a passive in Diyari, which is attested for only one group of transitive verbs, producing a passive 'process' meaning. The patient undergoing the process occurs as the S-NP in construction with the derived stem and the underlying agent is marked by LOC or INST (and is often deleted).

2It might be suggested that such constructions as the passive in (496) and (450), and the one just illustrated reveal a position of prominence in the clause in Wankumara (Galali) - which may be identified as subject position. The most semantically prominent NP in the clause - Agent in transitive clauses - the sole core NP in the underlying intransitive clause - normally occupy derived subject position, but may be 'demoted' in preference for a more concrete, referentially more prominent, NP.
} 
(482)

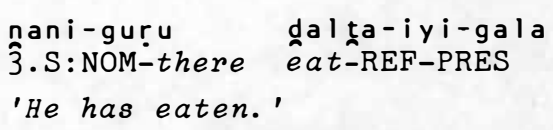

Here the construction seems (intuitively) to record a state of affairs as opposed to an activity or event. (Note that it can be contrasted with (504), a normally case-marked transitive clause and (203), a clause in which there are NPs in S-function and unmarked O-function. We have noted several interpretations possible of (203), including object incorporation.)

The uses of the : di suffix in Y1din is in some ways similar to that of -iyi. Dixon (1977:276) suggests that the :di suffix marks an infringement in the case marking of a transitive clause. The normal situation is one in which the underlying agent is marked in surface structure in the ergative case. Where the underlying agent is not marked ergative in surface structure, or where ergative marking occurs but agenthood (control) is not intended by the speaker, then the :di morpheme signals this deviation. Thus the -iyi suffix in (482) may register the speaker's focus on a situation where the subject NP is not seen as an instigator of an activity but as the experiencer of a state. This change of focus, of course, characterises passive sentences relative to active ones.

In reflexives, the underly ing agent is also clearly an 'experiencer' - affected by the action of the verb. It may be that some such spec1fication should be made in clauses marked by -iyi. If we interpret the -iyi suffix as a marker of the diminished 'agenthood' of underlying agent NPs, at least with some verbs, we are reasonably in accord with descriptions of the : di suffix in Y1din (D1xon 1977), the -tari suffix In Diyar1 (Austin 1978) and the -yi suffix in Dja:bugay (Hale 1976b:325).

\subsection{POSSESSION}

Allenable possession is expressed by dative case clitic on the possessor NP and no additional marking on the possessed NP. Inalienable possession usually involves NPs placed in apposition, as in sentence (197). However, there are a number of exceptions, as in (437) below:

(437) guka janta munkv-iyi-gala head I.DAT make-REF-PRES

'My head is hurting.'

There are a number of sentences with possessor of possessor constructions, where both NPs are marked by the dative inflection (see (168) below). One is always a pronoun. The dative of possession is never attested with further case-marking. 
(168) makura nani ganţa gaṇiga-ga nani

stick $3 . S: N O M$ I.DAT father-DAT 3 .S:NOM

'This is my father's stick.'

In the light of (168), the 'long' form of the dative case clitic - (a) gani should be looked at again. If the bound form-ani had appeared in (168) rather than the sentence-final nani, then an apparent dative clitic -(a)pani would have been identified - when in fact the form consisted of the dative-marked noun plus enclitic nominative pronoun.

We have mentioned that a bi-clausal construction may often be postulated to explain -ani-marked nouns in the text. The glosses involved are often simple English sentences, and one of the clauses of the postulated complex construction is a stative non-verbal clause, in which a bound nominative pronoun reflects the topic NP (for example see (101)). The possessive construction, too, represents this sort of relationship between clauses. Thus the 'long' form of the dative may derive from a normal morphological pattern in the language. Sentence (95), below, may then be analysed as shown.

$$
\begin{array}{llll}
\text { ganida-pa ganta nani-guru } & \text { diti-ani guti-dika-dika-gala } \\
\text { father-DAT } & \text { I.DAT } 3 \text { 3.S:NOM-there dog-NOM run-back-back-PRES }
\end{array}
$$

[( ganta) ganida-ga(-ani) diți-ani] [d’ți-ani guți-dika-dika-gala] S I.DAT father-DAT-3.S:NOM dog-NOM S S dog-NOM run-back-back-PRES S

The complex sentence relationship deletes one occurrence of the common NP dit i.

This is not to suggest that the long form of the clitic is always synchronically analysable as dative plus pronoun. It appears that the long form has been adopted as an alternative form of the dative clitic.

As mentioned earlier, the inalienable relationship is often expressed by juxtaposition of two NPs, possessed and possessor, with no dative case-marking. This is exemplified below.

(461) mara-ani nani duka-gala

hand-NOM I.NOM swe $2 l$-PRES

'My hand is swelling up.'

In (485) however, it is difficult to be certain of the grammatical status of the possessed body part, as it is unmarked. Most unmarked NPs appear to be in peripheral function. However, some unmarked NPs may reflect a (postulated) marginal option in the language for $S$ and $O$ NPs to appear in absolutive (unmarked) case. 


\subsection{COMPLEX SENTENCES}

\subsubsection{Conjoined Clauses}

Clauses which stand in a close semantic relationship and which are often translated by English sentence embedding or conjolning are simply juxtaposed simple sentences in the Wankumara (Galal1) text. The Wankumara (Galal1) clauses always share one or more common NP and have the intonational contour of a single sentence. One of the common NPs is occasionally, but not usually, deleted. This method of indicating the relationship between sentences is common in Australian languages. A similar situation was discussed by Smythe (1948:75) for Gumbayngir. He referred to the relationship as 'conjolning' and sa1d:

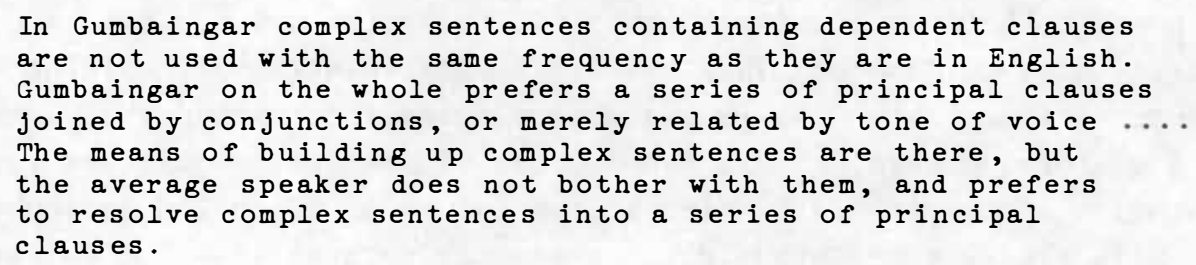

Thus the absence of any relative clauses in the Wankumara (Galal1) text indicates nothing of the resources avallable to the language for the creation of complex sentences. We will treat as complex those sentences which appear to be closely related in the text through intonational contour or through the deletion of one of a set of common $\mathrm{NP}$, as well as those sentences for which the relationshlp is indicated morphologically. Sentences in which there is no morphological indication of dependence will be termed 'conjolned', following Smythe.

Confunction of two transitive verbs is 1llustrated in (113).

$$
\begin{aligned}
& \begin{array}{lllll}
\text { natu } & \text { manda-na } & \text { winbi-na } & \text { nattu } & \text { wiyi-luna } \\
\text { I. ERG } & \text { hol̂́-PAST/P } & \text { throw-PAST/P } & \text { I.ERG } & \text { fire-LOC }
\end{array} \\
& \text { 'I picked it up and threw it on the fire.' }
\end{aligned}
$$

There are 21 examples of 'confolned' sentences in the text, Including those analysed as b1-clausal, but translated as simple sentences. Conjolned sentences always have common noun phrases, and the relationships of the NPs observed are, with one exception, e1ther $A=A$, or between any combination of $S$ and 0 . Sentence (398) appears to represent $0=A$. The predominant ergative-absolutive pattern glimpsed here may possibly be accidental.

\subsubsection{Temporal Clauses}

A temporal clause is a dependent clause which shares 1dentical time reference with the main clause, and which serves elther to specify the 
time of the event depicted in the main clause or to introduce add1tional information relevant at the time specified by the main clause. Temporal clauses in Wankumara (Galal1) correspond in meaning and structure to the adjoined clause of the T-relative type described by Hale (1976a:78-85) in Walb1r1. That is, they are morphologically marked as subordinate in surface structure and are marginally related to the main clause, rather than embedded. When the temporal clause 1s Inftial, a pause may be heard before the maln clause.

The temporal clause is attested in sentences (159), (178), (199), (302), (394) and (417).

In the first four of these, the temporal clause is marked by the factive inflection $\mathfrak{l}^{a}$. We have identified la in simple sentences as a morpheme indicating immediate anticipation or intention. (It is usually glossed 'now'.) Thus the exact time relationship holding between clauses marked by $l a$ and main clauses is of interest. There is a uniform pattern: In all cases it is used where two clauses express a simultaneous action/situation in the future or where the action of the main clause is relatively later (in the future) than the action of the subordinate clause. This type of relationship is exemplified in (199) below.

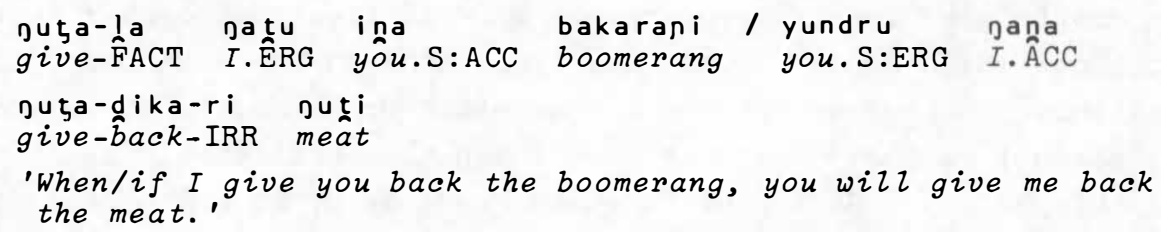

The other temporal clauses are marked by gula, a form homophonous with the verb 'sit'. Note that the temporal relationship expressed in (417) below differs in no obvious way from that of (199).

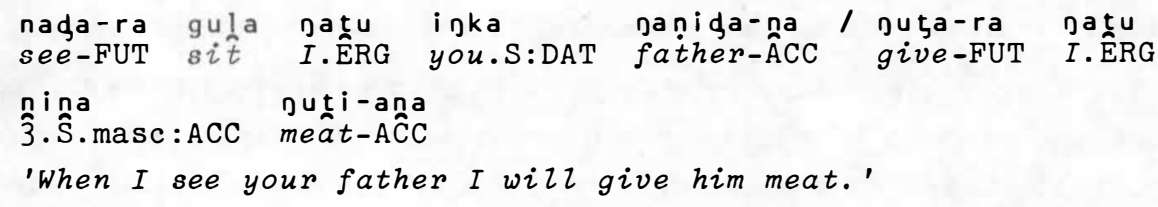

Here future time is indicated by -ra, with the subordinate relationship registered by gula. In both (199) and (417), the main clause and subordinate clause contain co-referential NPs. The readings are simllar, with no indication of how the different 1mplications. In (199) there 1s a greater sense of 1mmediacy than in (417), perhaps; but this cannot be observed in other examples in which la appears. This sort of distinction cannot be discerned in the text. 
However, there is one further difference worth mentioning. In (199) (w1th la) the co-referential NPs are $0=A$, whereas in (417) (w1th gula), they are $A=A$. In other words, the NP in subject function ( $S$ or A) in the main clause is co-referential with the NP in subject function in the subordinate clause in sentence (417) but not in (199). Moreover, in every temporal sentence contalning la, such NPs are not co-referential. There is not enough evidence in the text for any real consideration of $l a$ as a marker of a switch in reference between subject NPs - but the possibility is suggested by the presence of a switchreference pattern in Diyar1 and other Australian languages (Austin 1979). Note that if la is controlled by swltch reference, then the text reveals the phenomenon only in future temporal clauses. gula occurs in one sentence with non co-referential NPs in the past: ${ }^{1}$

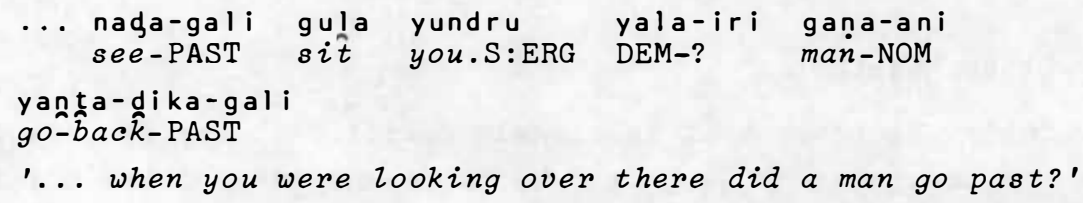

In clauses marked by $-1 \mathrm{a}$ and gula, the reading is ambiguous between conditional and temporal. In fact, in sentence (199) the English translation given is conditional. This ambigulty is mentioned for Walbir1 T-relative clauses by Hale (1976a), who notes that a conditional interpretation predominates when the dependent clause is in the irrealis mode, as 1 t is in sentence (199). Note, however, that another more specifically conditional construction is described in section 4.6.4.

\subsubsection{Purposive Clauses}

In a number of complex sentences, the action of the verb of the subordinate clause is implicated in the action of the verb of the main clause. The 1mplicated verb is marked by the suffix-ra. The 1mplication exists in time: the action of the main clause necessarlly precedes that of the subordinate clause. It also exists semantically: the action of the subordinate verb hinges on that of the main verb, while expressing intention or anticipation. The normal English

\footnotetext{
The use of the verb gula 'sit' as a relative clause marker is not altogether surprising in view of its use in a number of Australian languages to indicate continuous activity. For instance, I am informed by F. Morphy that a Yu:lgu construction involving the verb 'sit' may receive an English translation resembling a time clause. For example:

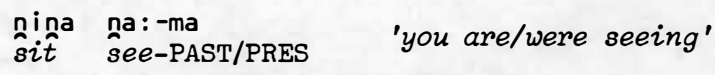

This may be interpreted 'while you were seeing'.
} 
translation would be 'in order to'. A typlcal example may be seen in (12) and (72) below.

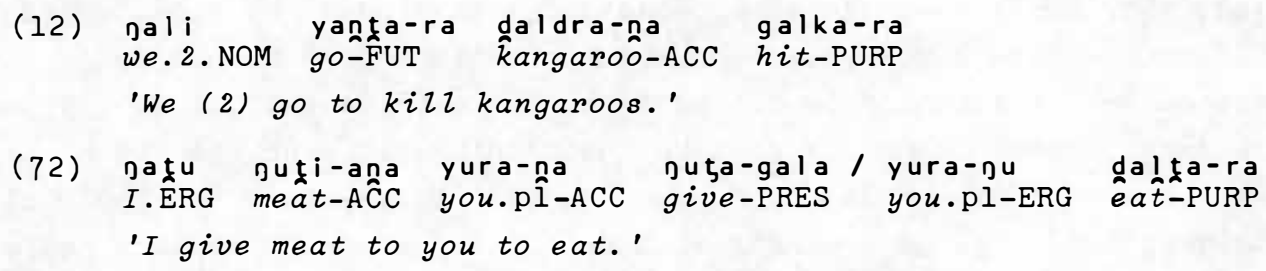

The relationships between NPs cover most possibilities: $S=A, A=$ $A, S=0, S=S$. Deletion, when 1t takes place, occurs between clauses without constraint by the grammatical function of the NPs. There is no reason to presume the structural relationship of the two clauses to be any closer in purposive than in temporal clauses.

\subsubsection{Other Clauses}

(1) A complex sentence that is clearly conditional may be seen in (416) below. The construction is marked by the occurrence of the modal suffix -lanu in both clauses:

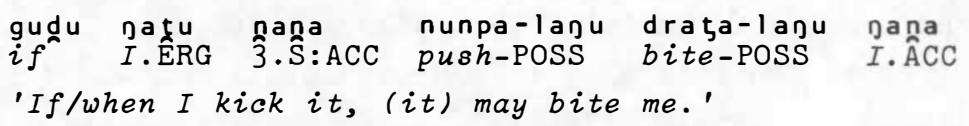

(2) The English translation of sentence (261), and intonation, suggest an implied resultative relationship between two clauses. There is only one such translated construction, but (369) seems likely to express the same sort of relationship.

(261) mura Dani garki-na nana-guru / guntu
finished I.NOM call-PAST/P 3̂.ŜAC-there so
nia-guru
3.S.masc:NOM-there back-FUT
'O.K. I called that man so he will come back.'


BIBLIOGRAPHY

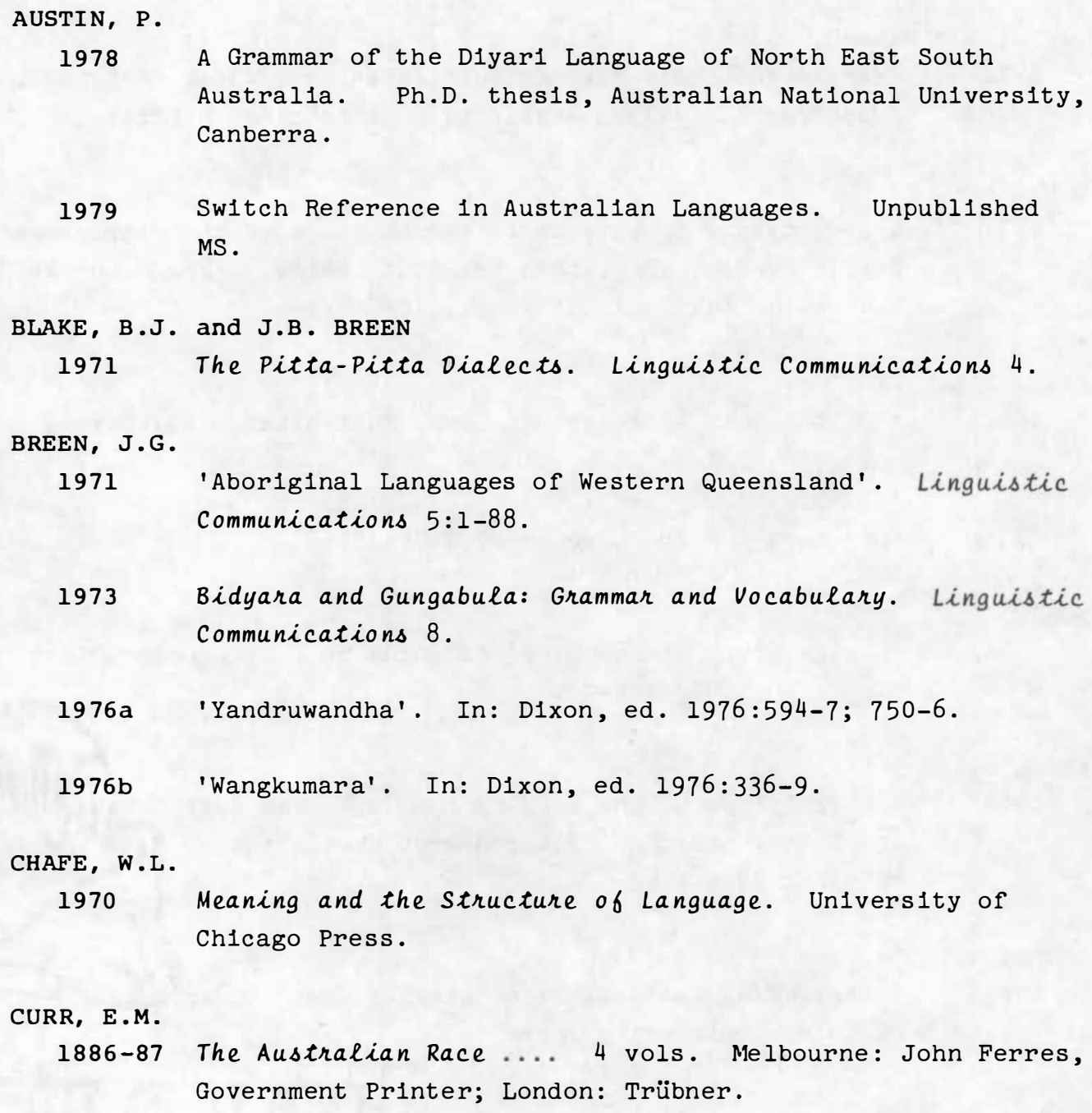


DIXON, R.M.W.

1972 The Dyirbal Language of North Queensland. London: Cambridge Un1vers1ty Press.

1977 A Grammar of Yidis. Cambridge Studies in Linguistics 19. Cambridge University Press.

1979 'On Ergativity'. Language 55/1:59-138.

DIXON, R.M.W., ed.

1976 Grammatical Categories in Australian Languages. AAS, L22. Canberra: Australian Institute of Aboriginal Studies.

DONALDSON, T .

1977 A Description of Nglyamba:, the Language of the Wana:ybuwan People of Central Western New South Wales. Ph.D. thesis, Australian National University, Canberra.

HALE, K.L.

1976a 'The Adjolned Relat1ve Clause in Austral1a'. In: Dixon, ed. $1976: 78-105$.

1976b 'Dja:bugay'. In: D1xon, ed. 1976:321-6.

HEATH, J .

1976 'Substant1val Hierarchies: Addendum to Silverstein'. In: Dixon, ed. 1976:172-90.

KEEN, S.L.

1972 A Description of the Yukulta Language - an Australian Aborlginal Language of North-west Queensland. M.A. thes1s, Monash Un1versity.

LYONS, J .

1968 Introduction to Theoretical Linguistics. Cambridge: Cambridge University Press.

MCDONALD, M.

1977 A Study of the Phonetics and Phonology of Yaraldi and Assoclated Dialects. M.A. thesis, Australian National University, Canberra. 
NILSEN, D.

1974 Toward a Semantic Specification of Deep Case. The Hague: Mouton.

SILVERSTEIN, M.

1976 'H1erarchy of Features and Ergat1v1ty'. In: D1xon, ed. 1976:112-71.

SMYTHE, W.E.

1948-49 Elementary Grammar of the Gumbaingar Language INorth Coast, N.S.w.l. Oceania 19/2:130-91; 19/3:254-99; 20/1:29-65. Reprinted in Oceania Monographs 8. Sydney: Australian National Research Counc1l.

STREHLOW, T.G.H.

1942 Aranda Phonetics and Grammar. Oceania Monographs 7.

TINDALE, N.B.

1940 'Distribution of Australian Aboriginal Tribes'. Transactions of the Royal Society of South Australia 64/1:140231. (Including: Comprehens1ve Map of Australian Aboriginal Tribes.)

1974 Aboriginal Tribes of Australia. Berkeley: University of Cal1fornia Press; Canberra: Australian National Un1vers1ty Press.

WURM, S.A.

1972

Languages of Australia and Tasmania. The Hague: Mouton.

1978 'Reefs-Santa Cruz: Austronesian, But ...!'. In: S.A. Wurm and Lo1s Carrington, eds Second International Conference on Austronesian Linguistics: Proceedings. Pacific Linguistics, c-61:969-1010. 



\section{TEXT}

$\begin{array}{lll}\text { (1) dana-guru-pu muraba-na } & \text { guna-ana } \\ \text { 3.S.-there-ERG } & \text { finish-PAST/P food-ACCC }\end{array}$

'All of them have finished this food.'

(2) dalta-ra yundru guna-ana

eat-IMP you.S:ERG food-AĈC

'Eat food here.'

(3) yula-guru-gu dalta-ra guna-ana

you. 2-there-ERG êt-IMP food-AĈC

'You (2) eat the food.'

(4) mura bula-guru-gu muruba-ga guna-ana

finished 3.dl-there-ERG finish-PAST/P food-AĈC

'O.K., they (2) have finished the food.'

(5) yura muruba-na

you.pl:NOM finish-PAST/P

'You alz are finished.'

(6) Danţa difi mipa

I. DAT dog bad

'My dog is bad.'

(7) dika-gala ganţa gura-ana nani-gari waba gampa back-PRES I.DAT camp-DAT 3.S:NOM-there (far) NEG far

nani-gari juku-laja

3.S:NOM-there (far) water-LOC

'I'm now going back to my camp / (it is) over there not far away / (it is) near the water.'

(8) bunti-na gali-gala nani-guru gana-ani

come-PAST/P we.2-LOC 3.S:NOM-there man-NOM

'That man came to us (2).' 
(9) ditgi-ani nani-guru gula-ga ganala bita-bura doog-NOM 3 .S:NOM-there siț-PAST/P I. IOC?

'That dog sat on top of me.'

(10) gala-ani inka gura where-3.S:NOM you.S:DAT camp

'Where is your camp?'

(11) Daka nani-gari waba wina

water 3.S:NOM-there NEG close

'Water is over there far away.'

$\begin{array}{llll}\text { (12) nali } & \text { yanta-ra daldra-na } & \text { galka-ra } \\ \text { we.2:NOM go-FUT kangaroô-ACC hit-PURP }\end{array}$

'We (2) go to kill kangaroos.'

(13) Duti-ana jandra-pu dalta-ra

meat-AĈC we.pl-ERG êat-FUT

'All of us will eat the meat.'

(14) mura gali wiyi-ana galka-ra / gali marpa-ra

finished we.2:NOM fire-AĈC hit-FUT we.2 cook-

'O.K., we (2) will light the fire. We will cook.'

(15) wa ba yanda wiyi-aña manda-ra yundru / wa ba

NEG go-IMP firewood-ACC get̂-PURP you.S:ERG NEG

wiyi-mundu

fire-PRÎV

'Go get wood, (there's) no fire.'

(16) wini-wini wiyi-ani / nani waba gari-gala bad-bad fire-NOM 3.S:NOM NEG burn-PRES

'This firewood is bad. It is not burning.'

(17) winbi-dika nana-guru / mipa-ani

throw-back-IMP 3.Ŝ:ACC-there bad-3.S:NOM

'Throw it away. It is bad.'

(18) nani-guru waba gari-gala

3.S:NOM-there NEG burn-PRES

'This one is not burning.'

$\begin{array}{lll}\text { (19) manda-ra } & \text { wiyi-ana } & \text { dali-ana } \\ \text { hoîdalgrasp-IMP } & \text { firewoôd-ACC } & \text { good-AĈC }\end{array}$

'Go and get good wood.'

(20) guna dalta-ra

'(I) am hungry.' 


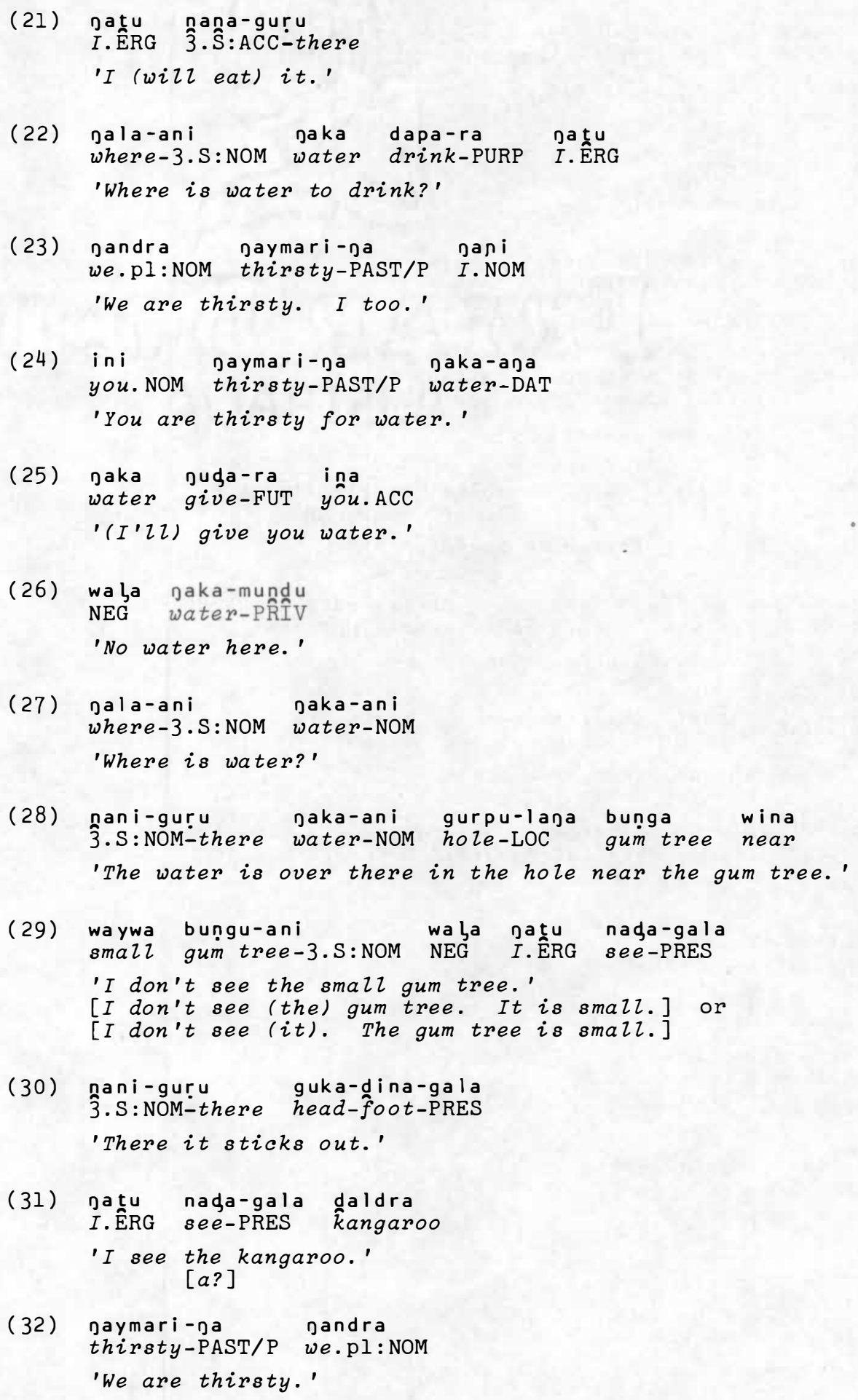


(33) yundru nada-gala daldra-ana you.S:ERG see-PRES kangaroo-ACC

'You see the kangaroo.'

(34) yana balti-gala

rain falt-PRES

'Rain is comming.'

(35) janţa naniga dika-gala wika!a I.DAT father back-PRES tomorrow

'My father is coming tomorrow.'

(36) Danta naniga buntigigali nilada I.DAT father come-PAST yesterday

'My father came yesterday.'

(37) naga-gala gațu ganţa nanida bunți-gala see-PRES I.ERG I.DAT father come-PRES

'Look there, my father is coming.'

(38) galka-ra diti-ana nandru makara-ndru hit-IMP dog-ACC 3 .S:INST stick-INST

'Hit the dog with this stick.'

(39) galka-nara-gala bula-guru gana-bula hit-RECIP-PRES 3.dl:NOM-there man-2

'They hit each other, the two men.'

(40) nandru-guru galka-na nana-guru gana-ana

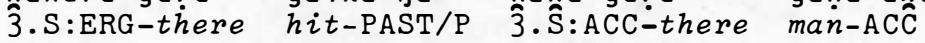

'He hit that man.'

(41) munkV-iyi-gala gani feel-sick-REF-PRES I. NOM

'I feel sick.'

(42) murta-gala ini hurt-PRES you.S:NOM

'Are you sick?'

(43) murta-iyi-gala nali

hurt-REF-PRES we. 2 :NOM

'We (2) feel sick.'

(44) murta-iyi-gala

hurt-REF-PRES

'He feels sick.' 
(45) munkV-iyi-gala

feel sick?-REF-PRES

'They feel sick.'

(46) wa ba murta-gala nani

NEG hurt-PRES I.NOM

'I am not sick.'

(47) galka-ra mara-ndru hit-IMP hand-INST

'Hit with hand.'

(48) jatu ina galka-ra makara-ndru I.ERG you.S:ACC hit-PURP stick-INST

'I hit you with the stick.'

(49) yundru galka-ra jana makara-ndru you.S:ERG hit-IMP I.ÂCC stick-INST

'You hit me with a stick.'

(50) yundru galka-ra gana mara-ndru you.S:ERG hit-IMP I.ÂCC hand-INST

'You hit me with your hand.'

(51) yundru galka-ra gali-na mara-ndru you.S:ERG hit-IMP us.2-ÂCC hand-INST

'You hit us (2) with your hand.'

(52) yundru galka-ra gandra-na mara-ndru you.S:ERG hit-IMP us.pl-AĈC hand-INST

'You hit us all with your hand.'

(53) galka-pa națu nana nilada hit-PAST/P I.ERG 3.S.:ACC yestêrday

'I hit him yesterday.'

(54) nandra-ju galka-ra nana we.pl-ERG hit-FUT 3.S.ACC

'We wizl hit him.'

(55) gatu galka-ra ina ganţa makura-ndru I.ÊRG hit-PURP you.ACC I.DAT stick-INST

'I hit you with my big stick.'

(56) gawa jali yanta-ra ganţa jura-anani come we.2:NOM go-F̂T I.DAT camp-DAT

'Come on, we (2)' 22 go to my camp.' 


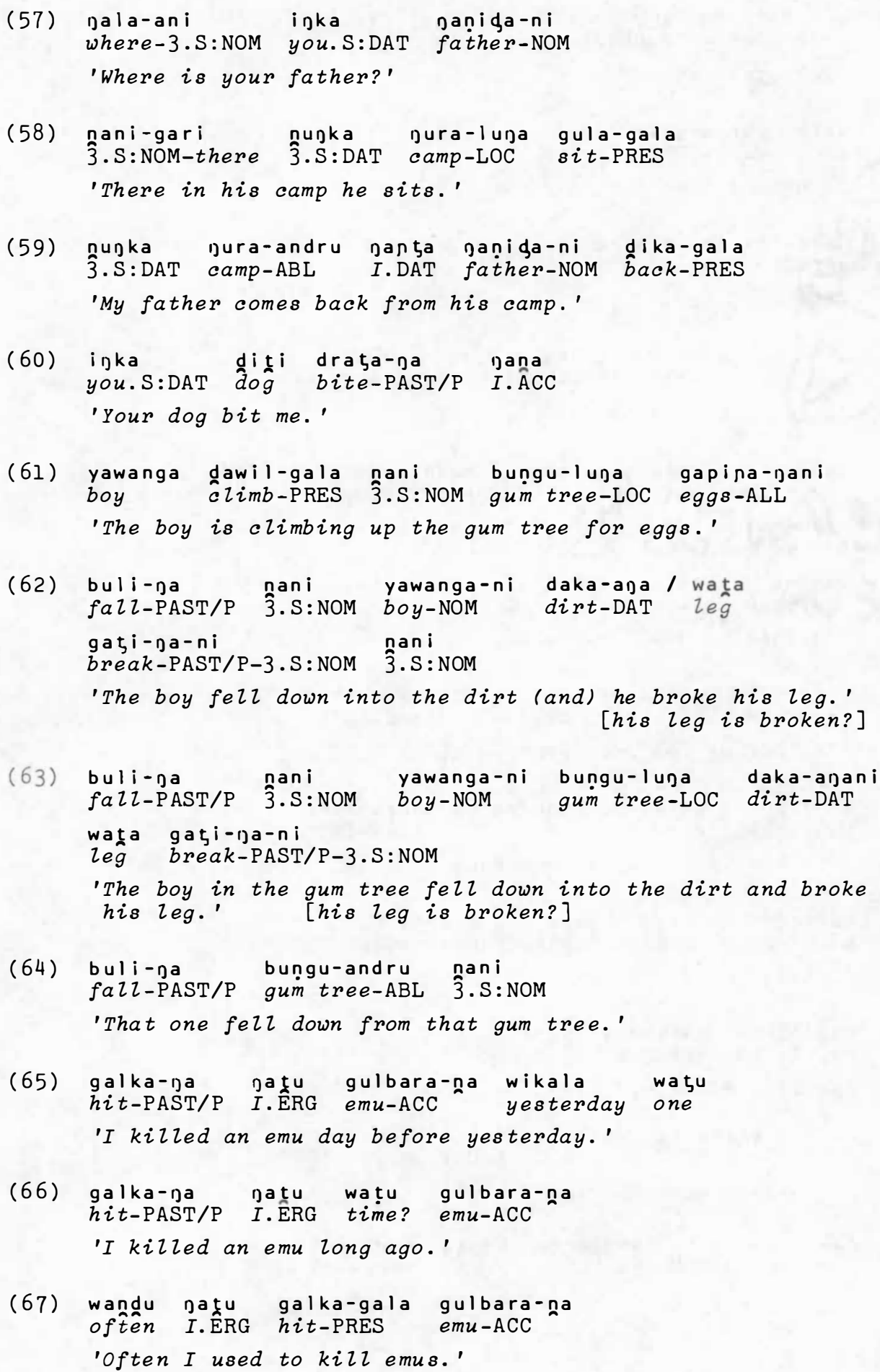




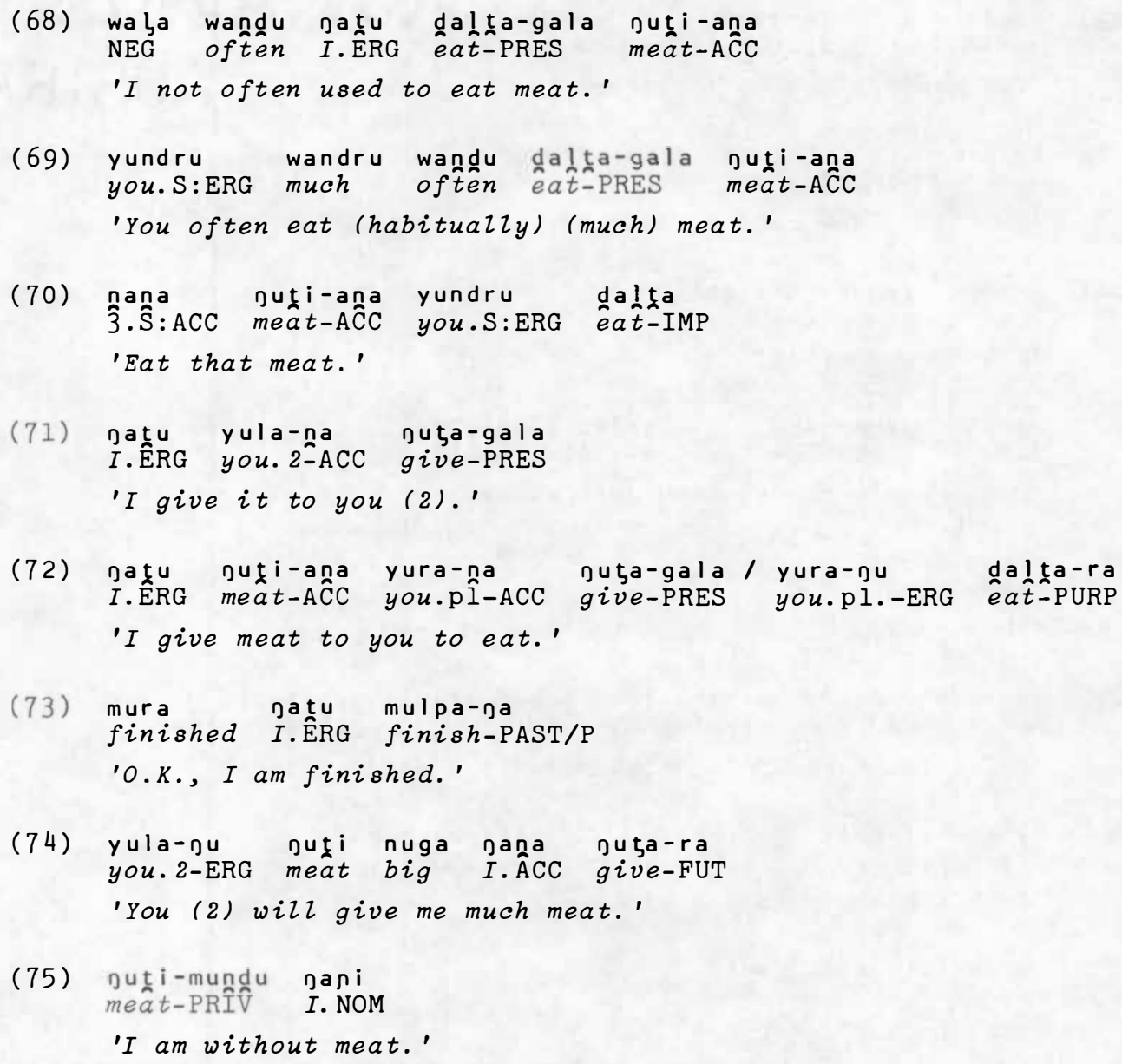

(76) nani ditti-ani dali

3.S:NOM dog-NOM good

'This dog is good.'

(77) diți nani-guṛu gali

dog 3.S:NOM-there good

'This dog is good.'

(78) nani-gari ditti-ani gampa dali-ani

3.S:NOM-there (far) dog-NOM far good-3.S:NOM

'That dog (far away) is good.'

(79) barkulu diti-bula

'Two dogs.' 
(80) gaṇa-bula bula-guru yanda-dika-gala man-2 3.dl:NOM-there go- $\overrightarrow{\mathrm{b}} a c \hat{k}$-PRES

'Two men are coming together.'

(81) bula-ba guri

3.dl: NOM-EMPH? this way?

'They (2) (are coming) this way.'

(82) wandru yanda-dika-gala

lot go-back-PRES

'A mob is coming.'

(83) wandru dana-guru galka-nala-gala

lot 3.pl:NOM-there hit-RECIP-PRES

'Many people are hitting each other.'

(84) mina-ana-ani

what-DAT-3.S:NOM

'What for?'

(85) gana-watu-andru mama-gali nuba(-)lapi nana-guru man-one-ERG steal-PAST wife-? 3 .Ŝ:ACC-there

'A fellow there stole another man's wife.'

(86) galka-iyi-gali nani-guru darana-andru hit-REF-PAST 3.S:NOM-there axe-INST

'He hit himself with a stone axe.'

(87) galka-iyi-gali gani

hit-REF-PAST I. NOM

'I hit myself.'

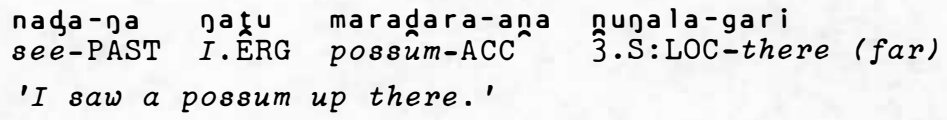

(89) Datu gada-gala ina

I. ERG see-PRES you. ACC

'I see you.'

(90) Dațu Dada-gala ñina

I. ÊRG see-PRES 3े. S. masc: ACC

'I see him.'

(91) waba gațu inga nada-gala / yuru walbiri-aña NEG I.ERG you.S:ACC see-PRES only shade-ACC

'I don't see you - only your shadow.' 
(92) gawa gali gula-ra walbiri-luga

come we.2:NOM sit̂t-FUT shade-LOC

'Come on, we (2) sit in the shade.'

(93) mila gandra-gala

sun shine-PRES

'The sun is shining hot.'

(94) wara-ga nani ditgi-ani guți-dika-dika-gala

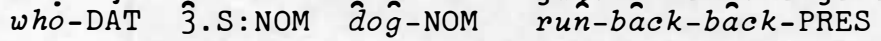

'Whose is this dog running around?'

(95) gaṇida-na nanta nani-guruu ditgi-ani guți-dika-dika-gala father-DAT I.DAT 3 .S:NOM-there doĝ-NOM ruñ-bâck-bâck-PRES

'My father's dog is running about.'

$\begin{array}{lll}\text { (96) yamba-dika } & \text { nana-guru } & \text { diti-ana } \\ \text { chase-back-IMP } & \hat{3} . \hat{S}: A C C-t h e r e & \text { dog-ACC }\end{array}$

'Chase that dog away.'

(97) draţa-laga nandru-guru waliwa-na

bite-POSS 3.S:ERG-there chizd-AĈC

'It could bite that $k i d$.'

(98) manda-wari yandra-ana nana-guru / baṇdi-dika-ra

ho $\hat{d}$-vertical-IMP stone-ACC $\hat{3} . \hat{S}: A C C-t h e r e$ move-bâck-PURP

nana-guru dit i-ana

3. S: ACC-there $\hat{d} \circ \hat{g}-\mathrm{ACC}$

'Pick up a stone, hit him away that dog.'

(99) gawaba-lu maña-gala bakarani

uncle-ERG maḱe-PRES boomerang

'Uncle is making a boomerang.'

(100) gawaba-lu nanta manna-gala bakarani

uncle-ERG I.DAT make-PRES boomerang

'My uncle is making a boomerang.'

(101) gawaba-lu manna-gala ganta bakarani-ani

uncle-ERG makke-PRES I.DAT boomerang-3.S:NOM

'Uncle is making it for me.'

[Uncle is making the boomerang. It is for me.] or

[Uncle is making (it). The boomerang is for me.]

(102) wa ba nani-guru inka bakarani-ani

NEG 3.S:NOM-there you.S:DAT boomerang-3.S:NOM

'This is not your boomerang.' 


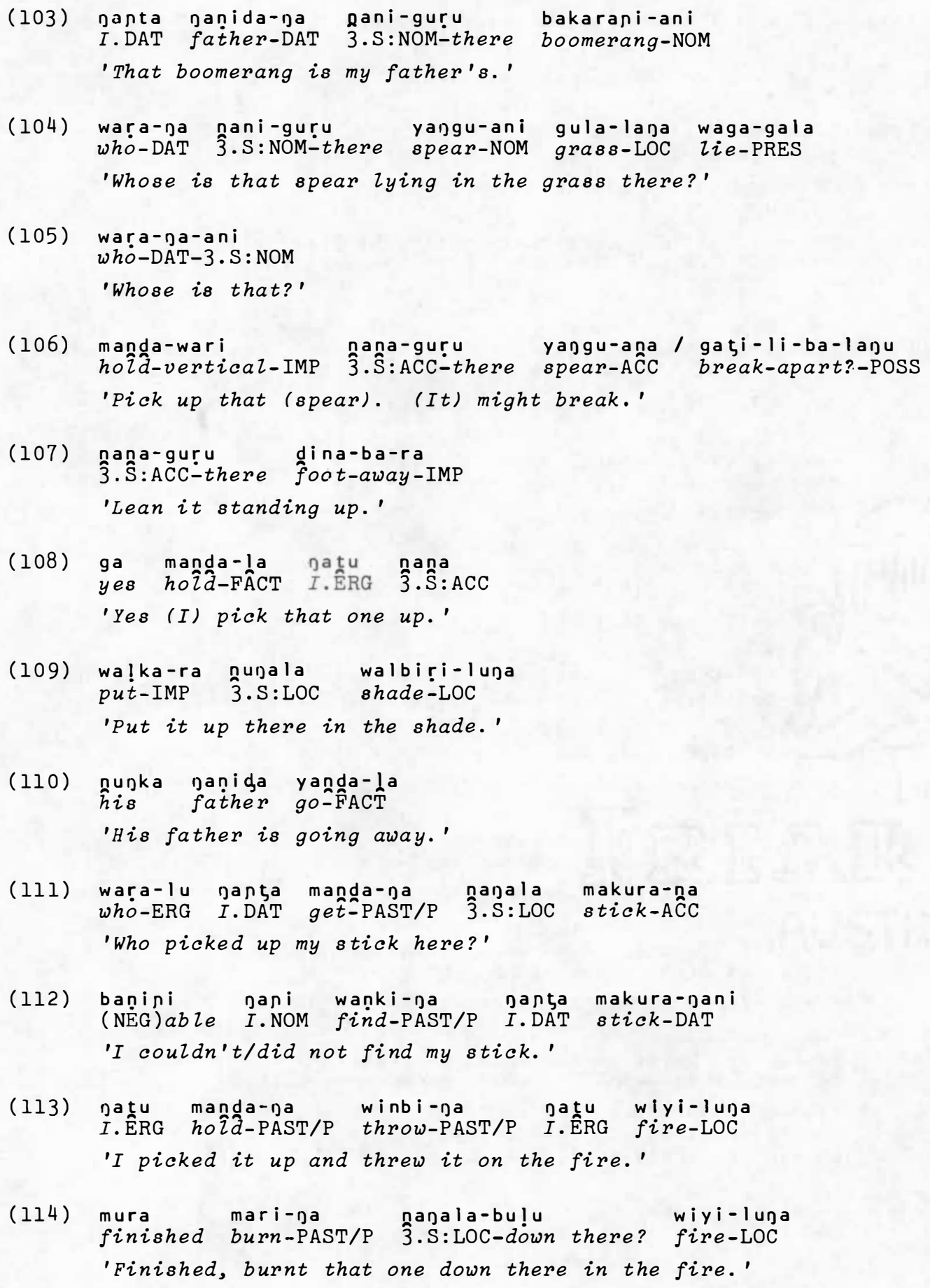


(115) manda-ra nattu inka makura-waţu-ana

hold-FUT I.ERG you. DAT stick-one-ACC

'I' 22 pick up a stick, that one/for you.'

$\begin{array}{lll}\text { (116) gawa diti-andru ina } & \text { draţa-lanu } \\ \text { come dôg-ERG } & \text { you.S:ACC bite-POSS }\end{array}$

'Come away the dog could bite you.'

(117) nunala-guru birki-birki-wa dali-luna dit ti-luna

3.S:LOC-there play-play-EMPH? good-LOC d̂ố-LOC

'That one down there is playing with the good dog.'

(118) diti-andru galka-gala nana-guru daldra-na

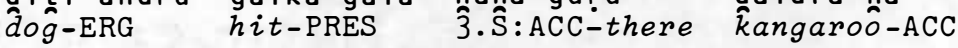

'The dog is fighting that kangaroo.'

(119) waba wina yanta-dira / galka-laju ina nandru-guru NEG close go-EMPH hit-POSS you.S:ACC 3.S:ERG-there

daldra-andru

kangaroo-ERG

'Don't go too close, the kangaroo could kill you.'

(120) gula-dika-wa galka-ra gali-gu yajgu-andru

sith-bâck-EMPH hit-FUT we.2:ERG spear-INST

'Stay back, we (2) will kill (it) with a spear.'

(121) dina-dika-wa

foot-back-EMPH

'Stand back.'

$\begin{array}{llll}\text { (122) waba nalka-na } & \text { natuu } & \text { nana } \\ \text { NEG } & \text { hit-PAST/P } & \text { I.ÊRG } & \text { 3.रे:ACC }\end{array}$

'I didn't hit it.'

(123) makura jana

stick I. ÂCC

'(Give) me a stick.'

$\begin{array}{llll}\text { (124) mura } & \text { națu galka-na } & \text { ñana } \\ & \text { finished I.ÊRG } & \text { hit-PAST/P } & \text { 3.Ŝ:ACC }\end{array}$

'Finished, I killed it.'

$\begin{array}{lll}\text { (125) garki } & \text { inka } & \text { ditti-ana } \\ \text { call-IMP } & \text { you.S:DAT d̂̀g-ACĈ }\end{array}$

'Call your dog off.'

(126) nandru-guru inda-inda-gala nana-guru guti-ana 3.S:ERG-there tear-tear-PRES 3.ŜACC-there meât-AĈC

'That one is tearing up the meat.' 
(127) nabba nana guta gaka-gaka-ra jut i-aña nana

knife I.ÂC give-IMP cut-cut-PURP meât-AĈC $3 . \hat{S}: A C C$

'Give me a knife to cut up the meat there.'

(128)

$\begin{array}{lllll}\text { nana } & \text { gațu } & \text { durka-ana walta-gala nanta gawulida-ana } \\ \text { 3.S } A C C & \text { I.ERG } & \text { leg-ACC } & \text { take-PRES } & \text { I.DAT uncle-DAT }\end{array}$

nura-ana nuţa-ra națu nana juti-aña

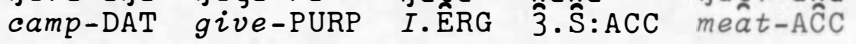

'I am taking this leg to my uncle's camp to give him the meat.'

(129) Dala-ana bula-guru gana-bula yanta-gala

where-DAT 3.dl:NOM-there man-2 go-PRES

'Where are the two men going?'

(130) nuti-ana bula-guru yanta-gala

meât-DAT 3.dl:NOM-there go-PRES

'The two are going for meat.'

(131) gala-aja ini yanta-gala

where-DAT you.S:NOM go-PRES

'Where are you going?'

(132) naka-ana yanta-gala mañda-ka-ra gațu

water-DAT go-PRES ho $\hat{\imath}$-?-PURP I. ERG

'I'm going to get water.'

(133) nala-andru ini

where-ABL you.S:NOM

'Where are you from?'

(134) naka-nuga-andru

water-big-ABL

' (I'm) from the big water.'

(135) miţi badu-ani ini / bakarani manna-ra yundru

? ability-NOM you.S:NOM boomerang make-PURP? you.S:ERG

'You have the ability to make a boomerang.'

(136) waba mi ti-munda-ani

NEG make?-PR̂IV-3.S:NOM

'No, (I) can't make it.'

[It (is) make-less]

(137) gunka-ra yundru ganta gakuda-na ask-IMP you.S:ERG I.DAT brother-ACC

'You ask my brother.'

(138) mura janta gakuga maṇna-ra inka bakarani finished I.DAT uncle make-PURP you.S:DAT boomerang

'O.K., my uncle wizl make you a boomerang.' 


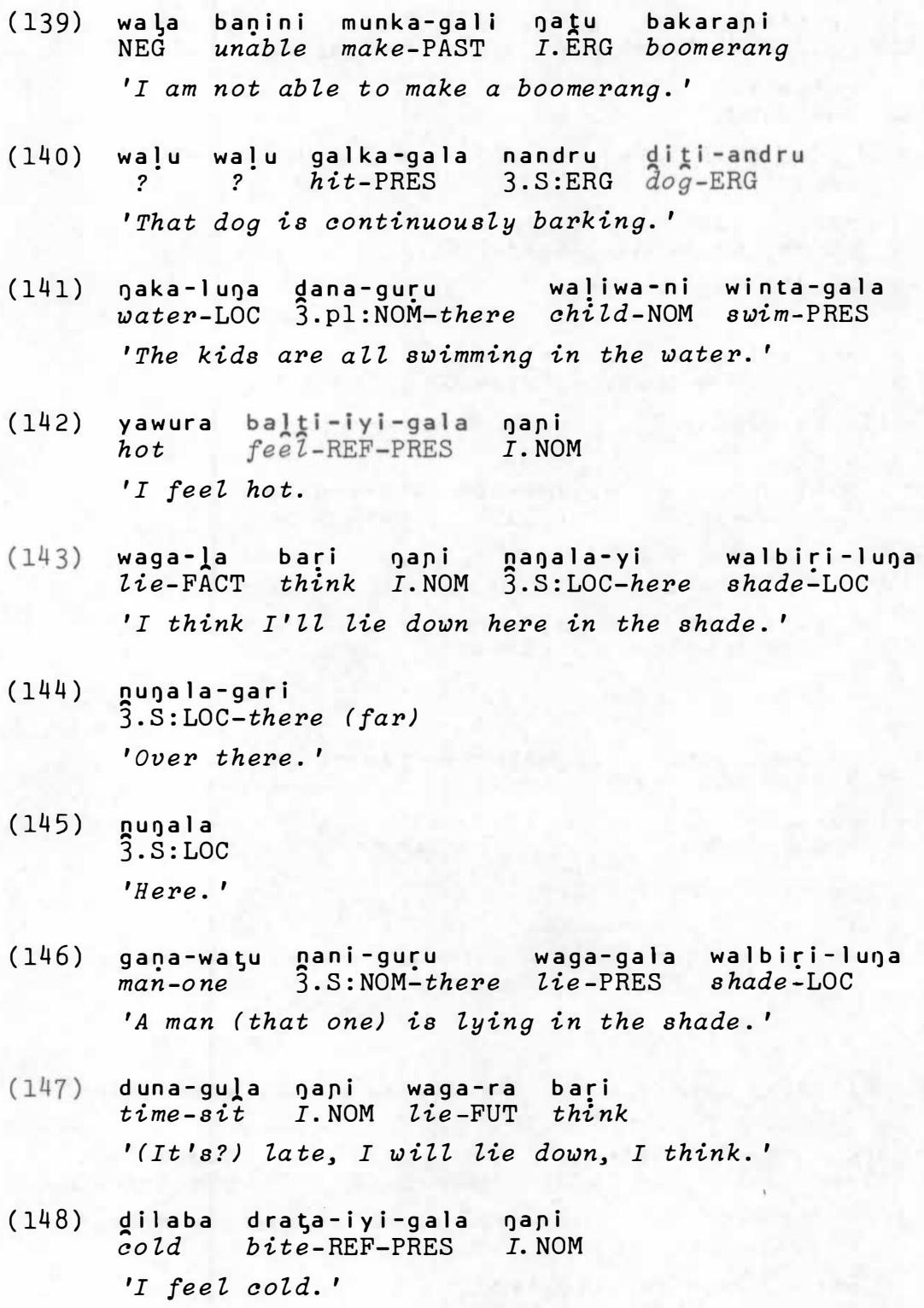


(150) dila-gala nani-guru dila bari / guru nana

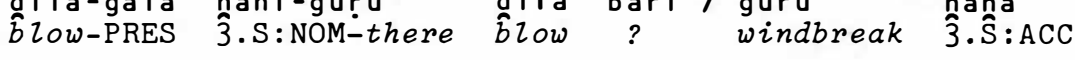

gali-gu gulpa-ra

we.2-ERG build-FUT

'This cold wind is blowing, we will build a windbreak.'

(151) wiyi-na bari loali-nu gulpa-ra

fire-ACC think we.2-ERG light-FUT

'I think we will light a fire.'

(152) ganuri-gala nani-guru wa!liwa-ni

cry-PRES 3.S:NOM-there child-NOM

'That child is crying.'

(153) mina-ıa nani-guru waliwa-ni ganuri-gala

what-DAT 3.S:NOM-there child-NOM cry-PRES

'Why is that child crying?'

(154) guti-na nani-guru waliwa-ni

run-PAST/P 3.S:NOM-there chizd-NOM

'That child ran.'

(155) buli-ga nani-guru / wața-na nani-guru

fail-PAST/P 3.S:NOM-there leg-ACC 3.S:NOM-there

murta-iyi-wa-na

hurt-REF-EMPH-PAST/P

'He fell down and hurt his leg.'

(156) mila-ani malţa galguri-gala / gali-l)u jura gali-ra

sun-NOM late set-PRES we.2-ERG camp make-FUT

nunala

3.S:LOC

'The sun is going down - late. We (2) make camp over there.'

(157) numala-guru bari gali-gu gura gali-ra bunga-luna 3.S:LOC-there think we.2-ERG camp build-FUT gum tree-LOC

'I think we (2) will make camp over there at the gum tree.'

(158) गali bari waga-ra ñugala

we. 2: NOM think lie-FUT 3.S:LOC

'We (2) I think will sleep here.'

(159) wika!a mila wa!pa-la jali yanța-ta-ra gali

tomorrow sun rise-FÂCE we.2:NOM go-âway-FUT we.2:NOM

yanta-ba-ra

go-âway-FUT

'Tomorrow when the sun comes up we (2) wizl go on.' 
$\begin{array}{llll}\text { (160) wikala nali } & \text { gampa yanta-ba-ra } \\ \text { tomorrow we.2:NOM far go-away-FUT }\end{array}$

'Tomorrow we (2) will go a long way.'

(161) gula-ra ini ganţa nura-lana

siťt-IMP you.S:NOM I.DAT camp-LOC

'Sit down in my camp.'

(162) wikala-watu gula ini yanta-ba-ra

tomorrow-one sith-IMP you.S:NOM go-away-FUT

'The day after tomorrow stay - (then?) you wizl go away.'

(163) gala ganta nani-guru guți-ani

hey I.DAT 3.S:NOM-there meât-NOM

'Hey, this is my meat here.'

(164) waba inka nani-guru guți-ani / guţa-dika-ri nana NEG you.S:DAT 3.S:NOM-there meât-NOM give-back-IRR me.ACC

'This is not your meat, give it back to me.'

(165) mura gatu ina guţa-dika-ra / inka

finished I.ERG you.S:ACC give-back-FUT you.S:DAT

nut i-a $\mathbf{n} \mathbf{i}$

meat-3.S: NOM

'O.K., I will give you back your meat.'

[Finished I will give it back to you. It is your meat.]

(166) ganta-wara natu nalka-na nana guti-ana

I.DAT-belonging I.ÊRG think-PAST/P $\hat{3} . \hat{S}: A C C$ meat-ACC

'I thought this meat here was mine.'

(167) waba nana-guru makura manda gana-waţu-na

NEG 3.S:ACC-there stick hoîd-IMP man-one-DAT

'Don't pick up this man's stick. (It is) this man's.'

(168) makura nani nanta nañida-ga nani

stick 3.S:NOM I.DAT father-DAT 3.S:NOM

'This is my father's stick.'

(169) yandra-ana nana-yi walpa-ba-ra natu stone-ACĈ 3. S:ACC-here lift-away-FUT I.ERG

'(I) lift this stone.'

(170) wa ba gini-ani nani

NEG heavy-NOM $3 . \mathrm{S}: \mathrm{NOM}$

'This is not heavy.'

(171) baṇini națu wa!pa-ba-lanu nana yandra-ana

unable I.ERG rise-away-POSS 3̂. S:ACC stone-ACC

'I am not able to lift up this stone.' 
(172) Datu wa!pa-ba-gala nana

I.ERG rise-away-PRES $\hat{3}$.Ŝ:ACC

'I am lifting this one.'

(173) gala yundru wa!pa-ba-ra nana bi!ka-aña

hey you.S:ERG rise-away-FUT 3.S.:ACC log-ACC

'Will you lift this log?'

(174) ga națu nana-guru walpa-ba-ra bilka-ana inka yes I. ERG 3.Ŝ:ACC-there rise-away-FUT log-ACC you.S:DAT

'Yes, I will lift this log for you.'

(175) gawa jali baṇi-ra gakala-waţu-anani

come we.2:NOM movelgo-FUT side-one-DAT

'Come we (2) will cross to the other side.'

(176) waba bandi-lanu naka-ni nani-guru / gi babaru-ani

NEG movelgo-POSS water-NOM 3.S:NOM-there deep-3.S:NOM

'Cannot cross the water, deep.'

[This water is not crossable. It is deep.]

(177) nnujka naṇida bunți-gala

3.S:DAT father come-PRES

'His father is coming.'

(178) duna-baṛi gali wira-ra buli-la nani-guru

$?$ ? we.2:NOM wait-FUT fail-FACT 3.S:NOM-there

Daka-ani

water-NOM

'We will wait, the water will fall.'

[We will wait until the water falls.]

(179) Danta diti dali-ani

I. DAT dog good-3.S:NOM

'My dog is good.'

(180) Dani yanta-ba-ra

I. NOM go-away-FUT

'I'm going away.'

(181) gala-apa ini yanta-gala

where-DAT you.S:NOM go-PRES

'Where are you going?'

(182) gampa jani yanta-gala

far I. NOM go-PRES

'I'm going far away.' 
(183) wandu-gutu ini dika-ra

much-? you.S:NOM back-FUT

'When will you return?'

(184) wika!a-waţu bani dika-ra

tomorrow-one $I$.NOM back-FUT

'I will return the day after tomorrow.'

(185) wandu-gutu yula dika-ra

much-? you. 2: NOM back-FUT

'When wizl you (2) return?'

(186) wikala-waţu jali dika-ra

tomorrow-one we. 2:NOM back-FUT

'We (2) will return the day after tomorrow.'

(187) wika!a-wa tu dika-ra

tomorrow-one back-FUT

'Day after tomorrow (he) will return.'

(188) gawa jali yanta-ra

come we.2:NOM go-F̂T

'Come, we (2) will go.'

(189) naga nana-guru / munaa-ani yandra-luna

\{ook-IMP 3.Ŝ:ACC-there snake-NOM stone-LOC

'Look at the snake on the stone.'

[Look at it/the snake is on the stone.]

(190) Jala-ani muṇa-ani / waba națu naga-gala

where-3.S:NOM snake-NOM NEG I.ERG see-PRES

'Where is the snake? I don't see (it).'

(191)

nani-guru yandra-luna bungu wina 3.S:NOM-there stone-LOC gum tree close

'That one on the stone by the gum tree.'

(192) ga mura jațu naga-gala nana-guru muna-ana yes $0 . K$. I. ERG see-PRES 3.Ŝ:ACC-there snake-ÂCC

'Yes I see the snake.'

(193) Datu nana galka-ra muna-ana

I.ERG 3.Ŝ:ACC hit-FUT snake-ÂCC

'I will kill the snake.'

(194) nada-wari draţa-lai)u ina muna-ndru see-vertical bite-POSS you.S:ACC snàke-ERG

'Look out the snake may bite you.' 
$\begin{array}{lllll}\text { inka } & \text { diți } & \text { wa ba } & \text { draţa-na } & \text { nana } \\ \text { you.S:DAT } & \text { doğ } & \text { NEG } & \text { bite-PAST/P } & \text { 3.S:ACC }\end{array}$

'Your dog did not bite me.'

(196) mura walga-ani buka yanta-ba-ra giga-ana manda-ra O.K. woman-NOM all go-away-EMP rushes-ACC get̃-PURP

'Now all of you women go out to fetch bullrushes.'

(197) diti dipa

dog tail

'Tair of a dog.'

(198) Dațu iña guta-dika-ra ijka guți I.ÊRG you.S:ACC give-back-FUT you.S:DAT meât

'I give back your meat to you.'

(199) juţa-la gațu ina bakarani / yundru gana give-F̂AT I.ERG you.S:ACC boomerang you.S:ERG I.ÂCC juta-dika-ri guti give-back-IRR meat 'When/if I give you back the boomerang, you will give me back
the meat.'

(200) juţa-dika-ri yangu-ana

give-back-IRR spear-AĈC

'Give back the spear.'

(201) diti-ani balu-gali

dैố-NOM die-PAST

'The dog died.'

(202) diti-ani gurida balu-ra bari nani-guru

doğ-NOM sick die-FUT think 3.S:NOM-there

'This dog is sick (and) it will die, I think.'

(203) Dandra guna dalta-ra

we.pl:NOM food êt-FUT

'We alz are hungry.'

(204) Danta ditti-ani balu-gali nilada

I.DAT dog-NOM die-PAST yestêrday

'My dog died yesterday.'

(205) diți-ani nani-guru balu-ra bari dog-NOM 3.S:NOM-there die-FUT think

'This dog will die, I think.'

(206) Janţa gaṇida balu-gali maţa

I.DAT father die-PAST Zong ago

'My father died long ago.' 


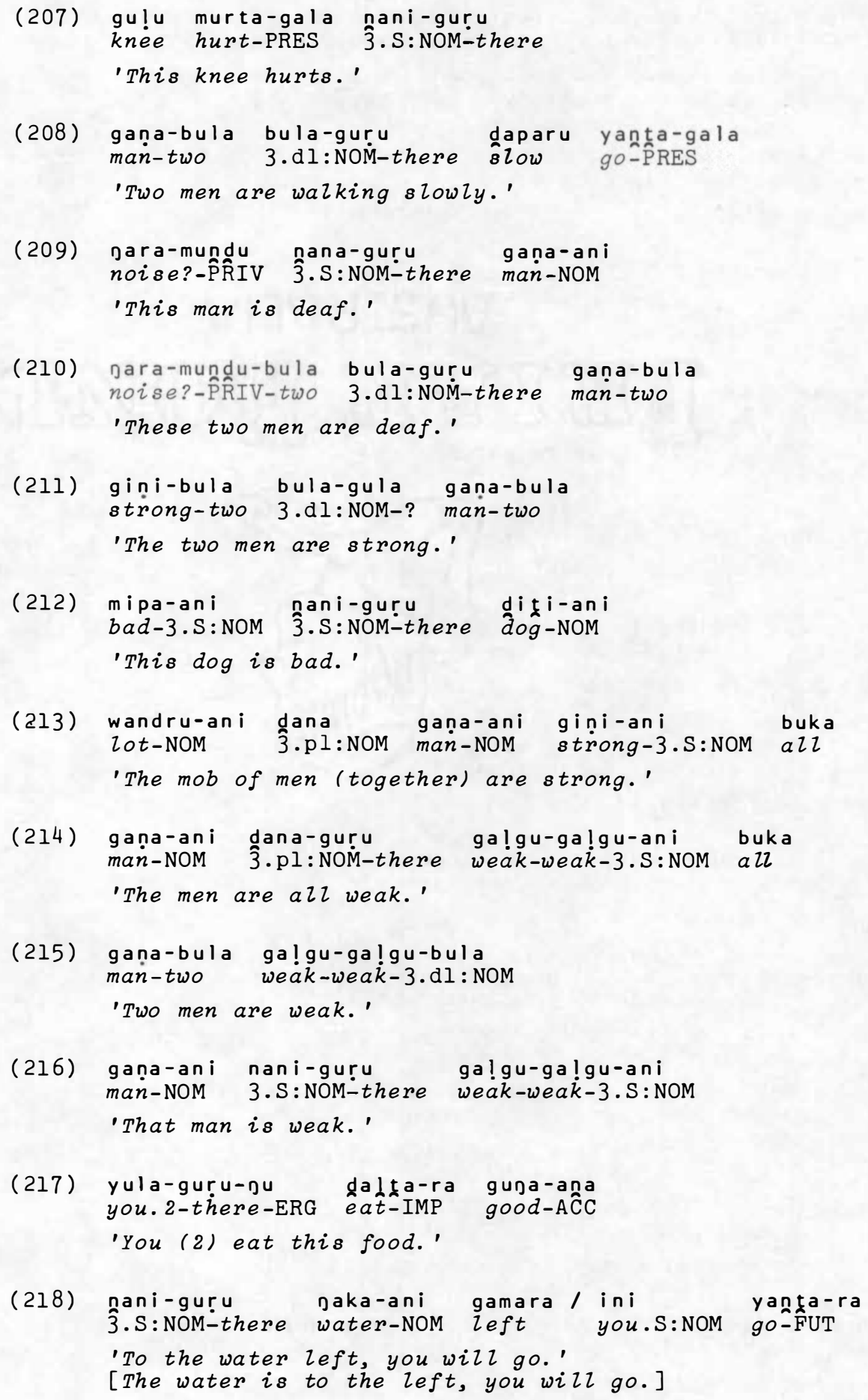


$\begin{array}{llll}\text { (219) nani-guru } & \text { naka-ani dutigali / ini } & \text { yanta-ra } \\ \text { 3.S:NOM-there water-NOM right } & \text { you.S:NOM go-FUT }\end{array}$

'To the water right, you will go.'

[The water is to the right, you will go.]

(220) mura jatu ina bura-ja

o.K. I.ÊRG you.S:ACC tei乙-PAST/P

'O.K., I told you.'

(221) mura gatu ina bura-gali yulu

O.K. I.ÊRG you.S:ACC teiz-PAST straight

'O.K., I told you correctly (straight).'

(222) duna-wari gațu ina bura-gala yulu

time-wait I.ÊRG you.S:ACC teil-PRES straight

'Wait, I will tell you straight.'

(223) waba yundru gana dumpa-indri-gali mandara

NEG you.S:ERG I.ÂCC show-?-PAST wrong

'You didn't tell me wrong.'

(224) mani nuga nani-guru walga-ani

fat big 3.S:NOM-there woman-NOM

'This woman is very fat.'

(225) muku-digga nani-guru walga-ani

bony-COM? 3.S:NOM-there woman-NOM

'This woman is bony.'

(226) guja janda-gala nani-guru gana-ani

food want-PRES 3.S:NOM-there man-NOM

'This man is hungry.'

(227) mina-ala nani-guru guma nanga-gala what-DAT 3.S:NOM-there food want-PRES

'Why is this one hungry?'

(228) waba nulu dalta-gali gurja-ana bala

NEG 3.S.masc:ERG êat-PAST food-AĈC today

'He didn't eat food today.'

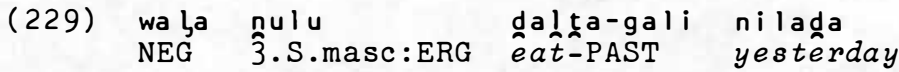

'He didn't eat yesterday.'

(230) mabu wa!pa-gala nani-yi gana-ani ganţa anger rise/lift-PRES $3 . \mathrm{S}: \mathrm{NOM}$-here man-NOM I.DAT

'This man is angry with me.' 
(231) mina-ana nani-guru
what-DAT 3.S:NOM-there I.DAT anger rise-PRES

'Why is that man angry with me?'

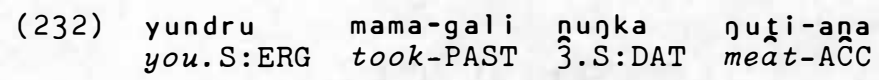

'You took away his meat.'

(233) yala-aja nani-guru inka mabu walpa-gala DEM-DAT 3.S:NOM-there you.S:DAT anger rise/lift-PRES

'That's why he is angry with you.'

(234) mura-wali gani waga-ra / galguri-gala gani muga-ana finished-? I. NOM lie-FUT? -PAST I.NOM sleep-DAT

'All right $I$ will lie down, I am tired [for sleep].'

(235) banini gani waga-ga / dilaba drata-iyi-gala unable I.NOM lie-PAST/P cold bite-REF-PRES

'I cannot sleep, (I) feel cold.'

(236) $\begin{array}{ll}\text { drata-iyi-na dilaba } \\ \text { bite-REF-PAST/P cold }\end{array}$

'(I) fert cold.'

(237) gana-bula bula-guru nuga-bula yanta-dika-gala-ri man-two 3.dl:NOM-there big-two go-back-PRES-IRR?

'Two big men are coming this way [returning?].'

(238) gana-bula bula-guru waywa-bula yanta-dika-gala-ri man-two 3.dl:NOM-there small-two go-back-PRES-IRR?

'Two small men are coming this way.'

(239) dapa-ra națu Daka-aña

drink-FUT I.ÊRG water-ÂCC

'I wizl drink this water.'

(240) Dani dina-ba-ra

I. NOM foot-away-FUT

'I stand up.'

(241) yula dina-ba-ra

you. 2: NOM foot-away-FUT

'(You 2) stand up.'

(242) yanda-gala ini galala-na

spêak-PRES you.S:NOM Gaṭali-ÂCC

'Do you speak Gal?ali?' 
(243) ga waywa nani yanda-gala
yes smazz I.NOM speâk-PRES

'Yes, I speak a little.'

(244) dali nani yanda-gala

good I. NOM speak-PRES

'I speak we zr.'

(245) gandugana-gala yundru dana-guru-ana / yawara-na understand-PRES you.S:ERG 3̂.S-there-AĈC Zanguage-ACC

dana-nani

3. S-DAT

'Do you understand them/their Zanguage?'

(246) ga mura gatcu gandugana-gala dana-na

yes finished I.ERG understand-PRES 3.S-ÂCC

'Yes well, completely I understand them.'

[O.K., I understand them.]

(247) yanda-ra nanala

spêak-IMP I. LOC

'speak to me.'

(248) yanda-ra nali

tâेर-FUT we.2: NOM

'We'lz talk.'

(249) yanda nalanala

tâk we. 2:LOC

'speak to us (2).'

(250) mura gani-ilpi inala yanda-dara-ra-ba

finished I.NOM-? you.S:LOC tâेर-?-FUT-EMPH

'Good, I will speak to you.'

(251) mura nali-ilpi inala

finished we.2-? you.S:LOC

'O.K., we (2) will speak to you.'

(252) mura gandra-ilpi yuranala

finished we.pl-? you.pl:LOC

'Good, we all will speak to you.'

(253) gawa nandra yanda-ra ñugala-bulu come we.pl:NOM tâेर-FUT $\hat{3}$.S:LOC-over there

'Come on, we will talk to that one over there.'

(254) nani-guru gaṇa-ani dali nani 3.S:NOM-there man-NOM fat/good $3 . \mathrm{S}: \mathrm{NOM}$

'That man is fat.' 


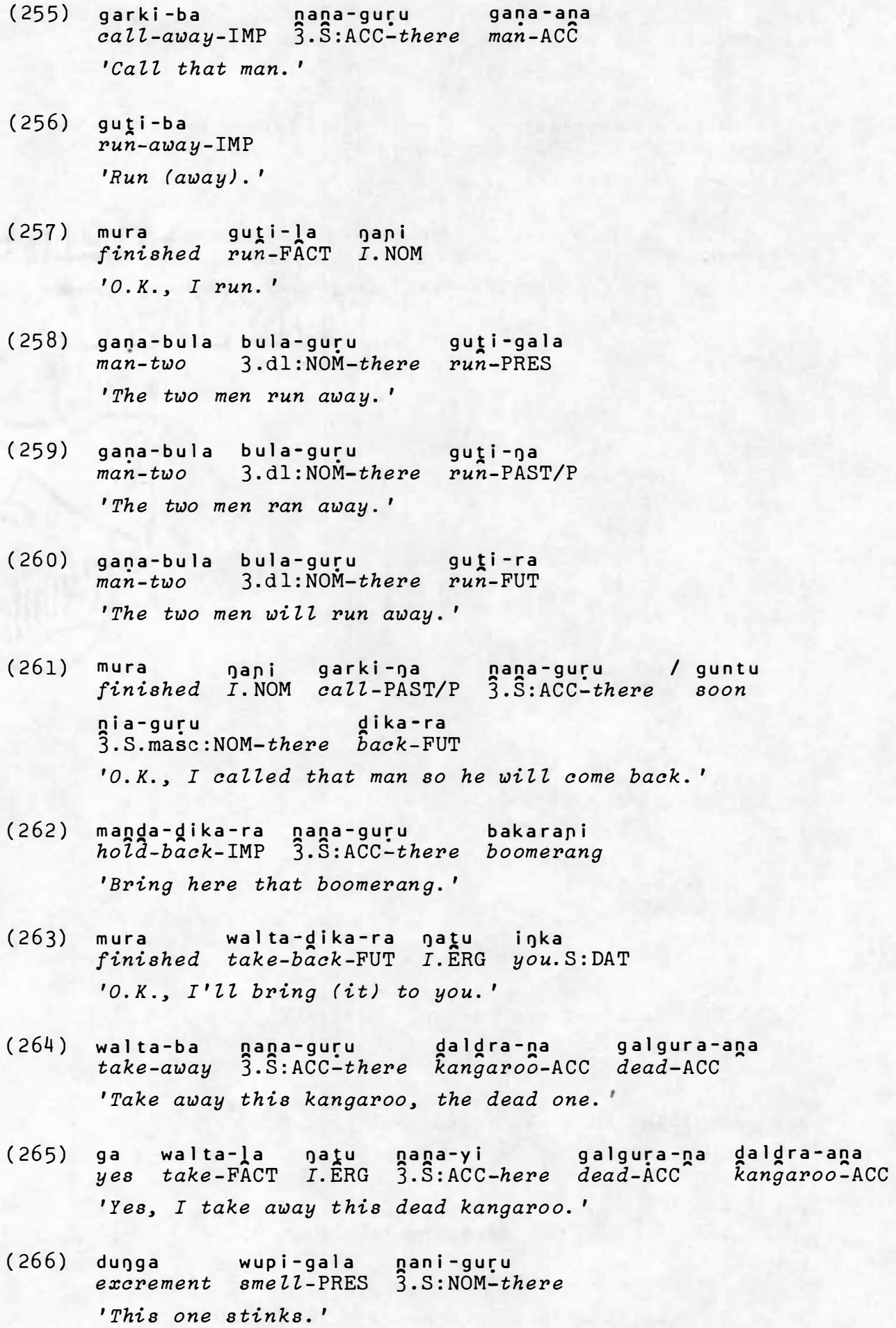




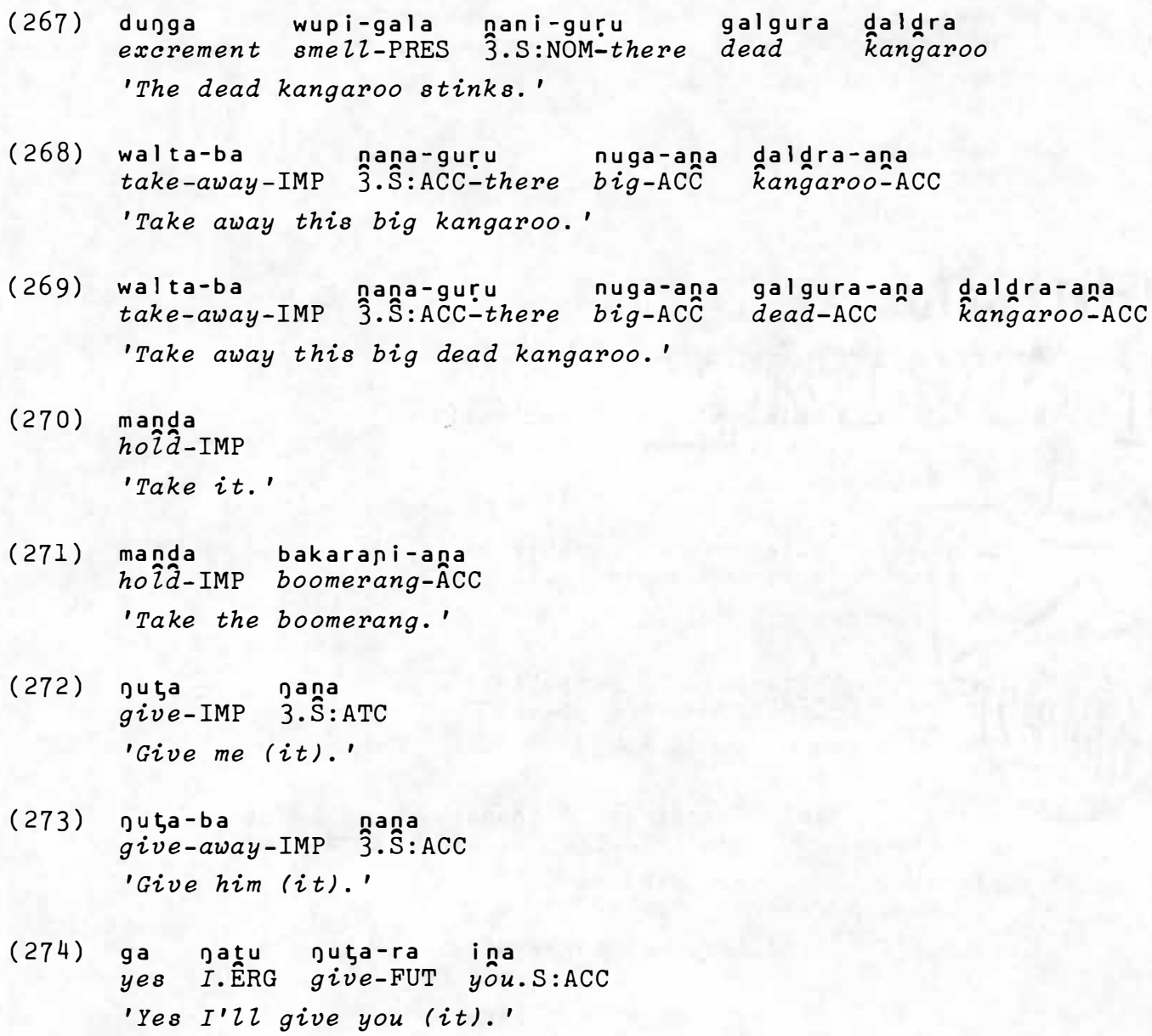




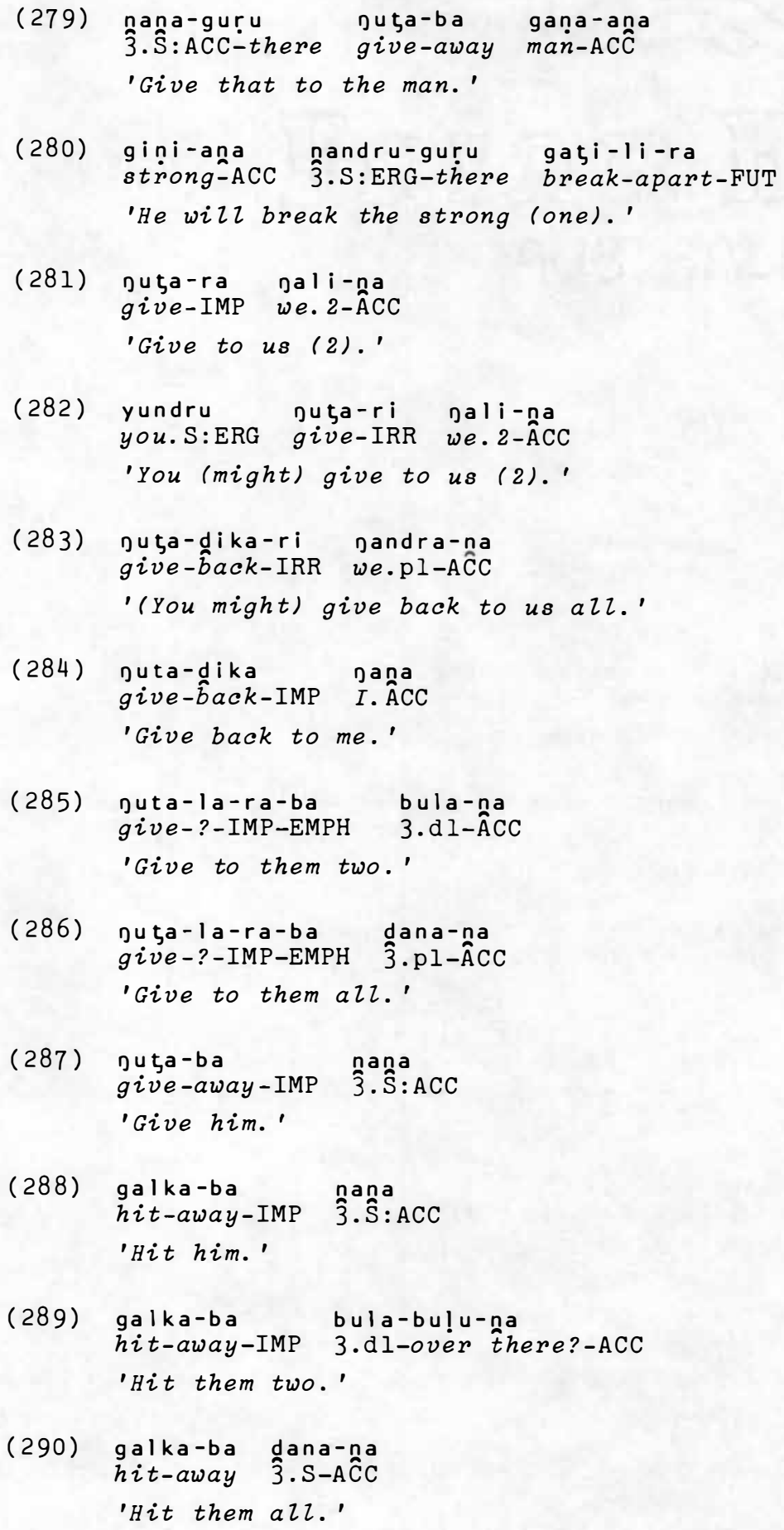



(291) galka-iyi-na nani yandra-andru dina-ana buli-na fon pani
hit-REF-PAST/P I.NOM stone-ABL foot-ACC fall-PAST/P I. NOM
'I knocked my foot (because of?) on the stone and fell down.'

(292) galka-iyi-na gani nupura-guru dina-ana buli-na gani hit-REF-PAST/P I.NOM 3.S:ABL-there foot-ACC fall-PAST I.NOM 'I knocked my foot (because of?) on it and fell down.'

(293) mura nali naga-nala-gali nilada finished we.2:NOM see-RECIP-PAST yestêrday 'O.K., we (2) were looking at each other yesterday.'

(294) naga-wari waba buli

see-vertical-IMP NEG fall-IMP

'Look out, don't fall down.'

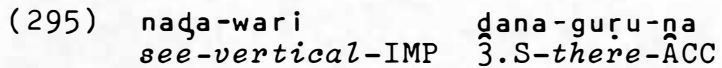

'Look at them.'

(296) ga mura jatu nada-ra dana-na

yes finished I. ERG see-FUT 3.S-AĈC

'Yes, O.K. I will look at them.'

(297) gula-ra ini dandradandra daldra-na ini

sit-IMP you.S:NOM watch-IMPP kैangaroo-ACC you.S:NOM

'Sit down and watch the kangaroos.'

(298) banini nani wira-dali-na nunka

unable I.NOM wait-ĈIRC ABILITY-PAST/P $3 . S: D A T$

'I can't wait for it.'

(299) baṇini nani wira-dali-na

unable I.NOM wait-ĈIRC ABILITY-PAST/P

'I can't wait.'

(300) baṇini națu nada-dali-na

unable I.ÊRG see-CÎRC ABILITY-PAST/P

'I could not see (it).'

(301) mura gampa gațu nada-gala daldra-ana

finished far I.ÊR see.PRES k̂ngaroo-ACC

'O.K., over there far I see the kangaroo.'

(302) duna-baṛi gali wira-ra / guṇṭu najka-yi dika-la ?-think we.2:NOM wait-FUT soon 3.S:DAT-here back-FACT

naka-aja / mura jali-ju galka-ra nana water-DAT finished we.2-ERG hit-FUT 3.

'Wait a while. We (2) will wait. Soon it comes to the water. We (2) will kill it.' [We will wait until it comes back to the water. Then we will kill it.] 
(303) Dara-gala yundru gugu-dari-ana

hear-PRES you.S:ERG wind-?-ACC

'Do you hear the wind?'

(304) wa ba gațu para-gala

NEG I.ERG hear-PRES

'I can't hear (it).'

(305) bați yandru yanda-gala / waba gatu ina gara-gala bad you.S:ERG tâेk-PRES NEG I.ERG you.S:ACC hear-PRES

'You talk bad. I don't hear you.'

(306) Danga-gala gani maṇi

like/want-PRES I.NOM corroboree

'I like corroboree.'

(307) gațu nada-ra wikala / dana birki-ra maṇi-aña

I.ERG see-FUT tomorrow $3 . \mathrm{pl}: \mathrm{NOM}$ dance-FUT corroboree-ACC

'Tomorrow I will see (them) dance a corroboree.'

(308) ganga-gala gani yanta-ra juku-ana

want/like-PRES I. NOM go-PURP river-DAT

'I want to go to the river.'

(309) nandru-gari gana-andru mamu-gali ganta guti-ana

3.S:ERG-there (far) man-ERG steal-PAST I.DAT meat-AĈC

'That man there stole my meat.'

(310) gunka-gala gațu ina

ask-PRES I.ERG you.S:ACC

'I ask you.'

(311) gunka-gali gatu ñina nilada

ask-PAST I.ERG 3.S. masc:ACC yestêrday

'I asked him yesterday.'

(312) duna-gula gațu nूina gunka-ra

?-sit I.ERG 3 . S.masc:ACC ask-FUT

'I wizl ask him by and by.'

(313) gunka-na națu nina / waba gana nulu ask-PAST I. ERG 3̂.Sิ.masc:ACC NEG I. ÂCC $3 . S . m a s c: E R G$

gala-ba-na

answer-away-PAST/P

'I asked him. He didn't answer me.'

(314) gala-ba gana

answer-away I. ÂCC

'Answer me.' 
$\begin{array}{lll}\text { (315) buba } & \text { nana-guru } & \text { wiyi-ana } \\ \text { blow-IMP } & \text { 3.S:ACC-there } & \text { fire-ACCC }\end{array}$

'Blow that fire.'

(316) mila mura nani walpa-gala

sun finished 3.S:NOM rise-PRES

'The sun is coming up now.'

(317) mura mila-ani walpa-na

finished sun-NOM rise-PAST/P

'Already - the sun came up.'

(318) guntu-ţiri mila-ani walpa-ba-ra

soon-? sun-NOM rise-away-FUT

'Soon the sun will come up.'

(319) walpa-gala mirkirini-ani

rise-PRES moon-NOM

'The moon is coming up.'

(320) gunțu-ţiri mirkirini-ani walpa-ba-ra

soon-? moon-NOM rise-away-FUT

'Soon the moon will come up.'

(321) ந̣ațandi-ra yundru bi !ka-ana

jump-FUT you.S:ERG log-ACC

'You will jump over the log.'

(322) waba gațu nhana-guru gattandi-ri / lapu NEG I.ERG 3.Ŝ:ACC-there jump-IRR POSS

'I won't/can't jump it.'

(323) birta-bura-ani nani-guru

high-?-3.S:NOM 3.S:NOM-there

'That one is high.'

(324) mura gațu nana-guru gațandi-ra

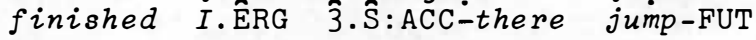

'O.K., I will jump this.'

(325) mura gațu gațandi-ra / lapu nana-guru finished I.ERG jump-FUT POSS 3.Ŝ:ACC-there

'O.K., I will/can jump that one.'

$\begin{array}{lll}\text { (326) diti-gala nani-guru } & \text { gaṇa-ani } \\ \text { Zaúgh-PRES } & 3 . S: N O M-t h e r e & \text { man-NOM }\end{array}$

'That man is Zaughing.' 


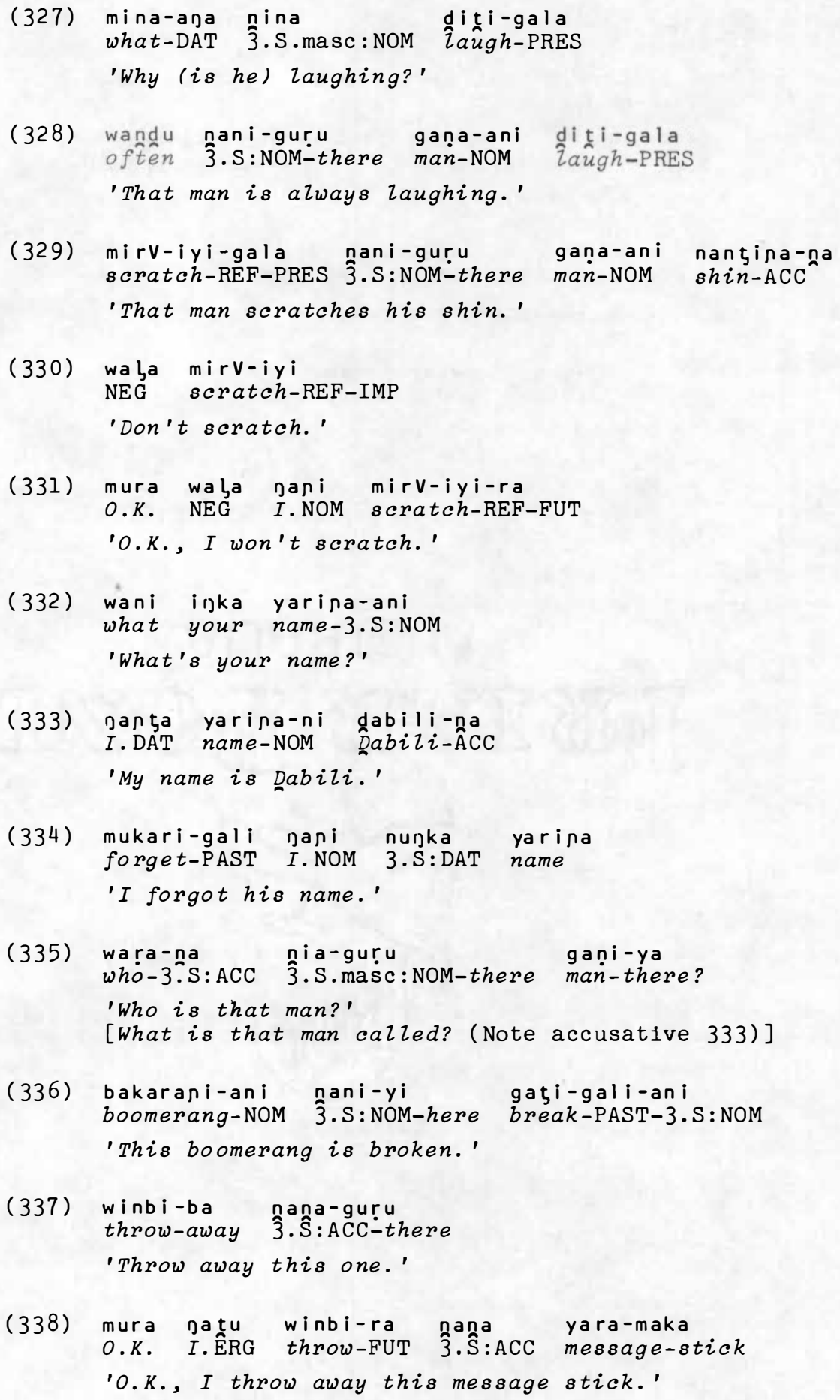


$\begin{array}{ll}\text { (339) yanda-ra dana } & \text { yalu-ana } \\ \text { taik-FUT 3.pl:NOM meeting-ACC }\end{array}$

'(They) will talk, have a meeting.'

(340) yagama-gala dana-guru-nu jandra-nani yara-maka-ana send-PRES 3.pl-there-ERG 3.pl-DAT message-stick-ACC

'They are sending us a message stick.'

(341) wanki-ra bari gandra bakarani-ana

look for-FUT think we.pl:NOM boomerang-DAT

'I think we will look for your boomerang.'

(342) gani wanki-ra nunka bakarani-ana

I. NOM look for-FUT 3.S:DAT boomerang-DAT

'I will look for his boomerang.'

(343) wanki-na baṇini nani wanki-na numka

look for-PAST/P unable I.NOM look for-PAST/P 3.S:DAT

bakarani-aina

boomerang-DAT

'I look, I cannot find his boomerang.'

(344) yamba-nara-gala walga-ni buka dana-guru fight-RECIP-PRES woman-NOM all 3.pl:NOM-there

'That lot of women are having a row.'

(345) nilada-watu dana-guru yamba-nara-gali walga-ni buka yesterday-one $3 . \mathrm{pl}$ :NOM-there fight-RECIP-PAST woman-NOM a $\mathrm{l}$

'Day before yesterday the women all fought.'

(346) yamba-nara-ra dana wika!a walga-ani buka

fight-RECIIP-FUT 3.pl:NOM tomorrow woman-NOM a 22

'Tomorrow the women all will fight (together).'

(347) wiyi-ani nani-guru mari-gala / dupu-ana gatu wupi-gala fire-NOM 3.S:NOM-there burn-PRES şmoke-ÂCC I.ÊRG sme 2 -PRES

'This fire is burning, I smell smoke.'

(348) walga-andru yamba-gala nana waliwa-ana

woman-ERG fight-PRES $\hat{3} . \hat{S}: A C C$ child-ACĈ

'The woman is scolding this child.'

(349) nampa nana-guru daldra-ana dupla-andru

cover-IMP 3.Ŝ:ACC-there k̂angaroo-ACC ashes-INST

'Cover up this kangaroo with ashes.'

(350) mura Datu nana nampa-ra juti-ana

finished I.ERG 3.. S:ACC cover-FUT meât-AĈC

'O.K., I will cover this meat.' 


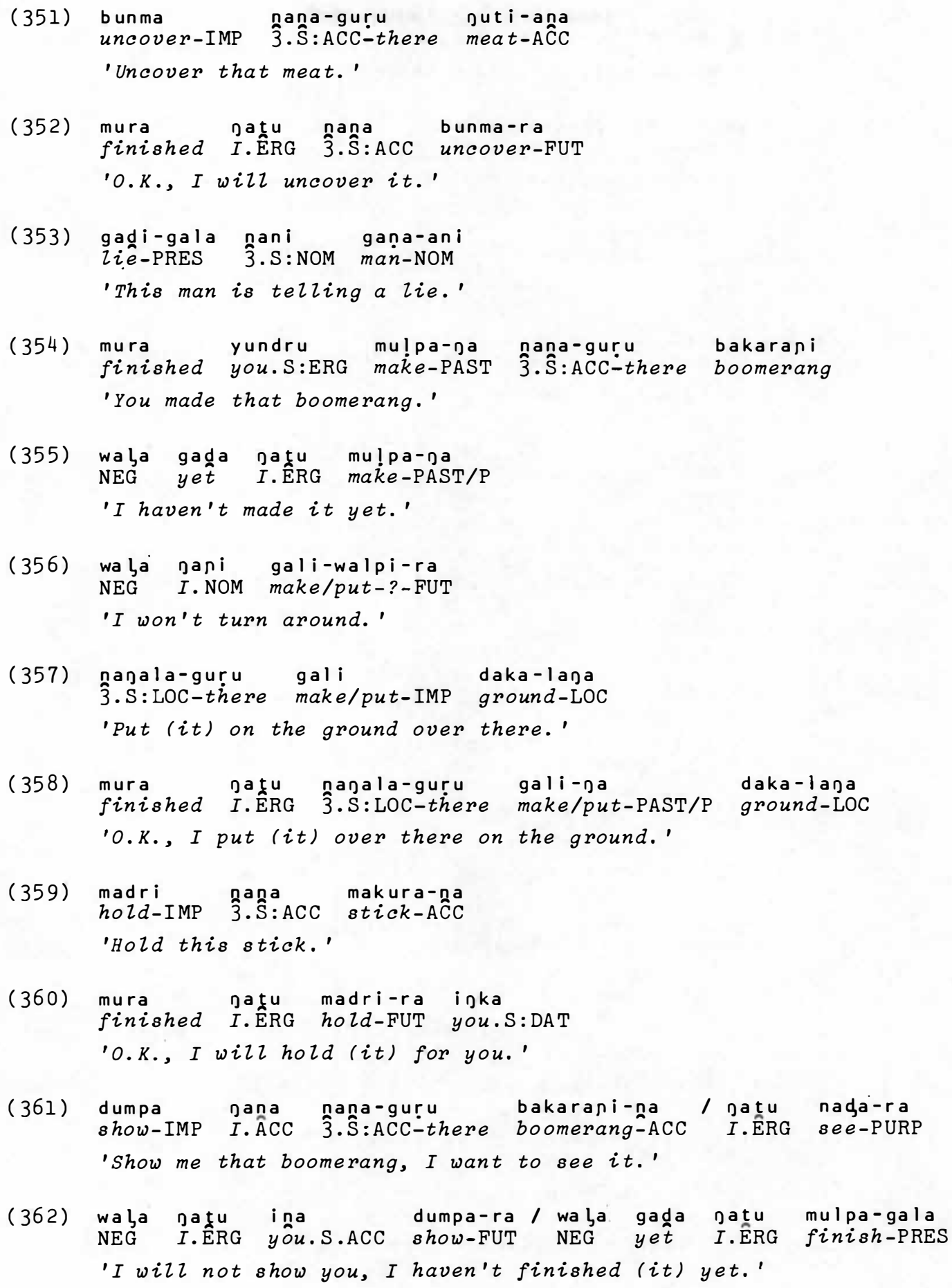




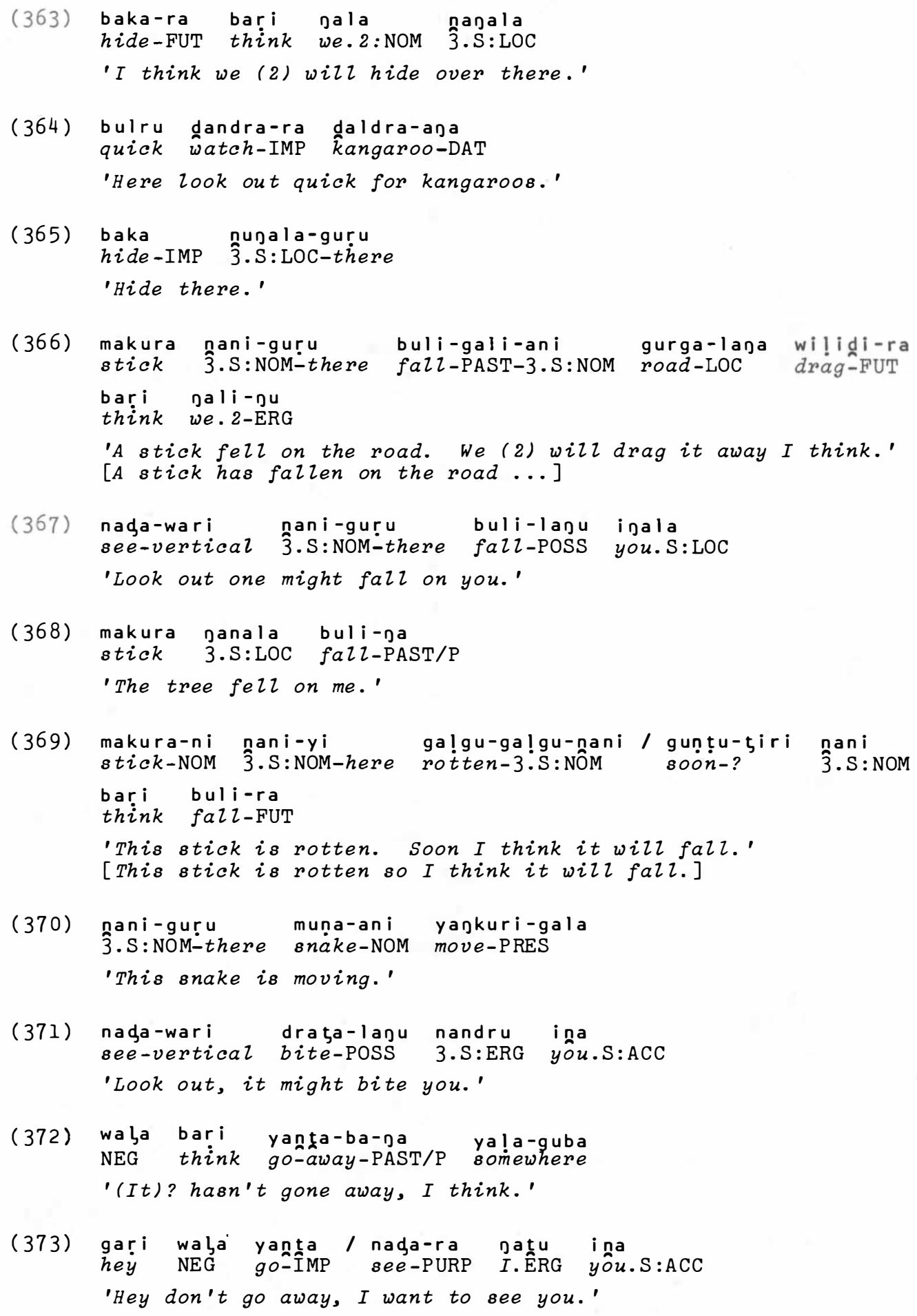




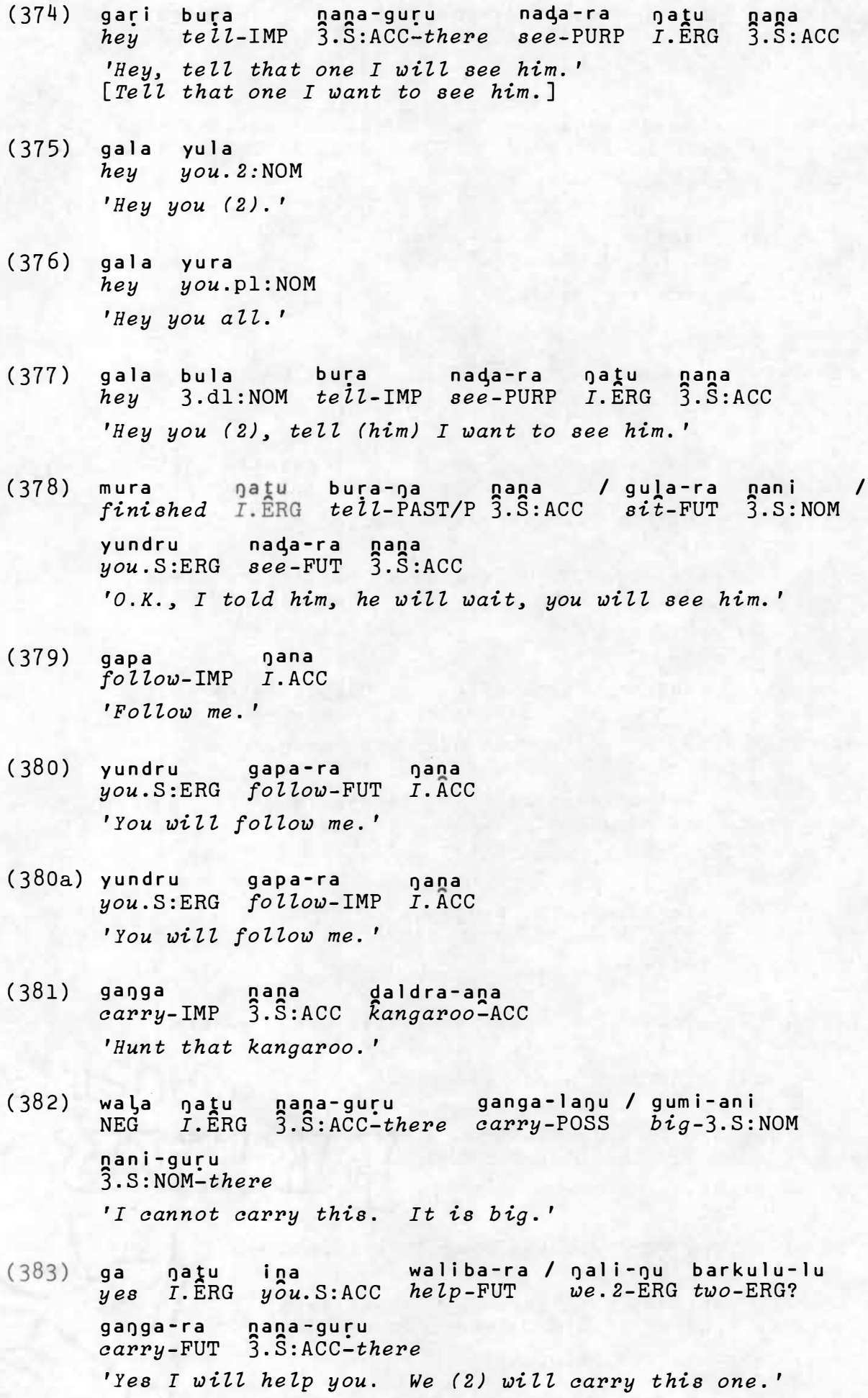


(384) mura gatu muna-manda-na inka nañida-na

finished I.ERG ?-hold-PAST/P you.S:DAT father-ÂCC

'O.K. I met your father.'

(385) mura
finished bika-dika-na bck-back-PAST/P I.NOM show-?-PURP $\begin{aligned} & \text { nani / dumpa-indri-ra ina } \\ & \text { finou.S:ACC }\end{aligned}$

'O.K., I came back to telz you.'

(386) waba yañta-gali ganţa gaṇida-ni

NEG go-PAST I.DAT father-NOM

'My father didn't go away.'

(387) yala-guba-nu ini yanta

DEM-?-? you.S:NOM go-TिM

'over that way you go.'

(388) yundru muna-manda-ra nina najala gabi

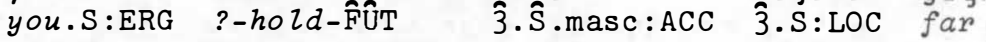

'You wizl meet him over there far away.'

(389) mura bula-guru gaṇa-bula buñti-dara-na-ba

finished 3.dl:NOM-there man-two come-?-PAST/P-EMPH

'O.K. two men arrived.'

$\begin{array}{llll}\text { (390) duna-wira guṇu-nu dana-guru } & \text { bunți-na-ra } \\ & \begin{array}{l}\text { d-wait } \\ \text { soon-? }\end{array} & 3 \text { 3.pl:NOM-there come-?-FUT }\end{array}$

'Wait a while, soon they all will come past.'

(391) maţa dika-manţa-na-ba gaṇa-bula

long ago back-move-PAST/P-EMPH man-two

'Long ago two people went past.'

(392) mura bula-guru bunt i-na

finished 3.dl:NOM-there come-PAST/P

'O.K. they (2) came here.'

(393) nilada gida-ni buka waga-bala-gali nanala yestêrday cattle-NOM alz lie-?-PAST 3 .S:LOC

'Yesterday many cattle camped here.'

(394) gari nada-gali gula yundru yala-iri gaṇa-ani hey see-PAST sit you.S:ERG DEM-? mañ-NOM

yanta-dika-gali

go-back-PAST

'Hey when you were looking over there did a man go past?'

(395) mura $\begin{array}{lll}\text { waliwa nani-guru manta-gala } \\ \text { finished child }\end{array}$

'O.K. this baby is crawling.' 


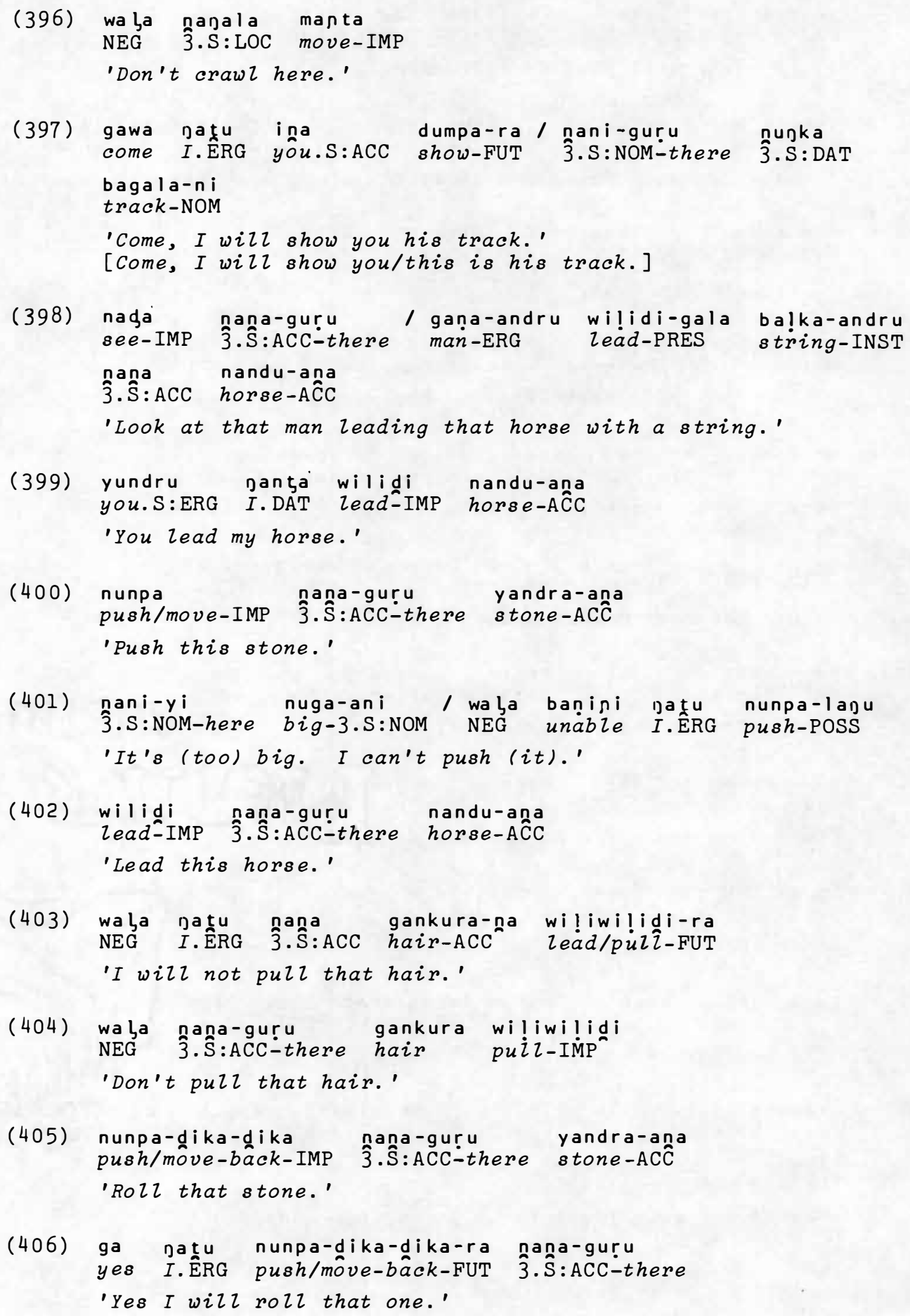


(407) yandra nani-guru
stone buli-ra naka-lana

'This stone will fall in the water.'

(408) yandra nani-guru buli-wari-ra mirgala-luna gaka-ana stone 3.S:NOM-there fall-vertical-FUT bank-LOC water-DAT

'This stone will fall down along the steep bank into the water.'

(409) mirgala-ni nani-guru giţa-baru-ani bank-NOM 3.S:NOM-there ?-?-3.S:NOM

'This bank is steep.'

(410) yandra nani-guru nunpa-dika-dika-ra gaka-laga stone 3.S:NOM-there push-bâck-bâck-FUT water-LOC

'This stone will roll into the water.'

(411) manda-ra gali-gu nana-guru durugara-ana get-FUT we.2-ERG $3 . \hat{S}: A C C-t h e r e$ goanna-ACC

'We (2) will catch this goanna.'

(412) gạ̣ra nana-guru gulbara-na yangu-andru spear-IMP 3 .Ŝ:ACC-there emu-ACC spear-INST

'spear this emu with a spear.'

(413) ga mura gatu nana gadra-la

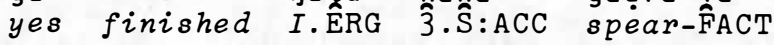

'Yes, already I am spearing it.'

(414) ga mura gatu nana gadra-ga yes finished I.ÊRG 3.. S:ACC spear-PAST/P

'Yes, already I have speared it.'

(415) nunpa nana-guru diti-ana

push-IMP 3.Ŝ:ACC-there d̂og-ACĈ

'Kick this dog.'

(416) gudu gatcu nana nunpa-laju draţa-laju gana if I.ERG 3. Ŝ:ACC push-POSS bite-POSS I. ÂCC

'If/when I kick it, (it) may bite me.'

(417) nada-ra gula gatcu igka ganiga-na / guta-ra gatcu see-FUT sit I.ÊG you.S:DAT father-ÂCC give-FUT I. ÊRG

$\begin{array}{ll}n \text { nina } & \text { puti-ana } \\ \text { 3.S. masc:ACC meât-ACC }\end{array}$

'When I see your father I will give him meat.'

(418) ini wilbi you.S:NOM whistze-IMP

'You whistze.' 


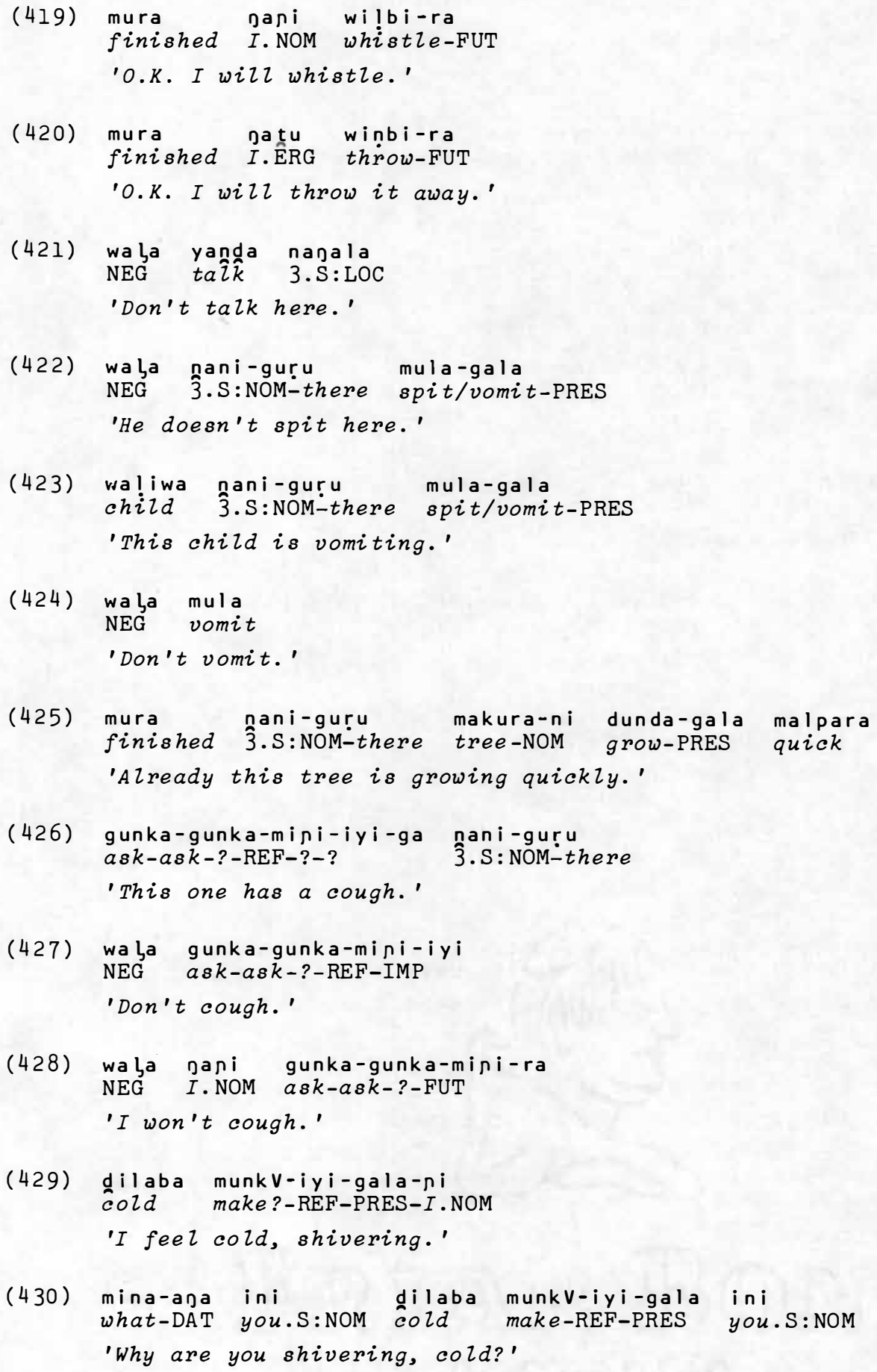




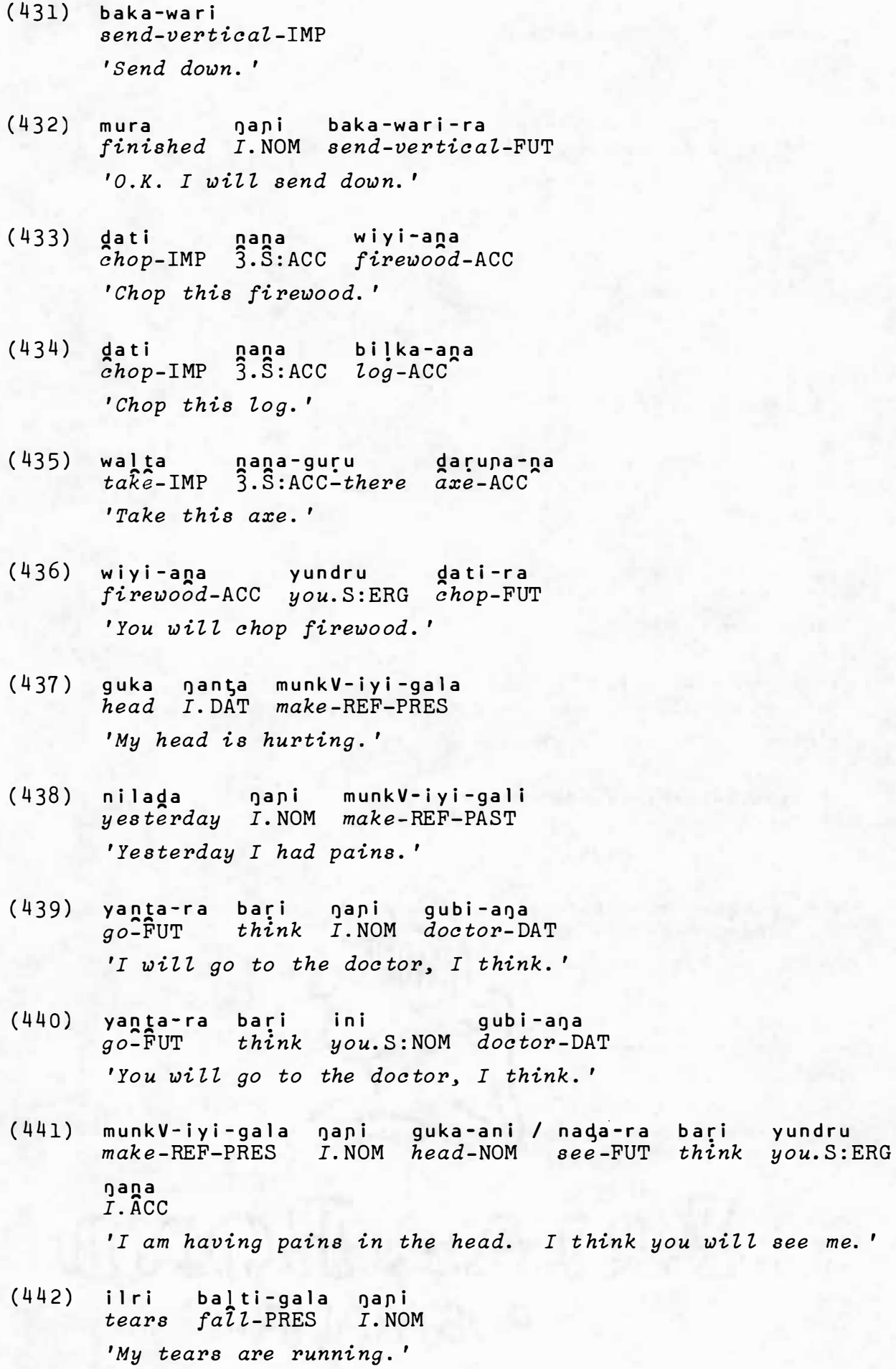




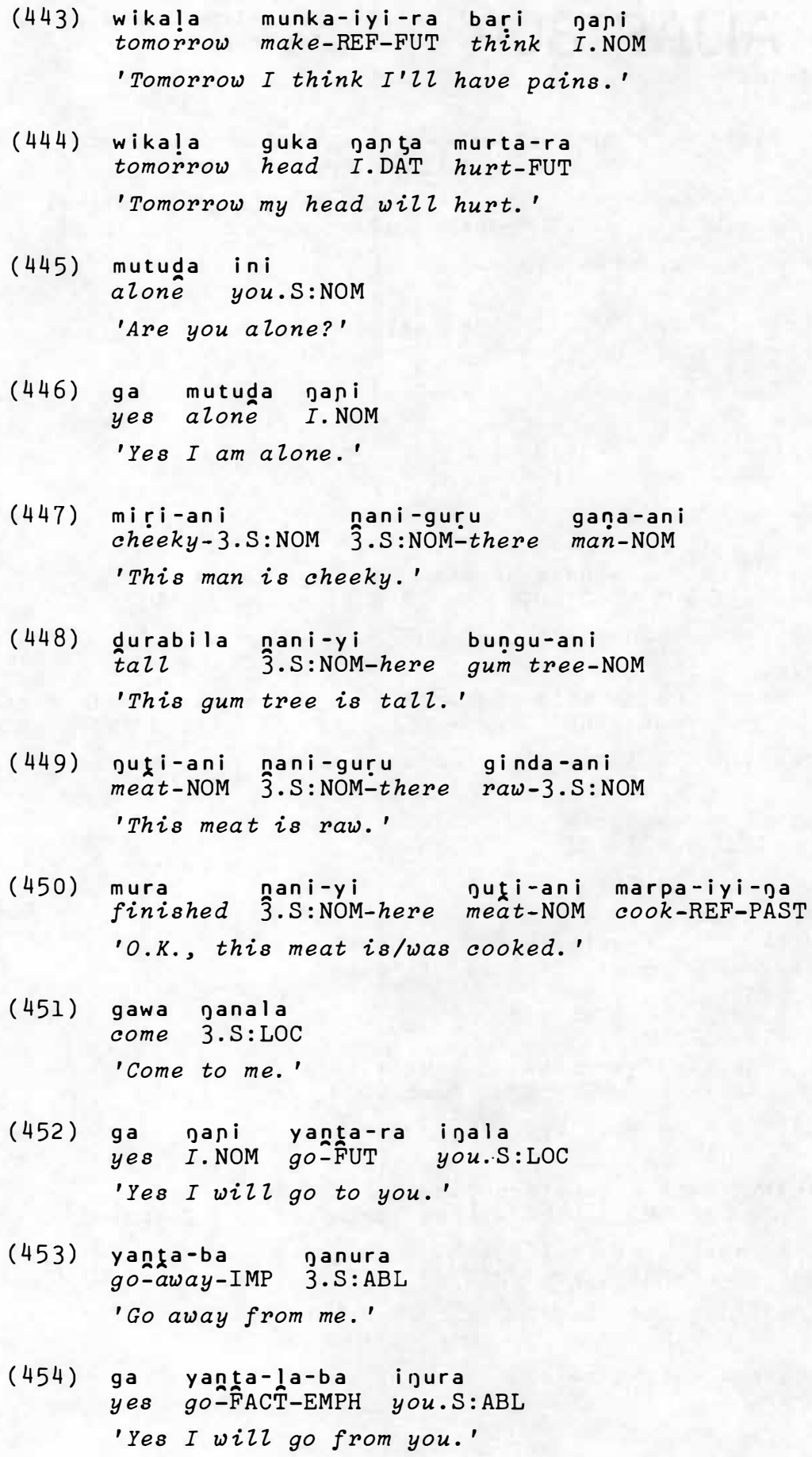




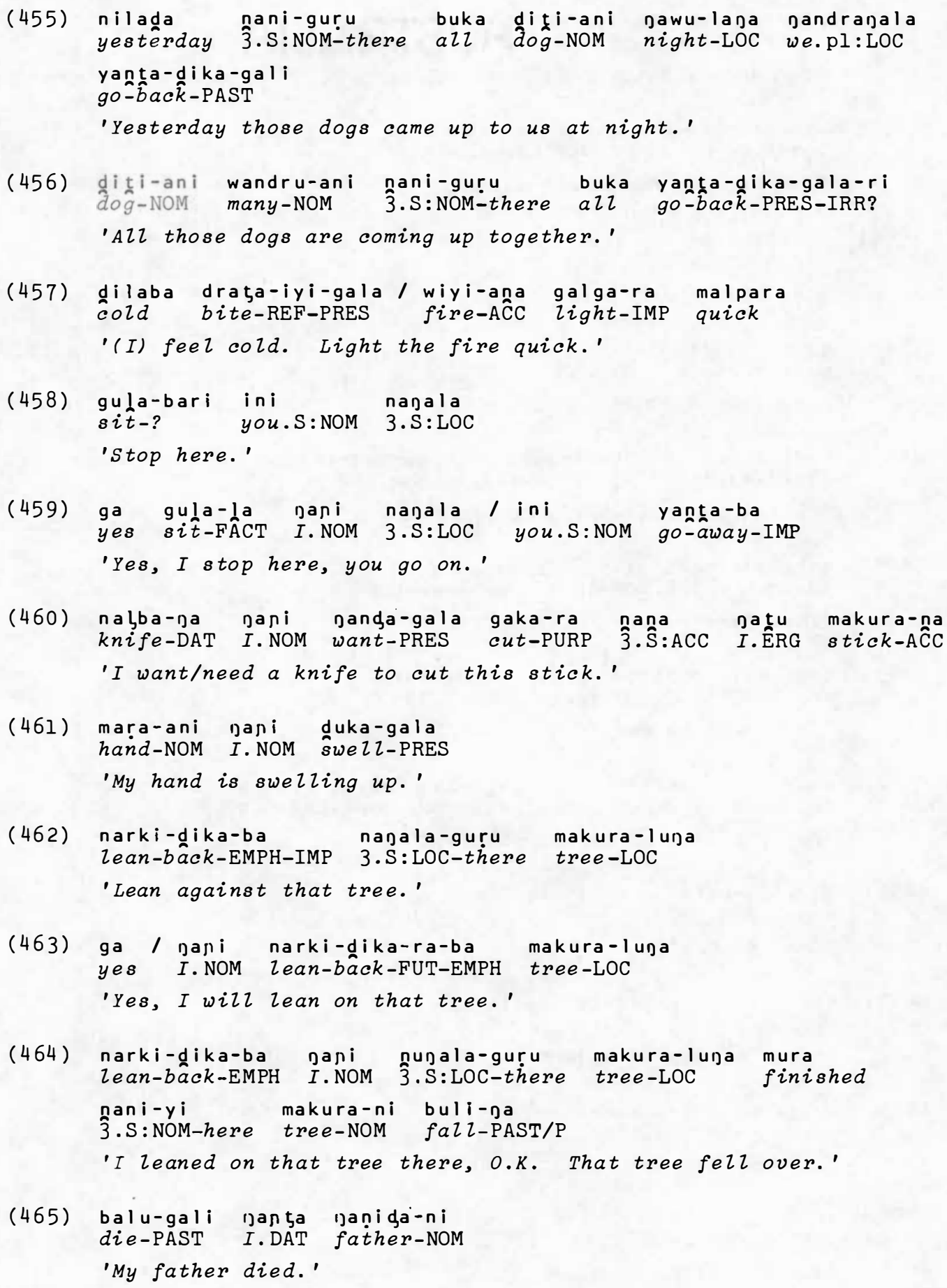




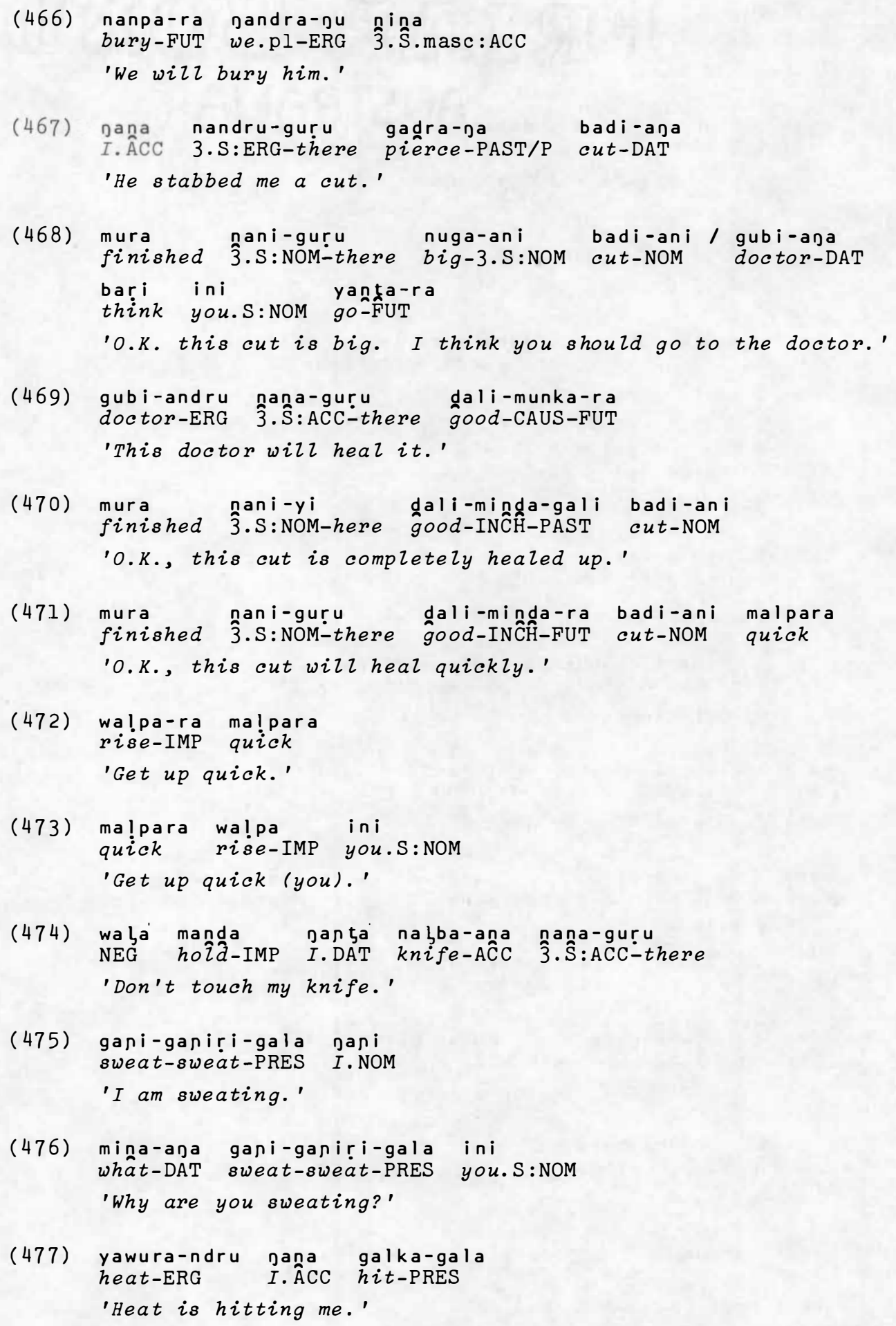


(478) guna juta nana-guru nandu-ana food give-IMP 3.Ŝ:ACC-there horse-ACC

'Give that horse food.' $\begin{array}{llll}\text { (479) Dunawali-andru Dana draba-na } & \text { miranda-ni } \\ \text { mosquițo-ERG } & \text { I.ÂCC } & \text { bite-PAST/P } & \text { itch-I.NOM }\end{array}$

'A mosquito bit me - I (have an) itch.'

(480) mara-ani gani biți-bițiri-gala

hand-NOM I.NOM itch-PRES

'My hand is itching.'

(481) waba nạa-guru yandra-ana jugka NEG 3.Ŝ:ACC-there stone-ACC swallow-IMP

'Don't swarlow that stone.'

(482) nhani-guru dalta-iyi-gala

3.S:NOM-there éat-REF-PRES

'He has eaten.'

(483) bunkula gula-wari

knee sit-vertical-IMP

'Kneer.'

(484) mura gani bunkula gula-wari-ra

finished I.NOM knee sit-vertical-FUT

'O.K. I will kneel.'

(485) mara dapa-gala gana diti-andru

hand iick-PRES I. ÂCC d̂og-ERG

'The dog is licking my hand.'

(486) mura dana-guru gana-ani buka mari-mari-gala finished 3.pl:NOM-there man-NOM all dance-dance-PRES

maṇi-anan $i$

corroboree-DAT

'O.K. the people all together are dancing a corroboree.'

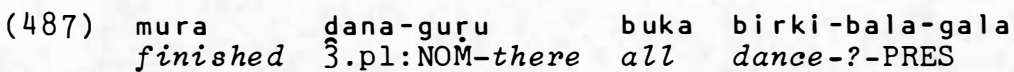

'O.K. they all are dancing a corroboree.'

(488) nada-ba dana-guru-naa

look-away 3.pl-there-ACC

'Look at them.'

(489) mina yarinani nani-yi mañi-ani

whât name-3.S:NOM 3.S:NOM-here dance-NOM

'What name is this dance?' 


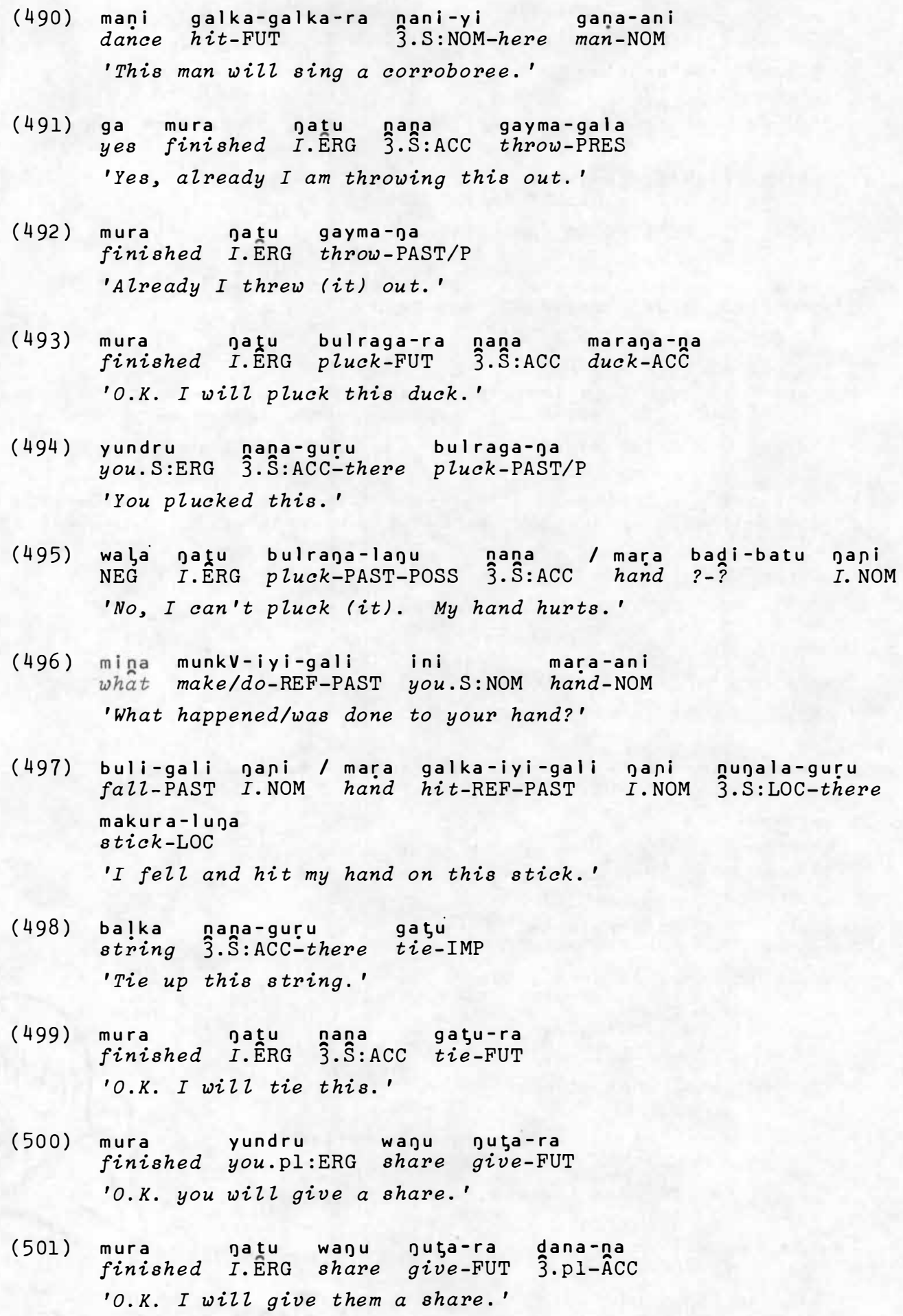




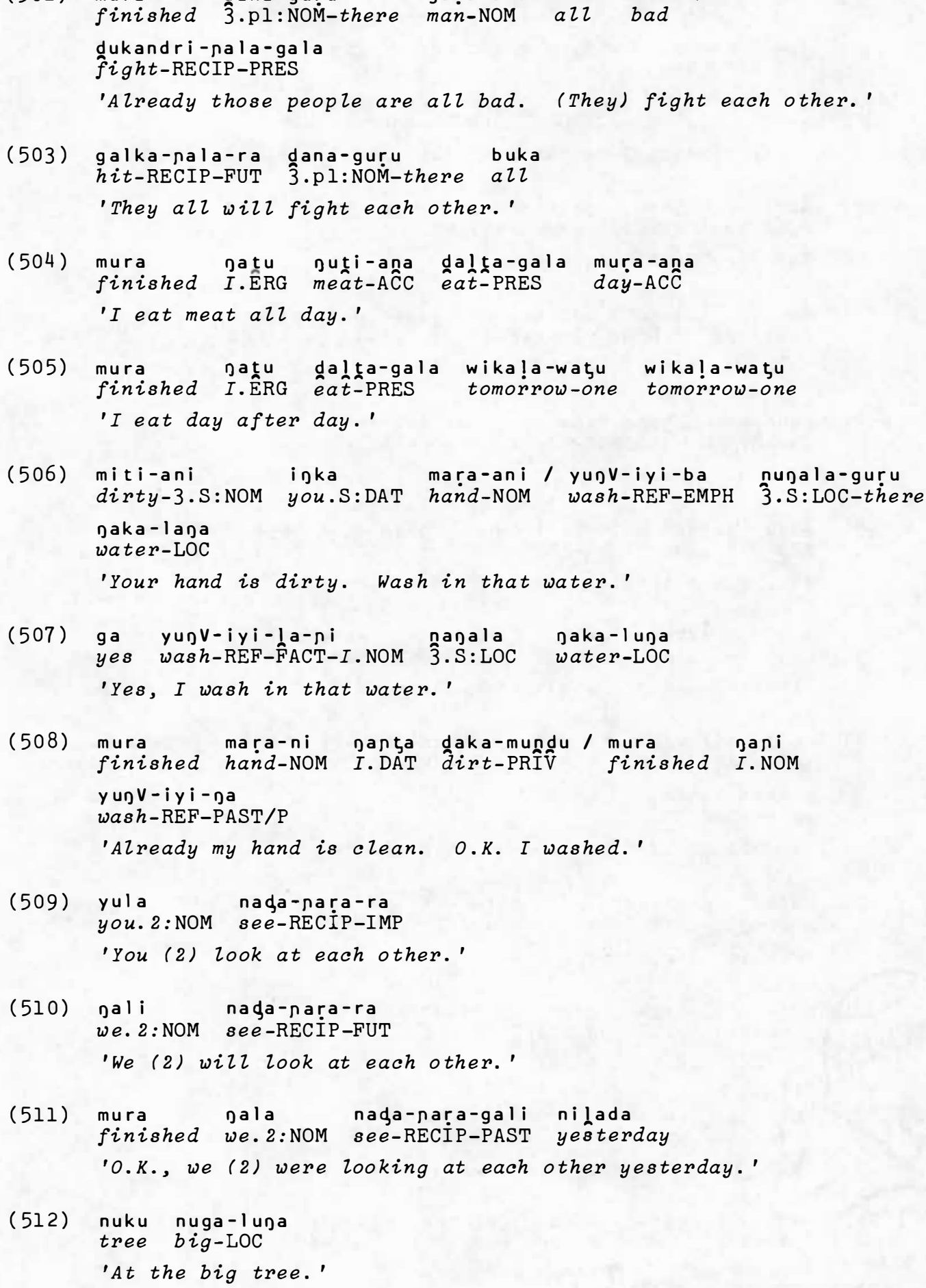


(513) wanda-wara daldra-ani

much-belonging k̂nangaroo-NOM

'How many kangaroos are there?'

(514) mura bunma-ra mura

finished take-IMP finished

'Take (it) out, O.K.' 

VOCABULARY

\begin{tabular}{|c|c|}
\hline babada 'husband' & bița 'dark' \\
\hline badi 'cut (on skin)' & bițubițu 'kitty hawk' \\
\hline bagala 'road, track' & bita 'Zight' \\
\hline baka 'hide' & bitta-bitta 'Zightning' \\
\hline bakarani 'boomerang' & buba 'blow' \\
\hline bala 'today' & 'azz' \\
\hline balpara 'kitty hawk' & buli 'fazz' \\
\hline balu 'die' & bulraga 'pluck' \\
\hline ba!gara 'root' & bulru 'eye' \\
\hline ba!ka 'string' & bultarani 'Zungs' \\
\hline balti 'fall, come down' & bulțura 'down feather' \\
\hline bampuli 'wild orange (other type)' & bubura 'mud' \\
\hline bạ̣abuţa 'hawk' & bundi 'baton' \\
\hline baṇdi 'cross' & bunkula 'knee' \\
\hline barkulu 'two' & bunma 'uncover' \\
\hline baṛada 'dish' & bungu 'gum tree' \\
\hline bari' 'think' & bunți 'come' \\
\hline bațiguru 'ezbow' & bun tyu 'fur, skin hair' \\
\hline bikana 'naiz' & bura 'feather' \\
\hline bilibili 'butterfly' & burgu 'shiezd' \\
\hline bilti 'yezzow' & burkaya 'bandicoot' \\
\hline bi lka 'Zog' & bura 'tezz' \\
\hline bindrina 'grasshopper' & 'flower' \\
\hline bingu 'fin' & daka 'earth' \\
\hline bintalani 'bat' & dalara 'cloud' \\
\hline bindagalka 'changing, swapping' & dibira 'centipede' \\
\hline bingana 'one pound (bark)' & diti 'star' \\
\hline birtabura 'top, high' & draba 'sting' \\
\hline
\end{tabular}




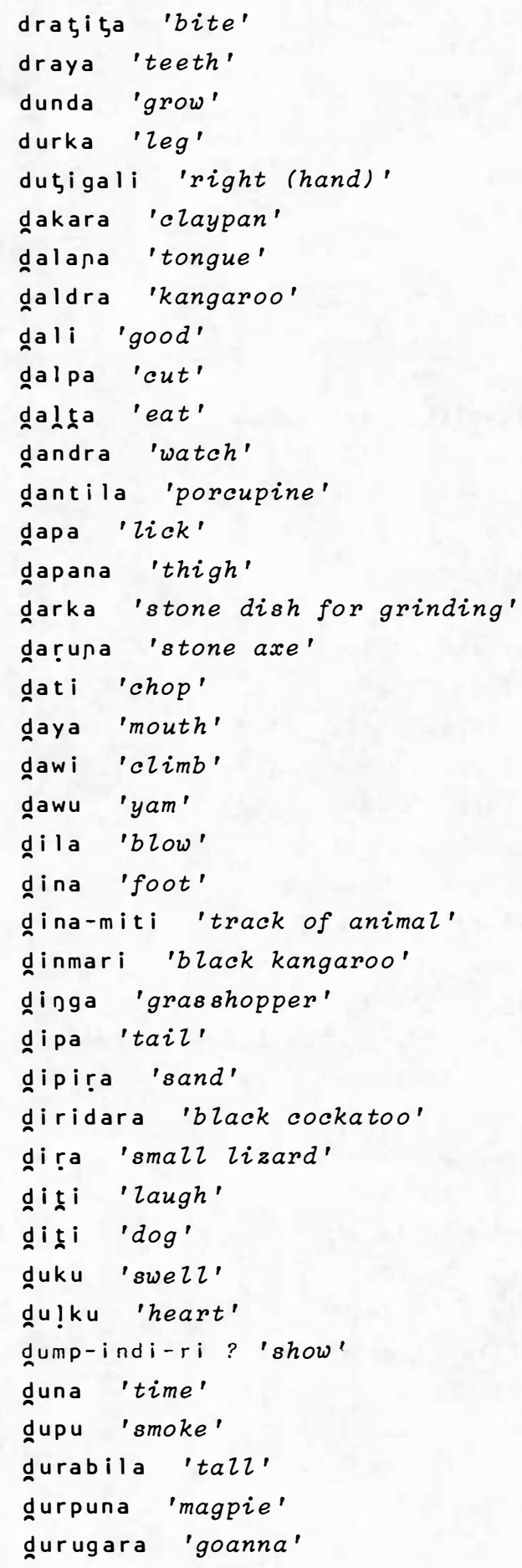

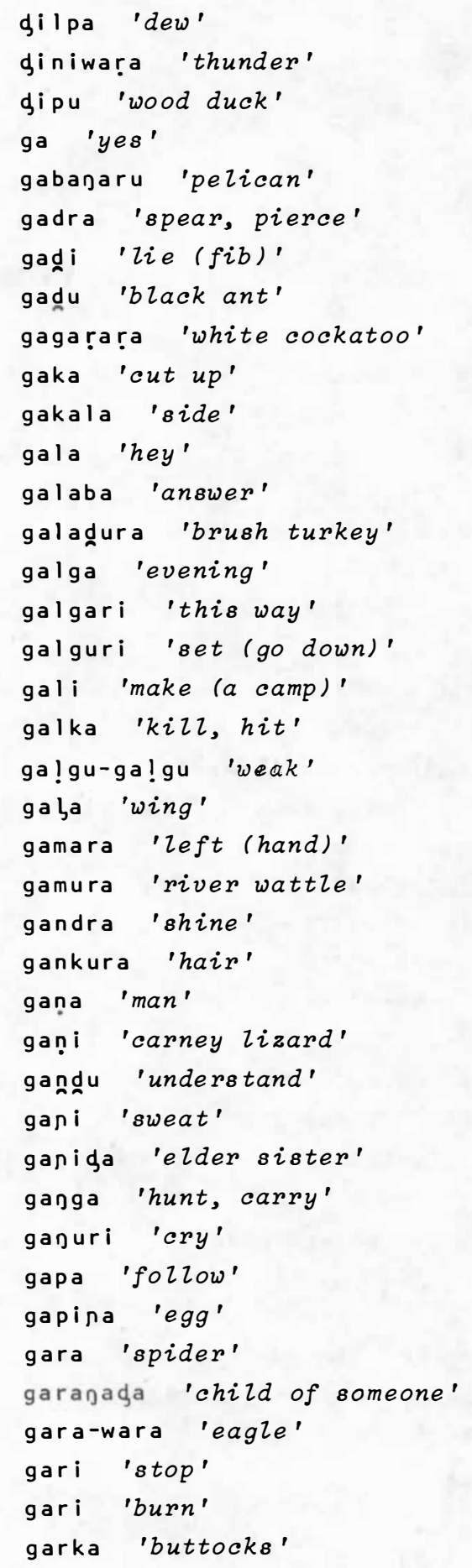




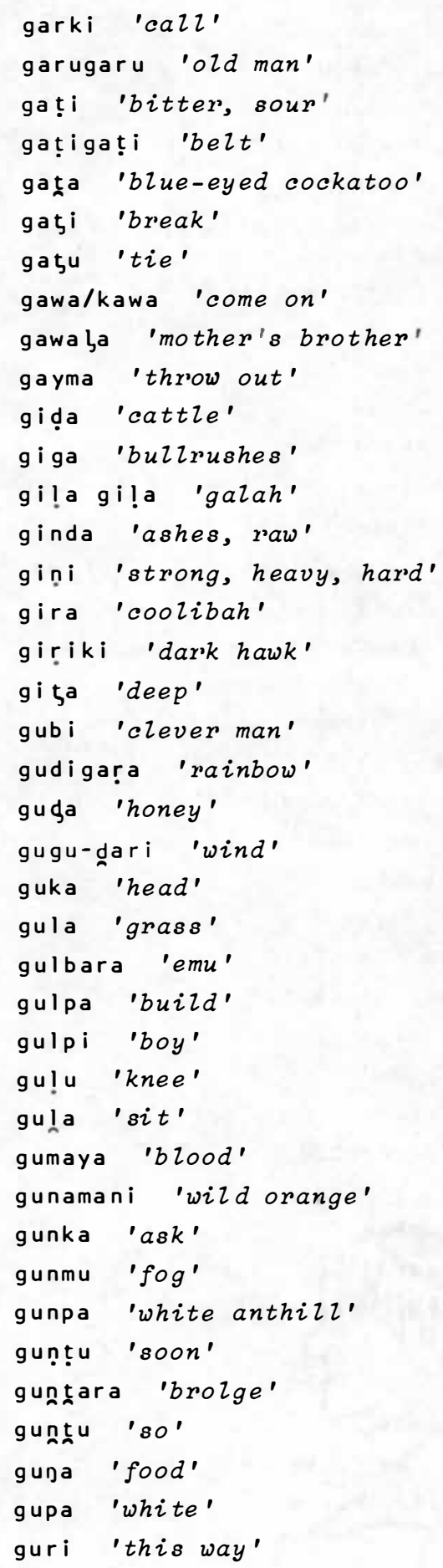

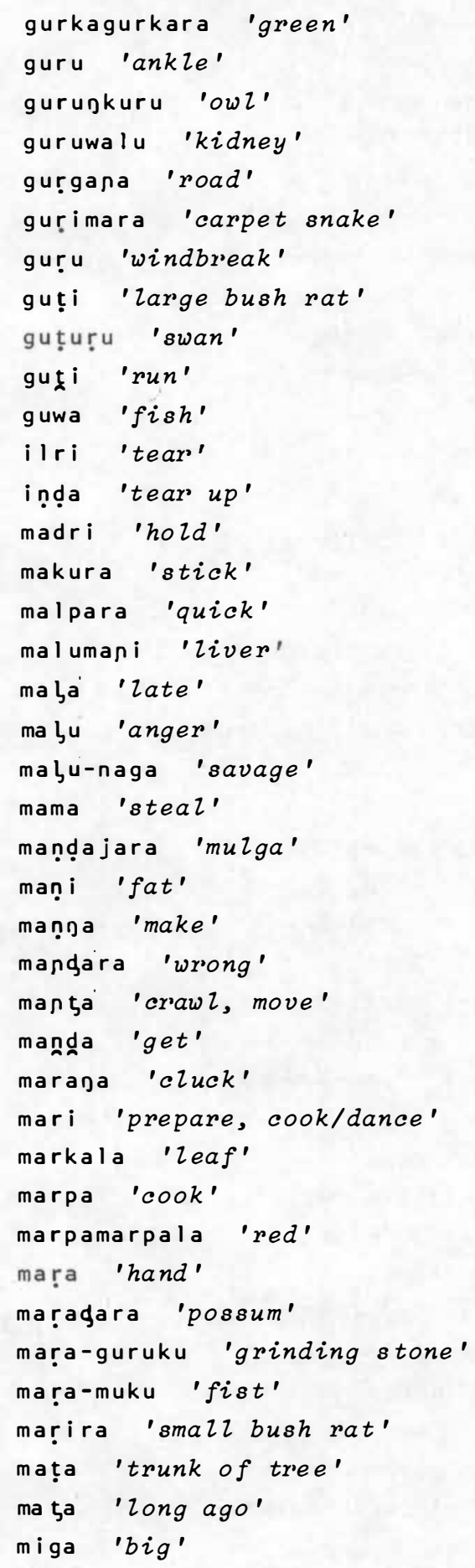




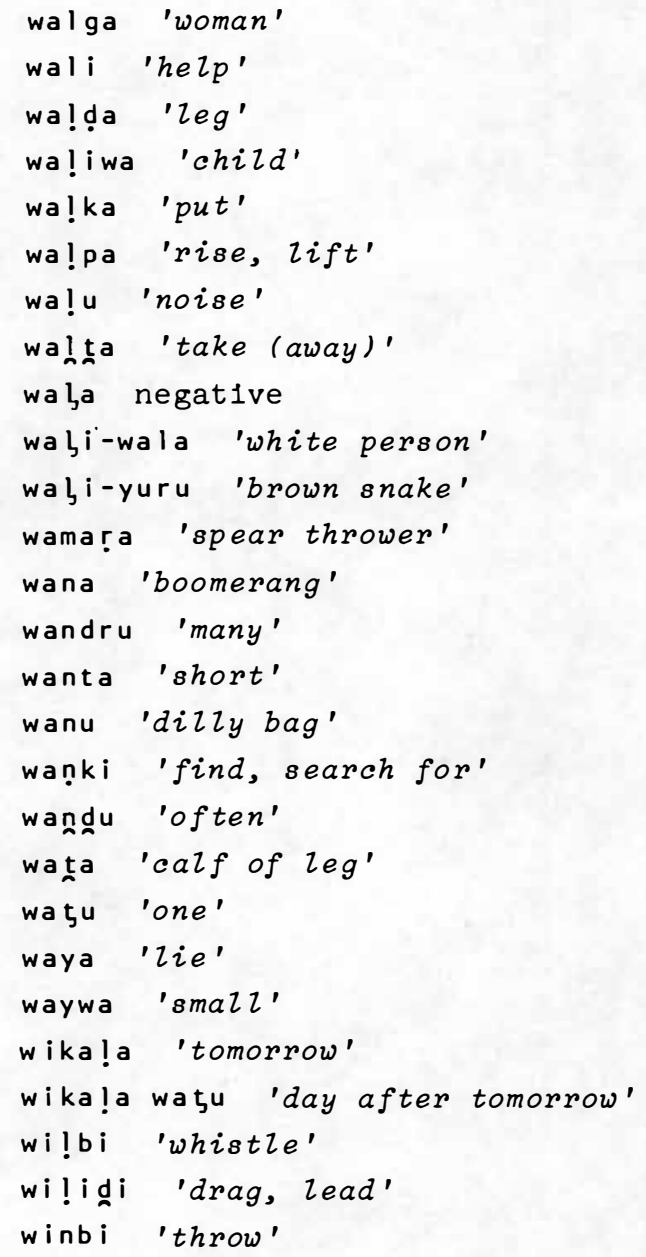

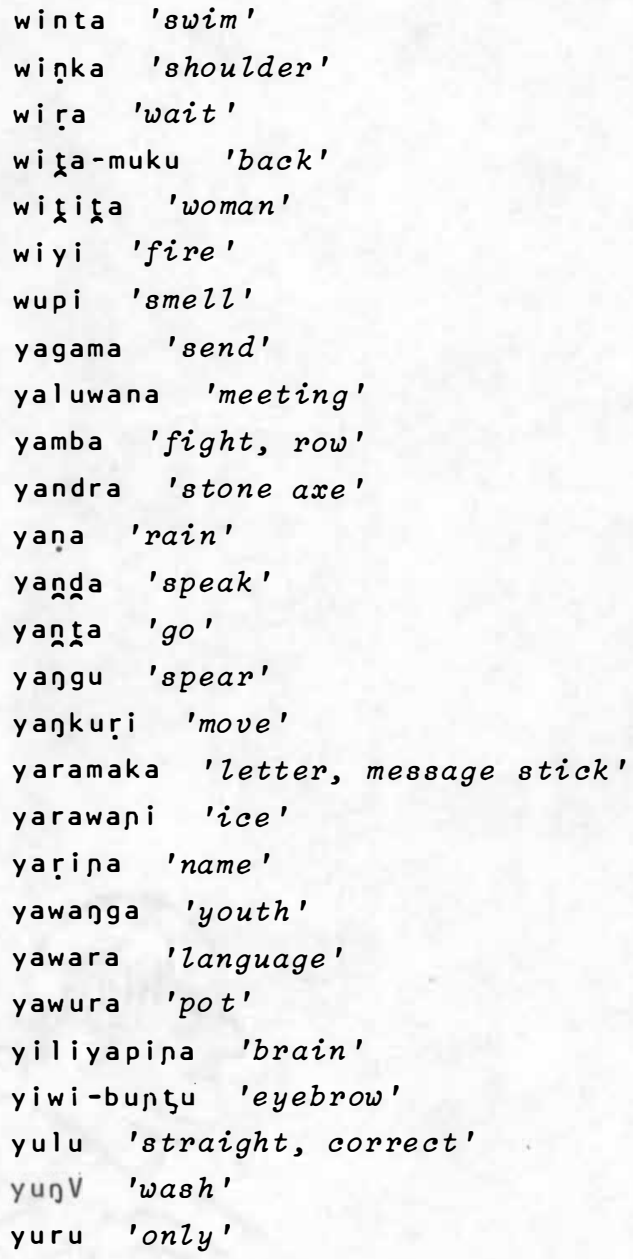




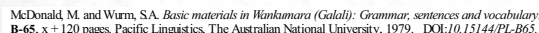

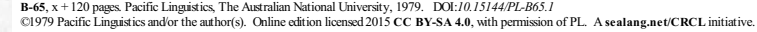

